Identificação de outliers em redes complexas baseada em caminhada aleatória 

Data de Depósito:

Assinatura:

\title{
Identificação de outliers em redes complexas baseada em caminhada aleatória
}

\author{
Bilzã Marques de Araújo
}

Orientador: Prof. Dr. Zhao Liang

Dissertação apresentada ao Instituto de Ciências Matemáticas e de Computação (ICMC) da Universidade de São Paulo (USP) como parte dos requisitos para obtenção do título de Mestre em Ciências de Computação e Matemática Computacional.

USP - São Carlos

Agosto de 2010 

"Conheço um homem em Cristo

que foi arrebatado até ao terceiro céu.

E sei que o tal homem foi arrebatado ao paraíso

e ouviu palavras inefáveis,

de que ao homem não é lícito falar."

(II Coríntios 12.2-4) 
À minha mãe.

Uma Maria lutadora

e trabalhadora. 


\section{Agradecimentos}

Todo a ciência que temos não é mais do que gotas diante de toda a imensidão de águas que refletem toda a sabedoria implícita na obra divina. Por isso me sinto obrigado a agradecer a todos os que contribuíram direta e indiretamente para o desenvolvimento desse trabalho e para que eu pudesse adquirir uma nova gota de entendimento.

Mãe, muito obrigado por seu amor, por sua força e por todo o suporte. Nos dias em que senti-me só, você foi um exemplo de força no qual me espelhei. O pai estaria orgulhoso pelo que estamos alcançando.

Nelma, obrigado por me amar e suportar momentos difíceis ao meu lado; pelas vezes em que diminuístes os seus problemas para ajudar-me nos meus. Você é uma esposa maravilhosa. Uma mulher que edifica o lar.

Acássia, sei que sou um modelo para você. Você é um dos motivos que me fazem enfrentar a dificuldade de estar tão longe de casa.

Prof. Zhao, certamente você é uma das pessoas mais geniais com quem lidei em toda minha vida. Me desculpe por muitas vezes ser aquém e incapaz. Gostaria de dizer que a cada discussão que temos me sinto mais esclarecido. Me orgulho de tê-lo como orientador e como amigo.

Sou grato aos grandes professores que tive tanto na ÁREA1 como no ICMC. Especialmente à Prof(a). Graça Nunes, ao Prof. Marcus Cincinato, ao Prof. Rodrigo Tejo, à Prof(a). Renata Meneghetti e ao Prof. Ricardo Campello. Vocês são modelos de professores.

Prof. Francisco Rodrigues, muito obrigado pela parceria em alguns dos meus trabalhos. Tenho certeza que ainda iremos trabalhar muito juntos.

Sou grato também a cada um dos meus amigos e colegas de estudo, de laboratório, de futebol e da igreja. Especialmente à Lilian Berton e ao Jean Huertas, parceiros de perquisa. Cada um de vocês tem sido muito importante para minha estada em São Carlos.

Gostaria de agradecer às meninas do Serviço de Pós-Graduação pela compreensão nas mais diversas situações. Obrigado a cada um dos funcionários do ICMC-USP. Todos vocês têm uma parcela de contribuição nesse trabalho. 
Agradeço ao CNPq pelo suporte financeiro durante boa parte desse Mestrado.

Por fim, gostaria de agradecer a ti, Senhor meu Deus e meu Pai, pelo entendimento que tens me dado, por cada pessoa que tens colocado na minha vida, e por toda autoridade que tens instituído sobre mim. Sei que nada do que fazes é em vão. Peço-te que perdoes minhas falhas e minha incompetência. Sei que a ti nada é impossível. Obrigado por sua Graça infalível. Obrigado Senhor Jesus, obrigado Espírito Santo. Obrigado! 


\section{Resumo}

Na natureza e na ciência, dados e informações que desviam significativamente da média frequentemente possuem grande relevância. Esses dados são usualmente denominados na literatura como outliers. A identificação de outliers é importante em muitas aplicações reais, tais como detecção de fraudes, diagnóstico de falhas, e monitoramento de condições médicas. Nos últimos anos tem-se testemunhado um grande interesse na área de Redes Complexas. Redes complexas são grafos de grande escala que possuem padrões de conexão não trivial, mostrando-se uma poderosa maneira de representação e abstração de dados. Embora um grande montante de resultados tenham sido reportados nesta área de pesquisa, pouco tem sido explorado acerca de detecção de outliers em redes complexas. Considerando-se a dinâmica de uma caminhada aleatória, foram propostos neste trabalho uma medida de distância e um método de ranqueamento de outliers. Através desta técnica, é possível detectar como outlier não somente nós periféricos, mas também nós centrais $(h u b s)$, depedendo da estrutura da rede. Também foi identificado que existem características bem definidas entre os nós outliers, relacionadas a funcionalidade dos mesmos para a rede. Além disso, foi descoberto que nós outliers têm papel importante para a rotulação a priori na tarefa de detecção de comunidades semi-supervisionada. Isto porque os nós centrais são bons difusores de informação e os nós periféricos encontram-se em regiões de borda de comunidade. Baseado nessa observação, foi proposto um método de deteç̧ão de comunidades semi-supervisionado. Os resultados de simulações mostram que essa abordagem é promissora. 


\section{Abstract}

In nature and science, information and data that deviate significantly from the average value often have great relevance. These data are often called in literature as outliers. Outlier identification is important in many real applications, such as fraud detection, fault diagnosis, monitoring of medical conditions. In recent years, it has been witnessed a great interest in the area of Complex Networks. Complex networks are large-scale graphs with non-trivial connection patterns, proving to be a powerful way of data representation and abstraction. Although a large amount of results have been reported in this research area, little has been explored about the outlier detection in complex networks. Considering the dynamics of a random walk, we proposed in this paper a distance measure and a outlier ranking method. By using this technique, we can detect not only peripheral nodes, but also central nodes (hubs) as outliers, depending on the network structure. We also identified that there are well defined relationship between the outlier nodes and the functionality of the same nodes for the network. Furthermore, we found that outliers play an important role to label a priori nodes in the task of semi-supervised community detection. This is because the hubs are good information disseminators and peripheral nodes are usually localized in the regions of community edges. Based on this observation, we proposed a method of semi-supervised community detection. The simulation results show that this approach is promising. 


\section{Conteúdo}

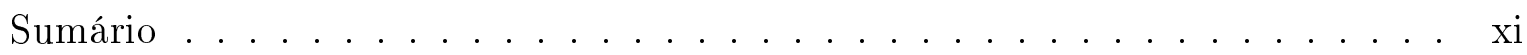

Lista de Figuras . . . . . . . . . . . . . . . xiii

1 Introdução 1

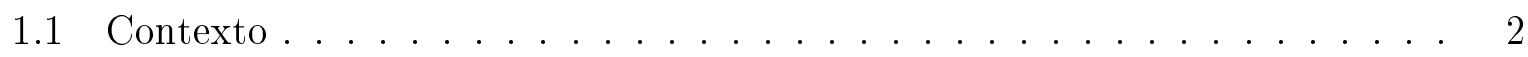

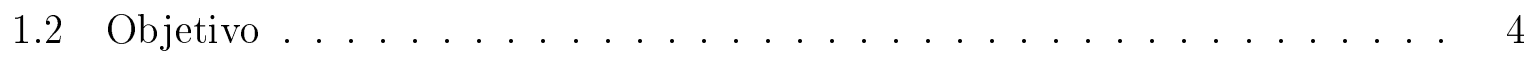

1.3 Organização do Documento . . . . . . . . . . . . . . . . 4

2 Deteç̧ão de Outliers 5

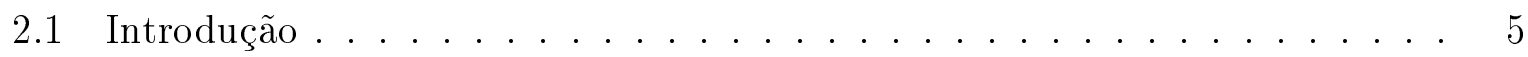

2.2 Aspectos Gerais . . . . . . . . . . . . . . . . . 7

2.2.1 Natureza do Conjunto de Dados . . . . . . . . . . . . . . 8

2.2 .2 Tipos de Outliers . . . . . . . . . . . . . . . . 8

2.2 .3 Disponibilidade de Rótulos . . . . . . . . . . . . . . . . 10

2.2 .4 Rigidez do Método . . . . . . . . . . . . . . . . . . 10

2.3 Deteç̧ão de Outliers em Dados Univariados . . . . . . . . . . . . . . . 11

2.4 Deteç̧ão de Outliers em Dados Multivariados . . . . . . . . . . . . 12

2.4 .1 Métodos Estatísticos . . . . . . . . . . . . . . . . . 13

2.4.2 Métodos Baseados em Mineração de Dados e Aprendizado de Máquina 14

2.5 Deteç̧ão de Outliers Espaciais . . . . . . . . . . . . . . . . 17

2.6 Considerações Finais . . . . . . . . . . . . . . . . . . . . 17

3 Redes Complexas e Detecção de Comunidades 21

3.1 Introdução . . . . . . . . . . . . . . . . . . . . . . 21

3.2 Definição e Propriedades . . . . . . . . . . . . . . . . . . . 23

3.2 .1 Distribuição de Grau . . . . . . . . . . . . . . . . . . . 25

3.2 .2 Transitividade . . . . . . . . . . . . . . . 26

3.2 .3 Efeito de Pequeno Mundo . . . . . . . . . . . . . . 27

3.2 .4 Estruturas de Comunidades . . . . . . . . . . . . . . 27

3.3 Modelos de Redes . . . . . . . . . . . . . . . . . . . . . . 28

3.3 .1 Redes Randômicas . . . . . . . . . . . . . . . 28 
3.3.2 Redes de Pequeno Mundo . . . . . . . . . . . . . . . . . . 30

3.3.3 Redes Livre de Escala . . . . . . . . . . . . . . . 31

3.3.4 Redes com Estruturas de Comunidade . . . . . . . . . . . . . . 32

3.3.5 Redes Geográfica . . . . . . . . . . . . . . . . 33

3.4 Detecção de Comunidades . . . . . . . . . . . . . . . . . . 34

3.4.1 Método Baseado em Betweenness . . . . . . . . . . . . . . 35

3.4.2 Método Baseado em Modularidade . . . . . . . . . . . . . . 37

3.4.3 Método Baseado em Caminhada Aleatória . . . . . . . . . . . . 38

3.4.4 Método Baseado em Competição de Partículas . . . . . . . . . . . 39

3.5 Considerações Finais . . . . . . . . . . . . . . . . . . . 41

\section{Identificação de Outliers em Redes Complexas e Aplicação à Deteç̧ão} de Comunidades $\quad 45$

4.1 Medida de Distância de uma Caminhada Aleatória . . . . . . . . . . . 46

4.1.1 Caminhada Aleatória em Redes . . . . . . . . . . . . . . . . . 46

4.1.2 Cadeias de Markov . . . . . . . . . . . . . . . . . 47

4.1 .3 Medida de Distância . . . . . . . . . . . . . . . . . 49

4.2 Método de Detecção de Oultiers em Redes . . . . . . . . . . . . . . . . 49

4.3 Como Funciona o Método de Detecção de Outliers . . . . . . . . . . . . . 50

4.4 Resultados Obtidos em Redes Reais . . . . . . . . . . . . . . . 52

4.4 .1 Rede do Clube de Karatê . . . . . . . . . . . . . . . . 52

4.4.2 Rede de Colaboração entre Cientistas . . . . . . . . . . . . . . 54

4.4.3 Redes de Interações entre Proteínas . . . . . . . . . . . . . . 55

4.5 Aplicação à Detecção de Comunidades . . . . . . . . . . . . . . . . . 59

4.5.1 Método de Propagação de Rótulo . . . . . . . . . . . . . . . 60

4.5.2 Rotulação de Dados Guiada por Outliers . . . . . . . . . . . . . . 61

4.6 Considerações Finais . . . . . . . . . . . . . . . 63

5 Conclusão $\quad 65$

5.1 Trabalhos Futuros . . . . . . . . . . . . . 66

$\begin{array}{ll}\text { Referências } & 74\end{array}$ 


\section{Lista de Figuras}

2.1 Histograma produzido com base em 13634 nascimentos registrados por Chamberlain (1970). As observações dos casos M.-T. vs. M.-T. e Hadlum vs. Hadlum desviam-se acentuadamente da distribuição. Figura adaptada de (Barnett, 1978). . . . . . . . . . . . . . . .

2.2 Outliers em um conjunto de dados bidimensional. As observações $o_{1}$ e $o_{2} \mathrm{e}$ o subconjunto $\mathrm{O}_{3}$ podem ser identificados como outliers. Figura adaptada de (Chandola et al., 2009). . . . . . . . . . . . . 7

2.3 Série temporal de temperatura: $t_{2}$ é um outlier contextual. Embora a temperatura seja a mesma em $t_{1}$ e em $t_{2}$, apenas no contexto de $t_{2}$ essa observação é outlier. Figura adaptada de (Chandola et al., 2009). . . . . . 9

2.4 Outlier coletivo destacado (em vermelho), correspondendo a uma contração prematura do átrio em um eletrocardiograma. Figura obtida de (Chandola et al., 2009). . . . . . . . . . . . . . . . . .

2.5 Conjunto de dados bidimensional com variáveis correlacionadas. A observação $o_{1}$ é uma observação outlier. No entanto, tratando as variáveis independentemente, não é possível detectar $o_{1} \ldots \ldots$. . . . . . . . . . 12

2.6 Conjunto de dados bidimensional com variação de densidade. Nesse caso, métodos baseados em densidade local apresentam performance melhor que métodos baseados em densidade global. Figura adaptada de (Chandola et al., 2009). . . . . . . . . . . . . . . . . . 15

2.7 Tipos de outliers identificados segundo o método proposto em (Costa et al., 2009). O outlier aparece destacado em preto. Os autores identificam (a) como $h u b$ de retransmissão global, (b) como hub de retransmissão local, (c) como integrador local, (d) como integrador, (e) como centro de comunidade, (f) como extremidade-cluster, (g) como cluster-cluster, e (h) como extremidade. Figura adaptada de (Costa et al., 2009) . . . . . . . . . . 18 
3.1 Problema das sete pontes de Königsberg. (a) Ilustração da cidade de Königsberg. (b) Grafo representando o problema das sete pontes de Königsberg. Cada porção de terra é representada por um nó e cada ponte é representada por uma aresta. . . . . . . . . . . . . . 22

3.2 Wold Wide Web. Páginas conectam-se a outras páginas através de ligações direcionadas. Páginas muito conectadas entre sí podem caracterizar temas relacionados. Além disso, a distribuição de grau influencia diretamente em como a informação se propaga na rede. . . . . . . . . . . . . . . . . . 23

3.3 Rede social entre alunos de uma escola americana. As cores representam as etnias. Note-se que existe uma separação bem definida com relação a etnia dos indivíduos. Além disso, existe uma separação bem definida entre os alunos que cursam o high school e os alunos que cursam o medium school. Essas estruturas são conhecidas como comunidades. Figura obtida de $($ Newman, 2003) . . . . . . . . . . . . . . . . . . 24

3.4 Distribuição cumulativa de grau de seis redes reais: (a) rede de colaboração entre matemáticos; (b) rede de citações; (c) a World Wide Web; (d) a Internet; (e) rede de energia do lado oeste dos Estados Unidos; (f) rede de interações entre proteínas. Em cada gráfico, o eixo das abcissas representa o grau $k$ (o grau de entrada, $k^{i n}$, no caso da rede de citações e da World Wide Web) enquanto que o eixo das ordenadas representa a probabilidade da distribuição, $P(k)$. Dessas redes, as representadas em (c), (d) e (f), possuem distribuição de grau que segue a lei de potência. Como representada em escala log-linear, (e) segue uma lei exponencial. Embora (a) e (b) sejam representadas em escala log-log, ambas desviam-se acentuadamente da distribuição alvo, especialmente com relação a nós com alto grau. Figura adaptada de (Newman, 2003) . . . . . . . . . . . . 26

3.5 Rede com três estruturas de comunidades bem definidas. Nós que pertencem a mesma comunidade estão densamente conectados, enquanto que ligações entre nós de comunidades distintas são esparsas. Figura obtida de (Newman \& Girvan, 2004). . . . . . . . . . . . . . . . 28

3.6 Configurações de redes randômicas com 8 vértices: (a) $p=0$; (b) $p=0.1$;

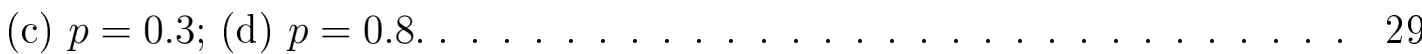

3.7 Distribuição de grau média de 10 redes randômicas com 1000 nós e probabilidade $p=0.1$. Uma distribuição de Poisson. . . . . . . . . . . . . 29 
3.8 Modelo de redes de pequeno mundo de Watts \& Strogatz (1998). Para $p=0$ temos uma rede regular. Quanto maior a probabilidade $p$, mais o modelo se aproxima de uma rede randômica. Para $0.01<p<0.1$ a rede se comporta como uma rede de pequeno mundo. Note-se que a distância entre os nós identificados em vermelho e em azul diminui, enquanto que o coeficiente de clustering mantem-se alto. Figura adaptada de (Watts \& Strogatz, 1998) . . . . . . . . . . . . . . . . . .

3.9 Comportamento da distância média e do coeficiente de clustering em função de $p$, segundo o modelo de Watts \& Strogatz (1998). Tanto o coeficiente de clustering como a distância média são apresentados em razão dos respectivos valores máximos. Para $0.01<p<0.1$ temos o efeito de pequeno mundo. Figura obtida de (Newman, 2003). . . . . . . . . . . . .

3.10 Distribuição de grau média de 10 redes geradas segundo o modelo de Barabási \& Albert (1999) com 1000 nós e $m=5$. . . . . . . . . . . . . 32

3.11 Exemplo de rede com 64 nós e 4 estruturas de comunidades bem definidas gerada segundo o modelo de Girvan \& Newman (2002). . . . . . . . . . . .

3.12 Arvore hierárquica (ou dendograma) ilustrando o resultado do método de detecção de comunidades de Newman \& Girvan (2004) aplicado a rede da Figura 3.5. Os círculos na base da figura representam os nós da rede. Movendo-se sentido a raiz da árvore, temos partições cada vez maiores. No caso do algoritmo de Newman \& Girvan (2004), trata-se de um método divisivo. Nesse caso, a visualização mais adequada é a partir da raiz sentido as folhas. O corte horizontal refere-se a partição de comunidades com maior índice de modularidade. Figura obtida de (Newman \& Girvan, 2004). . . . 36

3.13 Ilustração do processo de detecção de comunidades segundo o método de competição de partículas e caminhada aleatória. A rede possui 128 vértices, 4 comunidades bem definidas, grau médio $\langle k\rangle=16$ e proporção de conexões entre comunidade $p_{\text {out }}=0.2$. (a) Configuração inicial: quatro partículas nas cores amarelo, ciano, laranja, e azul são colocadas em vértices aleatórios da rede; os vértices em vermelho estão livres. Em (b) domínio das partículas na iteração 250. Em (c) domínio das partículas na iteração 3500. Em (d) domínio das partículas na iteração 7000. Figura obtida de (Quiles et al., 2008)

3.14 Fração de nós identificados corretamente em sua comunidade segundo o método de Quiles et al. (2008) em relação ao nível de determinismo da caminhada. Cada ponto da curva representa a média de 200 execuções em uma rede com 128 nós, $\langle k\rangle=16$, e $p_{\text {out }}=0,5$. A barra de erro representa o desvio padrão. Figura obtida de (Quiles et al., 2008). . . . . . . . . . . 
4.1 Caminhada aleatória em redes: (a) probabilidade de o caminhante moverse a partir do nó 1 até os nós vizinhos em uma iteração; (b-e) probabilidade de o caminhante mover-se a partir do nó 1 até os nó 1, 2, 3 e 4 em duas iterações. . . . . . . . . . . . . . . . . . . 47

4.2 (a) Resultado da aplicação do método de detecção de outliers em uma rede com 5 nós. Estão identificados em vermelho os nós com maior escore de outlier. (b) Matriz de dissimilaridade $\Lambda$. Quanto mais vermelho, maior o índice $\Lambda(i, j)$. (c) Ranque de outliers. . . . . . . . . . . . . . 50

4.3 (a) Resultado da aplicação do método de detecção de outliers em uma rede com 9 nós. Estão identificados em vermelho os nós com maior escore de outlier. (b) Matriz de dissimilaridade $\Lambda$. Quanto mais vermelho, maior o índice $\Lambda(i, j)$. (c) Ranque de outliers. . . . . . . . . . . . 51

4.4 (a) Resultado da aplicação do método de detecção de outliers em uma rede com 13 nós. Estão identificados em vermelho os nós com maior escore de outlier. (b) Matriz de dissimilaridade $\Lambda$. Quanto mais vermelho, maior o índice $\Lambda(i, j)$. (c) Ranque de outliers. . . . . . . . . . . . . 52

4.5 Resultado da aplicação do método de detecção de outliers proposto à rede do clube de karatê registrada por Zachary (1977). Os dez nós com maior escore de outlier aparecem coloridos. Quanto mais vermelho maior o escore de outlier do indivíduo. . . . . . . . . . . . . . . . . 5 53

4.6 Resultado da aplicação do método de detecção de outliers proposto à rede de colaboração entre cientistas registrada por Newman (2006). Os dez nós com maior escore de outlier aparecem coloridos. Quanto mais vermelho maior o escore de outlier do indivíduo. Os indivíduos mais colaborativos da rede também aparecem destacados.

4.7 Distribuição $(P(\sigma))$ do escore de outlier verificada na rede de interações entre proteínas do metabolismo da levedura Saccharomyces cerevisiae. Essa distribuição segue a lei de potência. . . . . . . . . . . . . . . . . 56

4.8 Fração $(\varphi)$ de proteínas relacionadas a cada grupo funcional entre os nós com maior escore de outlier. As proteínas relacionadas ao ciclo celular e processamento de DNA e as proteínas relacionadas ao metabolismo destacamse das demais. . . . . . . . . . . . . . . . . . 57

4.9 Proteínas mais outliers (em preto) e os respectivos arranjos locais. As proteínas YMR207c e YPR048w são proteínas relacionadas a função de metabolismo, enquanto que as proteínas YIL135c, YOR265w e YLR419w atuam no ciclo celular e processamento de DNA. As proteínas YJR091c e YJL194w estão relacionadas com ambas as funções. . . . . . . . . . . 58

4.10 Uma proteína tipicamente não outlier (em preto). A proteína com menor escore de outlier. . . . . . . . . . . . . . . . . 59 
4.11 (a) Rotulação de dados ideal de uma base de dados sintética do tipo banana com 200 exemplos, sendo 100 pertencentes a classe vermelha (circulo) e 100 pertencentes a classe azul (quadrados). (b) Rede geográfica do conjunto de dados em (a), construída segundo o método apresentado na Seção 3.3.5,

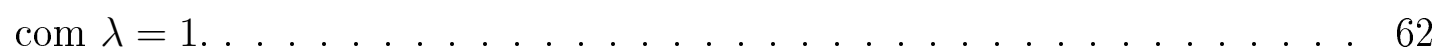

4.12 Resultado do método de propagação de rótulos proposto aplicado à rede construida a partir do conjunto de dados da Figura 4.11(a): (a) com base em 40 configurações de 10 nós rotulados a priori, escolhidos randomicamente, sendo 5 de cada comunidade; (b) com base nos 5 outliers centrais de cada comunidade. $\varphi$ é a precisão de detecção de comunidades a cada iteração. . . . . . . . . . . . . . . . . . . 62

4.13 Resultado do método de propagação de rótulos proposto aplicado à rede do clube de karatê (Figura 4.5): (a) com base em 20 configurações de 4 nós rotulados a priori, escolhidos randomicamente, sendo dois de cada comunidade; (b) com base nos nós 34, 1, 3 e 33, dois outliers centrais de cada comunidade. $\varphi$ é a precisão de deteç̧ão de comunidades a cada iteração. 63 


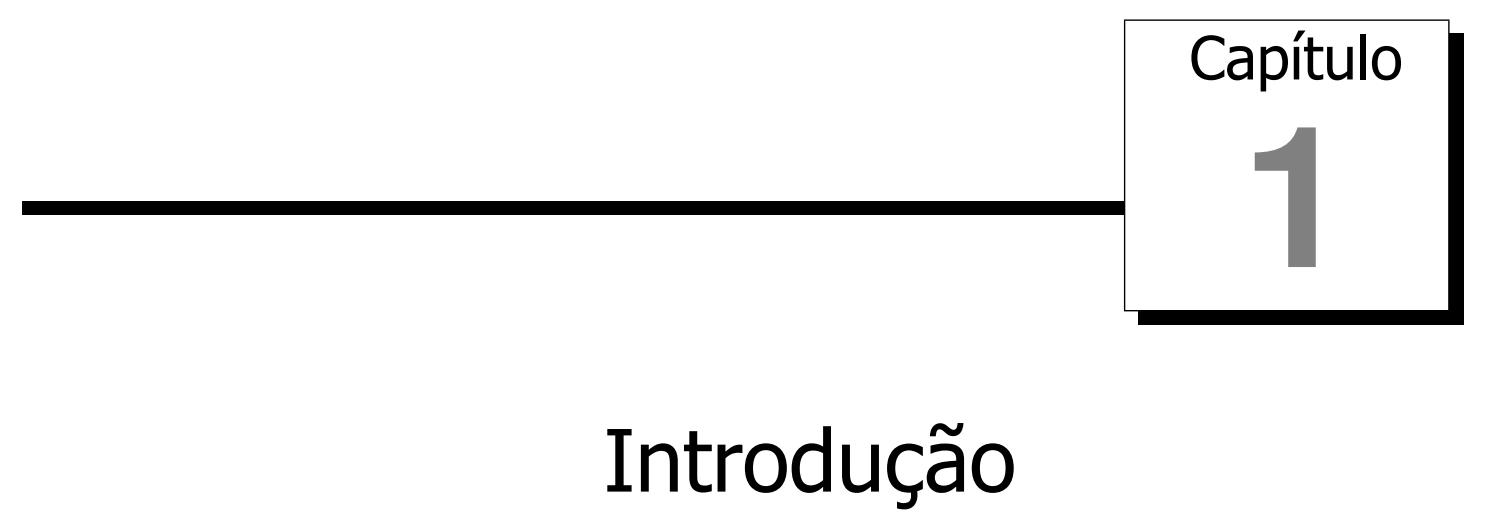

Na natureza e na ciência, dados e informações que desviam significativamente da média frequentemente possuem grande relevância. Se considerarmos, por exemplo, a atenção visual dos animais, os estímulos visuais que frequentemente atraem sua atenção são os contornos e arestas dos objetos, isto é, as regiões não homogêneas da cena, onde existem fortes variações na intensidade dos estímulos visuais (Marr, 1982). Dados e informações desse tipo, são geralmente referidos na literatura como outliers ou anomalias. Em um sentido geral, uma observação (ou subconjunto de observações) outlier parece desviar-se acentuadamente em relação aos outros membros da amostra em que ocorre, parecendo ser inconsistente em relação ao restante do conjunto de dados, de tal forma que se suspeite que tenha sido gerada por um mecanismo diferenciado (Grubbs, 1969; Hawkins, 1980; Barnett \& Lewis, 1994).

Por muito tempo pensou-se que observações outlier deviam-se a erros não contemplados na especificação de um modelo de aquisição de dados, portanto sendo considerados impurezas ou ruídos. Considerava-se que a introdução dessas observações na investigação serviria apenas para atrapalhar e confundir (Barnett \& Lewis, 1994). Por isso, tipicamente observações outliers eram eliminadas. No entanto, hoje em dia, existe uma variedade muito grande de aplicações nas quais observações outliers são bastante relevante. Exemplo disso são aplicações como: detecção de fraudes; processamento de pedidos de empréstimo; detecção de intrusão em sistemas; diagnóstico de falhas; monitoramento de condições médicas; entre outros. Nessas aplicações, observações outliers precisam ser detectadas para que possam ser tratadas adequadamente, de acordo com a necessidade da aplicação (Hodge \& Austin, 2004). 


\subsection{Contexto}

Nos últimos anos, tem-se testemunhado um grande interesse na área de Redes Complexas, motivado principalmente pela grande disponibilidade de recursos computacionais e de redes de comunicação, que têm permitido a análise de dados de grande escala. As redes complexas são grafos de grande escala que possuem padrões de conexões não trivial. Redes como a Internet (Faloutsos et al., 1999), a World Wide Web (Albert et al., 1999), redes de distribuição de energia elétrica (Albert et al., 2004), redes de colaboração entre cientistas (Newman, 2001), redes de interações sociais entre indivíduos (Scott, 2000), redes de interações entre companhias e organizações (Mizruchi, 1982), cadeias de contatos sexuais (Liljeros et al., 2001), cadeias alimentares (Montoya \& Solé, 2002), cadeias de interações metabólicas (Jeong et al., 2000), o sistema de distribuição da corrente sanguínea (West et al., 1999), redes neurais biológicas (Sponrs, 2002), entre outras, têm sido estudadas sob essa abordagem diferenciada. Propriedades triviais e soluções exatas têm deixado de ser o alvo, para dar lugar a propriedades complexas e soluções aproximadas (Newman et al., 2006). As redes complexas têm se mostrado uma poderosa maneira de representação e abstração de dados, constituindo um tópico unificador em sistemas complexos, presente em praticamente todos os ramos da ciência, e mudando a maneira com que vários sistemas interconectados são modelados (Bornholdt \& Schuster, 2003).

Segundo Costa et al. (2007), três tópicos têm sido os principais responsáveis pelo avanço dos estudos em Redes Complexas: o efeito de pequeno mundo (Watts \& Strogatz, 1998), a distribuição livre de escala (Barabási \& Albert, 1999), e as estrutura de comunidades (Girvan \& Newman, 2002). Tradicionalmente as redes complexas eram descritas de acordo com o modelo de Erdös \& Rényi (1959), conhecido como Grafos Randômicos ou Redes Randômicas. No entanto, Watts \& Strogatz (1998) descobriram que a media de caminhos mais curtos em uma rede pode ser drasticamente reduzida por alteração aleatória de poucas ligações em uma rede regular. A rede resultante foi denominada Rede de Pequeno Mundo. Em 1999, Barabási \& Albert (1999) descobriram que muitas das redes reais têm a distribuição de grau dos nós que obedece a lei de potência: $P(k) \sim k^{\gamma}$, onde $k$ é o número de conexões de um nó escolhido aleatoriamente e $\gamma$ o expoente de escala. O que significa que existe um pequeno conjunto de nós que possui um grande número de ligações $(h u b s)$ e um grande número de nós com poucas ligações. Estas redes são denominadas Redes Livre de Escala. Em 2002, Girvan \& Newman (2002) revelaram que em muitas redes reais, existem conjuntos de nós densamente conectados entre si, cujas ligações com nós de fora do grupo são esparsas. Essas estruturas foram denominadas comunidades. Desde então, muitas pesquisas têm sido conduzidas em Redes Complexas, tornando-na uma área de pesquisa bem definida. Como consequência, um grande montante de resultados de pesquisa têm sido reportados, especialmente relacionados às estruturas de comunidades, crescimento e auto-organização das redes, distribuição de grau, resiliência, processos epidemiológicos, sincronização, e outros (Albert \& Barabási, 2002; Newman, 
2003; Costa et al., 2007). Entretanto, pouco tem sido estudado acerca de outliers em redes complexas (Costa et al., 2009).

Tradicionalmente assumi-se que distribuições de dados são tipificadas por uma distribuição normal (Davies \& Gather, 1993). Entretanto, as redes livres de escala têm mostrado que essa abordagem nem sempre é verdadeira. Em uma distribuição normal, observações outliers são aquelas que desviam-se da média, e estão em regiões com desvio superior ao desvio padrão. Em uma rede livre de escala, se considerarmos a conectividade dos nós e o desvio padrão, os hubs podem ser denominados outliers, uma vez que sua conectividade desvia-se significativamente da conectividade dos demais nós. Porém, o fator determinante para essa classificação é que em redes livre de escala hubs são menos frequentes que os demais nós.

O aprendizado de máquina é uma área da ciência da computação que visa desenvolver métodos computacionais capazes de "aprender" através da experiencia (Mitchell, 1997; Bishop, 2006). De acordo com a disponibilidade de rótulos, o processo de aprendizado pode ser classificado como supervisionado, não-supervisionado, ou ainda semisupervisionado. No aprendizado supervisionado, o objetivo é induzir conceitos a partir de exemplos rotulados com uma classe conhecida. O processo de aprendizagem visa a construção de uma função de mapeamento entrada-saída com base na observação dos dados de treinamento fornecidos. No aprendizado não-supervisionado, o objetivo é agrupar os dados segundo algum critério de similaridade entre eles. O processo de aprendizagem é dito guiado pelos dados. O aprendizado semi-supervisionado constitui um meio termo entre a abordagem supervisionada e não-supervisionada. Nesse caso, poucos nós são rotulados a priori, e o objetivo é rotular os demais de acordo com o rótulo dos primeiros. Pode-se dizer que os exemplos rotulados a priori são responsáveis por guiar o processo de agrupamento dos dados (Chapelle et al., 2006).

Uma vez que as estruturas de comunidades representam padrões de interação bem definidos entre nós de uma rede, sua identificação é muito importante para o entendimento dos mecanismos de crescimento e formação das redes (Danon et al., 2005). Por isso, diversos métodos têm sido propostos nesse sentido (Zhou, 2003b,a; Newman \& Girvan, 2004; Newman, 2004b, 2006; Quiles et al., 2008). Do ponto de vista do aprendizado de máquina, esses métodos podem ser classificados como não-supervisionados. No sentido de aumentar a eficiência e eficácia desses métodos, alguns métodos têm sido propostos recentemente sob o paradigma semi-supervisionado (Allahverdyan et al., 2010; Ma et al., 2010; Breve et al., 2009). Essa abordagem é muito interessante, pois, embora não se conheça o rótulo de todos os indivíduos em uma rede, existem indivíduos bastante representativos que possuem rótulo bem definido. Do ponto de vista de redes de interações sociais, é o caso de líderes comunitários, responsáveis por representar sua comunidade. Contudo, pouco tem sido estudado acerca da relevância dos indivíduos rotulados a priori para o desempenho dos métodos de detecção de comunidades semi-supervisionados. 


\subsection{Objetivo}

O presente trabalho, tem como principal objetivo explorar o tópico detecção de outliers em redes complexas. Considerando-se a dinâmica de uma caminhada aleatória, foi proposta uma medida de distância, através da qual foi possível identificar os nós outliers em uma rede. Essa medida foi aplicada em diversas redes, de modo que foi possível identificar que existem características bem definidas nos nós identificados como outlier, relacionadas não apenas a estrutura dos nós da rede, como também a funcionalidade dos mesmos para o sistema complexo. Também, com base na medida de distância de uma caminhada aleatória, pudemos identificar que nós outliers são bons candidatos a rotulação a priori para a tarefa de detecção de comunidades semi-supervisionada, sendo elementos representativos de suas comunidades. Adicionalmente, será apresentado um método bioinspirado de detecção de comunidades semi-supervisionada. Esse método foi utilizado para verificar o desempenho da detecção de comunidades semi-supervisionada com relação aos nós rotulados a priori.

\subsection{Organização do Documento}

O presente trabalho irá mostrar a aplicação da caminhada aleatória para a detecção de outliers em redes, como também para a identificação de candidatos a rotulação a priori para a detecção de comunidades semi-supervisionada. Para isso, o presente trabalho está organizado da seguinte forma: O Capítulo 2 apresenta uma revisão sobre o tema detecção de outliers. O Capítulo 3 apresenta uma revisão sobre os temas redes complexas e detecção de comunidades. O Capítulo 4 apresenta um método baseado em caminhada aleatória proposto para identificação de outliers em redes, resultados obtidos, um método semisupervisionado proposto para a detecção de comunidades, e uma análise sobre a rotulação a priori de outliers para a tarefa de detecção de comunidades semi-supervisionada. Por fim, é apresentado no Capítulo 5 as principais conclusões do trabalho e perspectivas de trabalhos futuros. 


\section{Capítulo}

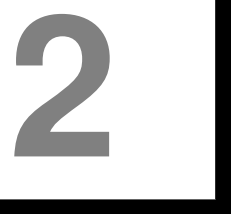

\section{Detecção de Outliers}

De um modo geral, detecção de outliers refere-se ao problema de identificar padrões que não se comportam segundo esperado. Esses padrões são referidos na literatura como anomalias, outliers, observações discordantes, exceções, peculiaridades, ou contaminantes. Desses, o termo mais comum é outlier. Esse capítulo irá apresentar uma revisão sobre esse tópico. Serão apresentadas definições, exemplos de aplicações, motivação e métodos de identificação de outliers.

\subsection{Introdução}

Existem diversas definições para outlier na literatura. Muitas delas atêm-se a um contexto de aplicação específico. No entanto, as seguintes definições podem ser tomadas em um contexto bastante amplo. Segundo Grubbs (1969), uma observação periférica, ou outlier, é aquela que parece desviar-se acentuadamente em relação aos outros membros da amostra em que esta ocorre. Hawkins (1980), por sua vez, afirma que um outlier é uma observação que desvia-se muitos das demais observações, a ponto de suspeitar-se que tenha sido gerada por um mecanismo diferenciado. Barnett \& Lewis (1994) definem outlier como uma observação (ou subconjunto de observações) que parece ser inconsistente em relação às demais no conjunto de dados.

Por muito tempo pensou-se que observações outlier deviam-se a erros não contemplados na especificação de um modelo de aquisição de dados, portanto sendo considerados impurezas ou ruídos. Considerava-se que a introdução dessas observações na investigação serviria apenas para atrapalhar e confundir. Por isso, tipicamente observações outliers eram eliminadas. No entanto, hoje em dia, existe uma variedade muito grande de aplicações nas quais observações outliers são bastante relevante. Exemplo disso são: 
Detecção de fraudes - o uso fraudulento de cartões de crédito, benefícios estatais, telefones celulares, entre outros precisam ser detectados - uma transação incomum ao perfil do cliente pode apontar a ocorrência de uma fraude;

Processamento de pedido de empréstimo - clientes potencialmente problemáticos precisam ser identificados - histórico de empréstimos anteriores pode indicar o potencial de inadimplência do cliente;

Detecção de intrusão - acessos não autorizado em sistemas informatizados, bancos de dados, redes de computadores, entre outros precisam ser detectados - um procedimento ou consulta incomum pode caracterizar uma intrusão;

Diagnóstico de falhas - em processos, linhas de produções, motores, caldeiras, instrumentos, etc - informações de sensores de temperatura, ruido, pressão, entre outros, podem caracterizar a ocorrência de uma falha;

Monitoramento de condições médicas - os sinais vitas do paciente, tais como frequência cardíaca, frequência respiratória, saturação, entre outros precisam ser monitorizados - curvas inconsistentes pode caracterizar condições de saúde instáveis.

Nessas aplicações, eventos inconsistentes, aqui denominados observações outliers, precisam ser detectados para que possam ser tratadas adequadamente, de acordo com a necessidade da aplicação. De um modo geral, a importância dessas observações deve-se ao fato de que, para essas aplicações, outliers representam informações relevantes, ou ainda, em alguns casos, informações críticas.

No ano de 1949, no processo legal Hadlum vs. Hadlum, o Sr. Hadlum tentou um recurso diante do fracasso da sua petição de divorcio. Ele reclamou adultério de sua esposa, Sra. Hadlum. A única evidência do adultério consistia no nascimento de uma criança no ano de 1945, 349 dias depois de o Sr. Hadlum ter deixado o seu país para ir à guerra. O Sr. Hadlum fundamentou seu recurso essencialmente no fato de que 349 dias de gestação seria demasiado, uma vez que o período médio de gestação humana é de 280 dias, i.e. 40 semanas. Os juízes do recurso concordaram que, embora improvável, 349 dias de gestação seria cientificamente possível. Por tanto, o recurso falhou. Naquele mesmo ano, no processo legal M.-T. vs. M.-T., 340 dias de gestação foi considerado "impossível a luz de evidências da ginecologia moderna". A Figura 2.1 mostra uma distribuição de períodos de gestação adaptada de (Barnett, 1978). Esse histograma foi concebido com base em 13634 nascimentos britânicos, registrados por Chamberlain (1970) alguns anos depois dos casos Hadlum vs. Hadlum e M.-T. vs. M.-T.. Note que a observação do caso M.-T. vs. M.-T., e mais ainda a observação do caso Hadlum vs. Hadlum, desvia-se acentuadamente em relação a distribuição normal. Houvesse sido feito um estudo mais aprofundado acerca dos períodos de gestação por ocasião, 349 dias de gestação certamente seria identificado como outlier, e o Sr. Hadlum teria ganho o caso. 


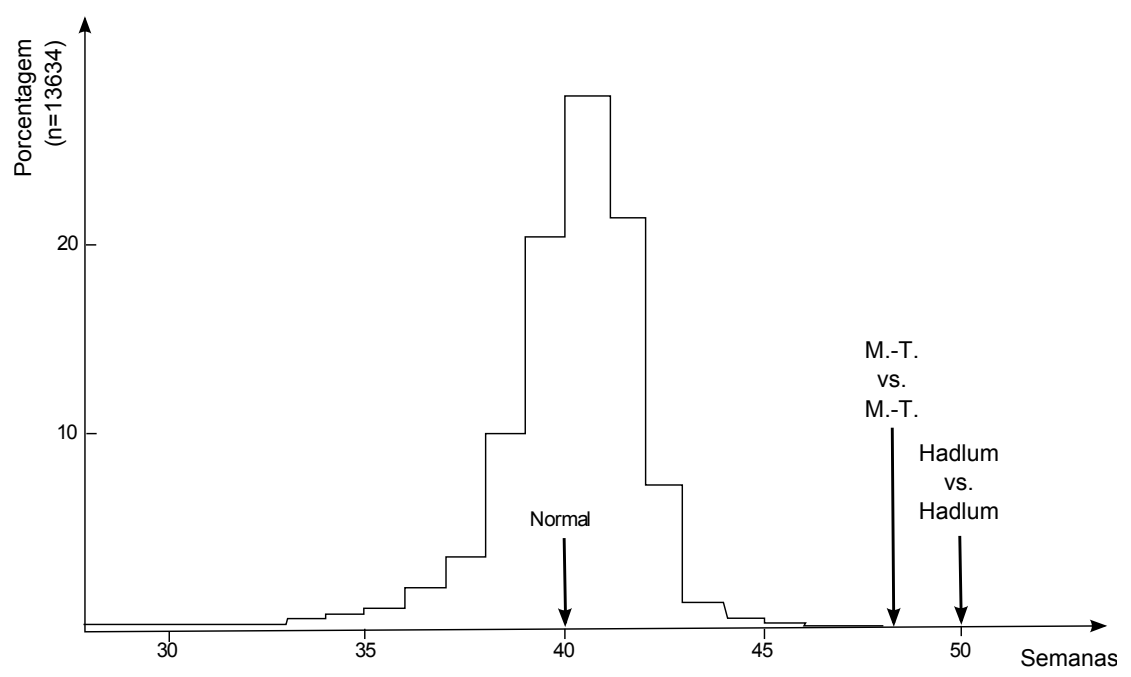

Figura 2.1: Histograma produzido com base em 13634 nascimentos registrados por Chamberlain (1970). As observações dos casos M.-T. vs. M.-T. e Hadlum vs. Hadlum desviamse acentuadamente da distribuição. Figura adaptada de (Barnett, 1978).

\subsection{Aspectos Gerais}

A representação da Figura 2.2 ilustra um conjunto de dados bidimensional. Os dados possuem duas regiões normais, $N_{1}$ e $N_{2}$, e outras observações que fogem a essas regiões. As observações que desviam-se acentuadamente dessas regiões, por exemplo, $o_{1}$ e $o_{2}$, bem como as observações da região $O_{3}$, podem ser identificadas como outliers. Usaremos esse e alguns outros exemplos, para apresentar alguns aspectos gerais acerca da identificação de outlier. Esses aspectos dizem respeito a natureza do conjunto de dados, a disponibilidade de rótulos para os dados, e a rigidez do método de identificação de outliers.

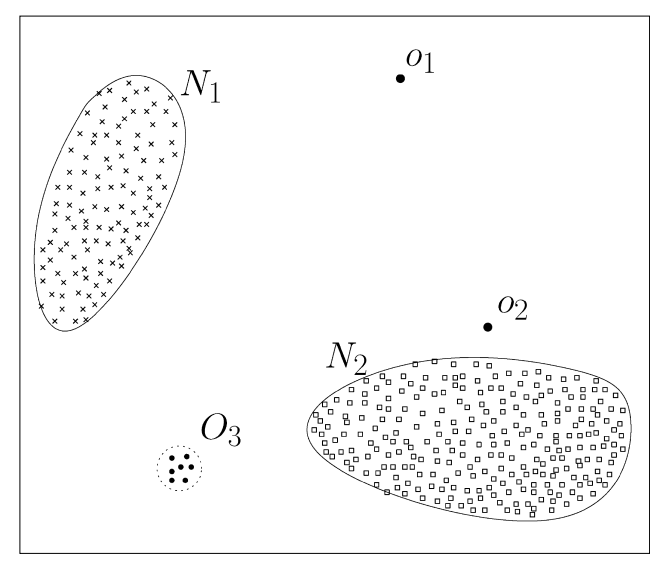

Figura 2.2: Outliers em um conjunto de dados bidimensional. As observações $o_{1}$ e $o_{2}$ e o subconjunto $\mathrm{O}_{3}$ podem ser identificados como outliers. Figura adaptada de (Chandola et al., 2009). 


\subsubsection{Natureza do Conjunto de Dados}

Nos métodos de identificação de outliers, geralmente, um conjunto de dados é apresentado como entrada. Esse conjunto de dados também referido como coleção, série, amostra, entre outros sinônimos, é composto por observações (instâncias, ou exemplos) que possuem um ou mais atributos, isto é, são uni ou multivariados. Cada atributo pode assumir valores de apenas um tipo específico, tais como contínuo, discreto, e binário (Jain \& Dubes, 1988). No caso de um conjunto de dados multivariado, todos os atributos podem ser do mesmo tipo, ou podem ser de tipos de dados distintos.

A natureza dos dados de entrada, isto é, os tipos de dados dos atributos interferem diretamente na performance do método de identificação de dados. No caso dos métodos univariados (Seção 2.3), diferentes tipos de modelos geradores precisam ser utilizados para diferentes tipos de dados. Em um método baseado em distância, um conjunto de dados multivariado precisará utilizar uma distância que comporte todos os tipos de dados dos atributos. Os tipos dos atributos influenciam diretamente os parâmetros dos métodos.

Eventualmente, instâncias de dados podem estar relacionadas entre si. É o caso de dados sequenciais, dados espaciais, e dados relacionais, como grafos. No caso de dados sequenciais, o que é o caso de uma série temporal, as instâncias estão relacionadas entre si linearmente. No caso de dados espaciais, cada instância está relacionada com suas instâncias vizinhas geograficamente. No caso dos grafos, cada instância é representada por um vértice e esta conectada a outras instâncias através de arestas. Dados que envolvem atributos espacias e temporais, compreende os chamados dados espaço-temporais.

\subsubsection{Tipos de Outliers}

Dependendo das características do conjunto de dados apresentado ao método de identificação de outliers, diferentes tipos de outliers podem ser identificados. Chandola et al. (2009) apresenta em seu trabalho 3 categorias de outliers: outliers pontuais, outliers contextuais, e outliers coletivos.

Quando uma instância é considerada anormal com relação a todo o conjunto de dados, ela é denominada um outlier pontual. Este é o tipo mais comum de outlier. Na Figura 2.2 os pontos $o_{1}$ e $o_{2}$, assim como os pontos da região $O_{3}$, estão situados fora das regiões normais, sendo portanto considerados outliers pontuais. No caso dos períodos de gestação, um período demasiadamente longo, ou demasiadamente curto pode ser considerado um outlier pontual.

Se uma instância é anormal em relação um contexto específico, mas não é em relação a todo o conjunto de dados, essa instância é dita um outlier contextual. Dados sequenciais, dados espaciais e grafos são tipicamente analisados dessa forma. No caso de uma série temporal o tempo é um atributo contextual, enquanto que os demais atributos são atributos comportamentais. Em dados climáticos por exemplo, enquanto que latitude, longitude, e período do ano são dados contextuais, a temperatura é um dado comporta- 
mental. A Figura 2.3 mostra um exemplo de série temporal de dados climáticos onde é apresentada a temperatura ao longo do ano em uma determinada localidade no hemisfério norte. A temperatura registrada em $t_{1}$ é uma temperatura normal durante o inverno, porém quando registrada em $t_{2}$, no verão, essa temperatura é um outlier.

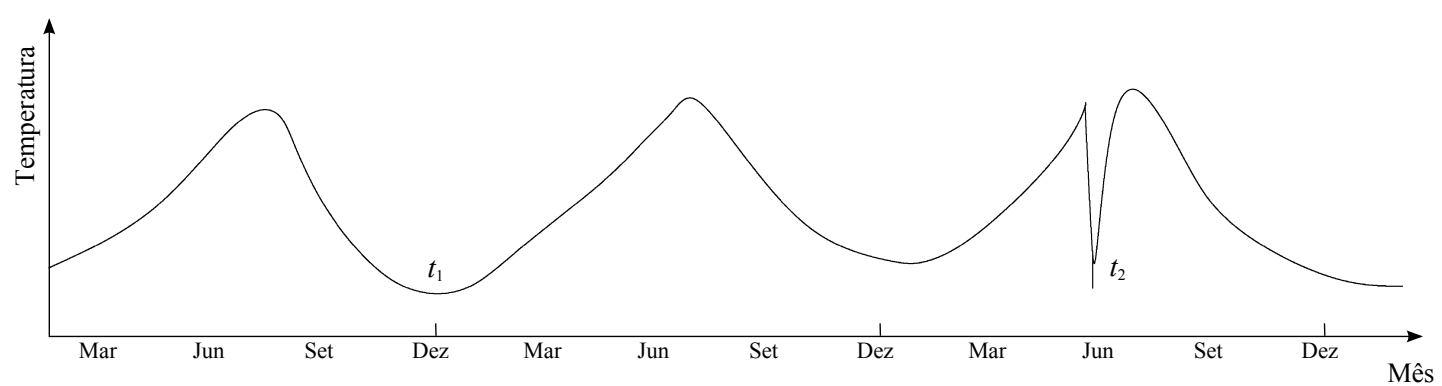

Figura 2.3: Série temporal de temperatura: $t_{2}$ é um outlier contextual. Embora a temperatura seja a mesma em $t_{1}$ e em $t_{2}$, apenas no contexto de $t_{2}$ essa observação é outlier. Figura adaptada de (Chandola et al., 2009).

Quando instâncias em um subconjunto são normais com relação ao todo, mas coletivamente são anormais, elas são denominadas outlier coletivo. A Figura 2.4 mostra a imagem de um eletrocardiograma. A região destacada (em vermelho) representa um outlier coletivo. Embora o valor verificado nessa região seja observado periodicamente, a continuidade do mesmo por um longo período de tempo é anormal. No caso desse eletrocardiograma, essa região equivale a uma contração prematura do átrio, uma anormalidade que deve ser avaliada.

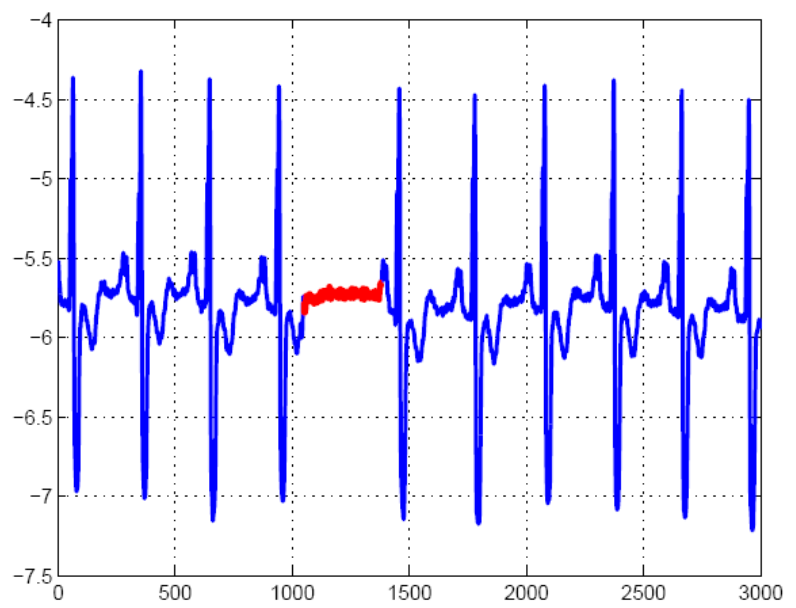

Figura 2.4: Outlier coletivo destacado (em vermelho), correspondendo a uma contração prematura do átrio em um eletrocardiograma. Figura obtida de (Chandola et al., 2009).

A decisão de aplicar um método de detecção de outliers pontual, contextual, ou coletivo dependerá apenas do domínio de aplicação do método. 


\subsubsection{Disponibilidade de Rótulos}

O aprendizado de máquina é uma área da ciência da computação que visa desenvolver métodos computacionais capazes de "aprender" através da experiencia (Mitchell, 1997; Bishop, 2006). Do ponto de vista do aprendizado de máquina, de acordo com a disponibilidade de rótulos, o processo de identificação de outliers pode ser classificado como supervisionado, não-supervisionado, ou ainda semi-supervisionado (Hodge \& Austin, 2004; Chandola et al., 2009).

Na abordagem supervisionada, é necessário que exista um conjunto de dados de treinamento, onde todas as instâncias devem estar rotuladas como normais ou como outliers. Desse conjunto de dados é construído um modelo de inferência capaz de classificar instâncias não vistas, como outliers ou não-outlier. No entanto a obtenção de rótulos representativos, especialmente para instâncias outliers, é um desafio.

Na abordagem semi-supervisionada o conjunto de treinamento possui apenas instâncias normais rotuladas. Uma vez que não requer a rotulação de observações outliers, essa abordagem torna-se mais aplicável. Técnicas desse tipo tipicamente constroem um modelo para a classe das instâncias normais, e utiliza esse modelo para identificar instâncias inconsistentes.

A abordagem não-supervisionada, por outro lado, não requer qualquer conhecimento prévio acerca da classificação como outliers ou não. Nesse caso, a partir das características intrínsecas do conjunto de dados, visa-se identificar quais instâncias são ou não outliers. Por não requerer um conjunto de treinamento, essa abordagem é a mais comum. É o caso das técnicas estatísticas baseadas em modelos geradores (Seção 2.3) e também das demais técnicas baseadas em mineração de dados e aprendizado de máquina (Seção 2.4.2). Uma vez que a disponibilidade de rótulos é um problema não solucionado, técnicas supervisionadas, e até mesmo técnicas semi-supervisionadas, são muito caras.

\subsubsection{Rigidez do Método}

Os métodos de identificação de outliers tipicamente retornam como saída escores ou rótulos. A atribuição de um escore de outlier, também conhecida como classificação fraca $^{1}$ não permite afirmar quais instâncias são ou não outlier. É possível apenas ordenar as instâncias de acordo com o potencial de outlier. Isso representa uma desvantagem pelo fato de requerer a parametrização do número de outliers. Por outro lado, é vantagem no sentido de oferecer um índice de confidência. A atribuição de rótulos, ou classificação rígida ${ }^{2}$, retorna a classificação dos nós como outliers ou não. Em contraponto à atribuição de escore, esta apresenta como desvantagem não identificar quais nós são mais outliers, porém não requer a parametrização do número de outliers.

\footnotetext{
${ }^{1}$ Do inglês: soft-label.

${ }^{2}$ Do inglês: hard-label.
} 


\subsection{Detecção de Outliers em Dados Univariados}

A identificação de observações outliers tem sido estudada há muito tempo na comunidade estatística, de modo que diversos métodos têm sido propostos. Muitos desses métodos foram originados com o objetivo de tratar conjuntos de dados univariados. $\mathrm{Na}$ estatística, o problema de identificação de outliers pode ser traduzido no problema de identificar se uma observação em um conjunto de dados é ou não genuína.

Supondo que existe um modelo gerador de uma distribuição alvo $F$, frequentemente uma distribuição normal, $N\left(\mu, \sigma^{2}\right)$, e que existe um modelo gerador pelo qual um pequeno número de observações, ditas contaminantes, é gerado aleatoriamente consistente com um conjunto de distribuições $\left\{G_{1}, \ldots, G_{k}\right\}$ diferentes de $F$. De acordo com Davies \& Gather (1993), para um grau de confiança $\alpha, 0<\alpha<1$, uma região $\alpha$ outlier pode ser definida como

$$
\operatorname{out}\left(\alpha, \mu, \sigma^{2}\right)=\left\{x:|x-\mu|>z_{1-\alpha / 2^{\sigma}}\right\},
$$

onde $z_{q}$ é o $q$ quartil da distribuição $N(0,1)$, isto é, $\Phi\left(Z_{q}\right)=q$. Assim, um valor $x$ é dito $\alpha$ outlier em relação a $N\left(\mu, \sigma^{2}\right)$ se $x \in$ out $\left(\alpha, \mu, \sigma^{2}\right)$. Logo, uma variável aleatória $X$ pertence a região $\alpha$ outlier com probabilidade

$$
P\left(X \in \operatorname{out}\left(\alpha, \mu, \sigma^{2}\right)\right)=\alpha \text {. }
$$

Conhecida a distribuição alvo, qualquer observação que desvie-se acentuadamente dela pode ser classificada como outlier. Dessa definição não é possível determinar se uma observação é contaminante, isto é, se foi gerada a partir de um modelo gerador diferente do modelo gerador de $F$, mas é possível identificar se uma observação está na região de outlier, sendo incompatível com a distribuição alvo $F$. Essa definição também pode ser estendida para qualquer outra distribuição unimodal simétrica com função de densidade positiva, inclusive distribuições multivariadas.

De um modo geral, se o conjunto de dados não possui contaminações, a média e o desvio padrão oferecem uma boa estimativa da localização e forma da distribuição alvo, permitindo a identificação de observações outliers com base em um modelo gerador. O exemplo a seguir mostra uma amostra de dados contaminada. Nela, as observações 81.5, 79.5 e 78.8 foram geradas a partir de um modelo gerador diferente do modelo gerador da distribuição alvo.

$$
\begin{array}{cccccccccc}
22.6 & 28.8 & 26.8 & 81.5 & 19.1 & 15.2 & 24.1 & 23.6 & 9.1 & 79.5 \\
18.6 & 78.8 & 23.1 & 11.9 & 20.1 & 20.3 & 17.3 & 25.8 & 14.1 & 26.5
\end{array}
$$

Estimando-se a média e desvio padrão, podemos descrever o conjunto de dados pela distribuição normal $N(20,25)$. Logo, para $\alpha=0.01$, podemos identificar as observações na região $\alpha$ outlier, isto é, out $(0.01,20,25)$. Logo, as observações contaminantes poderiam ser identificadas como outliers. 
Quando o conjunto de dados está contaminado, isto é, possui observações contaminantes, eventualmente a média e desvio padrão podem desviar-se acentuadamente dos valores de referencia da distribuição alvo. Isso pode acontecer por exemplo, em decorrência de uma única observação contaminante fora de escala. Nesse caso, a performance do método de identificação de outliers seria depreciado significativamente.

Liu et al. (2004) propuseram um filtro de dados resistente à inserção de contaminantes no conjunto de dados. Esse filtro combina on-line um modelo gerador com um filtro de Kalman modificado para a detecção e a eliminação de outlier. O método não requer qualquer conhecimento a priori do modelo gerador. Ele detecta e substitui observações outliers enquanto que preserva todas as outras observações do conjunto de dados. Liu et al. (2004) demonstram que o filtro é eficiente inclusive na detecção e eliminação de outliers em dados correlacionados.

\subsection{Detecção de Outliers em Dados Multivariados}

Atualmente, existe uma demanda muito grande de dados multivariados. Embora seja possível estender métodos univariados para tratar conjunto de dados multivariados, o que pode ser feito através do tratamento independente de cada variável, muitas vezes isso resultará na perda de performance do método. Isso ocorre especialmente quando existem variáveis correlacionadas. Um exemplo disso é apresentado na Figura 2.5. Nessa figura está representado um conjunto de dados bidimensional. A observação $o_{1}$ é uma observação outlier multivariada. Entretanto, se cada atributo for tratado independentemente, não será possível identificar essa observação como outlier, uma vez que $x\left(o_{1}\right)$ e $y\left(o_{1}\right)$ estão, respectivamente, muito próximos a média da distribuição dos respectivos atributos. Nesse caso, será necessário um método capaz de tratar o relacionamento entre os dois atributos.

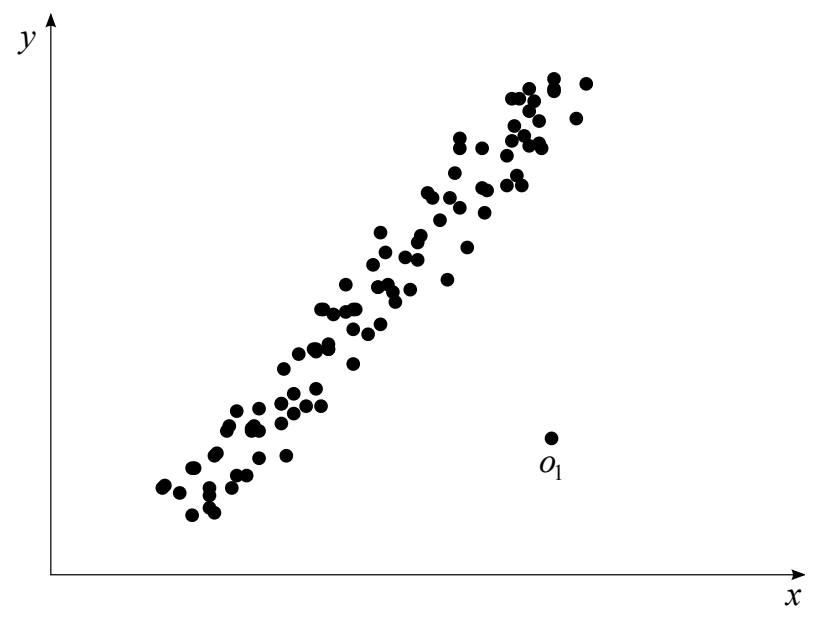

Figura 2.5: Conjunto de dados bidimensional com variáveis correlacionadas. A observação $o_{1}$ é uma observação outlier. No entanto, tratando as variáveis independentemente, não é possível detectar $o_{1}$.

De um modo geral, podemos separar métodos de detecção de outliers multivariados em métodos estatísticos e em métodos baseados em mineração de dados e aprendizado 
de máquina Hodge \& Austin (2004); Chandola et al. (2009). Os métodos estatísticos, assim como os métodos univariados, baseiam-se na estimação de uma distribuição alvo, nesse caso, uma distribuição multivariada. Os métodos baseados em mineração de dados e aprendizado de máquina, por outro lado, podem ser divididos principalmente em métodos baseados em distância, métodos baseados em agrupamento, e métodos baseados em densidade.

\subsubsection{Métodos Estatísticos}

Assim como no caso univariado, o objetivo dos métodos estatísticos é identificar observações que estão fora da distribuição alvo. Entretanto, nesse caso, apenas modelos resistente a variáveis dependentes devem ser utilizados.

A distância de Mahalanobis é um exemplo de modelo multivariado que serve muito bem a esse propósito. Como baseia-se na correção entre os atributos, é capaz de tratar adequadamente variáveis dependentes. Dada uma amostra com $n$ observações de um conjunto de dados $p$-dimensional, frequentemente $p<n$, onde a média é denotada pelo vetor $\bar{x}_{n}$, e a matriz de covariância é denotada por $V_{n}$,

$$
V_{n}=\frac{1}{n-1} \sum_{i=1}^{n}\left(x_{i}-\bar{x}_{n}\right)\left(x_{i}-\bar{x}_{n}\right)^{T},
$$

a distância de Mahalanobis de cada observação $i$ à distribuição normal, $i=\{1, \ldots, n\}$, é denotada por $M$,

$$
M=\sqrt{\sum_{i=1}^{n}\left(x_{i}-\bar{x}_{n}\right)^{T} V_{n}^{-1}\left(x_{i}-\bar{x}_{n}\right)} .
$$

A amostra deve ser ranqueada em ordem decrescente segundo a distância de Mahalanobis, de modo que as observações com maior distância podem ser identificadas como outliers. Adicionalmente a medida oferece um índice de confidência.

Penny \& Jolliffe (2001) apresentam um comparativo entre seis métodos estatísticos multivariados para a detecção de outliers. Esses métodos são adaptações do método baseado na distância de Mahalanobis. Desses, dois métodos utilizam-se de técnicas de redução de dimensionalidade, tais como PCA (Análise de Componentes Principais) ${ }^{3}$ e MDS (Escalonamento Multidimensional $)^{4}$ para a identificação dos atributos mais representativos à identificação de outliers. Isso porquê, o tratamento de conjuntos de dados com muitas dimensões através do método apresentado acima é muito custoso. Os resultados apresentados mostram que o método mais adequado a aplicação dependerá das características do conjunto de dados, tais como, se o conjunto de dados é ou não caracterizado por uma distribuição normal multivariada, a dimensão do conjunto de dados, os tipos de outliers presentes, a proporção de outliers no conjunto de dados e o quão contaminada está a

\footnotetext{
${ }^{3}$ Do inglês: Principal Component Analysis.

${ }^{4}$ Do inglês: Multidimensional Scaling.
} 
amostra. Portanto, os autores destacam que é necessário que ser aplique vários métodos multivariados em um conjunto de dados particular no sentido de identificar possíveis outliers.

\subsubsection{Métodos Baseados em Mineração de Dados e Aprendizado de Máquina}

Quando o conjunto de dados possui tipos diversos de dados, especialmente tipos discretos, a menos do pre-processamento de dados e tradução na forma de tipos contínuos, métodos estatísticos tornam-se inaptos à identificação de outliers (Hodge \& Austin, 2004). Nesse caso é mais apropriado a aplicação de técnicas baseadas em mineração de dados e aprendizado de máquina. Esses métodos além de serem tipicamente capazes de tratar dados com atributos de diversos tipos de dados, também distinguem-se dos demais devido a capacidade de tratar grandes conjuntos de dados. Contudo, uma vez que não foram desenvolvidos com o fim de identificar outliers, geralmente não são muito eficientes.

\section{Métodos Baseados em Distância}

Métodos para a detecção de outliers baseados em distância, isto é, baseados no método k-vizinhos mais próximos, tão utilizado para tarefas de classificação e agrupamento de dados, requerem a computação de uma distância, ou índice de similaridade, entra pares de observações. Uma vez que existe uma variedade muito grande de medidas de distância na literatura (Jain \& Dubes, 1988; Everitt et al., 2009), deve-se escolher a mais adequada de acordo com a natureza do conjunto de dados em questão.

Uma vez definido o valor da distância a cada um dos k-vizinhos mais próximos, um escore de outlier pode ser computado, por exemplo, a partir da soma das distâncias. As instâncias podem ser ranqueadas de acordo com esse escore, ou simplesmente pode-se definir um limiar par a classificação como outlier. Ramaswamy et al. (2000) escolheram como outliers as $n$ instâncias com maior escore de outlier. Esse método tem sido estendido de diversas maneiras, modificando a medida de distância utilizada, a maneira de computar o escore de outlier, ou ainda modificando o método dos k-vizinhos mais próximos no sentido de que seja mais eficiente. A adaptação mais popular é apresentada por Knorr \& Ng (1997) e estendida nos trabalhos (Knorr \& Ng, 1998, 1999; Knorr et al., 2000). Os autores propuseram computar o número de vizinhos dentro de uma hiperesfera com raio $d$, de modo que as instâncias com menor número de vizinhos são as mais outliers.

\section{Métodos Baseados em Densidade}

De um modo geral, métodos baseados em densidade estimam para cada instância uma densidade em relação a sua vizinhança. Se uma instância pertence a uma região de baixa densidade, e possui densidade ainda menor, ela pode ser classificada como uma instância outlier, caso contrário, será classificada como uma instância normal. 
O método proposto por Knorr \& Ng (1997), apresentado na seção anterior, computa o número de vizinhos dentro de uma hiperesfera com raio $d$ para cada instância, equivalente a densidade. Entretanto, este método não pode ser classificado como um método baseado em densidade, pois, se o conjunto de dados possui regiões de variação de densidade, esse método têm sua performance depreciada. Considere o conjunto de dados bidimensional representado na Figura 2.6. Devido a baixa densidade do cluster $C_{1}$, para qualquer instância $q$ em $C_{1}$, a distância entre $q$ e seus vizinhos é maior que a distância entre $p_{2}$ e seu vizinho mais próximo em $C_{2}$. Nesse caso, a técnica proposta por Knorr \& Ng (1997) seria incapaz de identificar $p_{2}$ como outlier, pois não poderia diferenciar $p_{2}$ de qualquer instância em $C_{1}$, ainda que consiga identificar facilmente a instância $p_{1}$ como outlier.

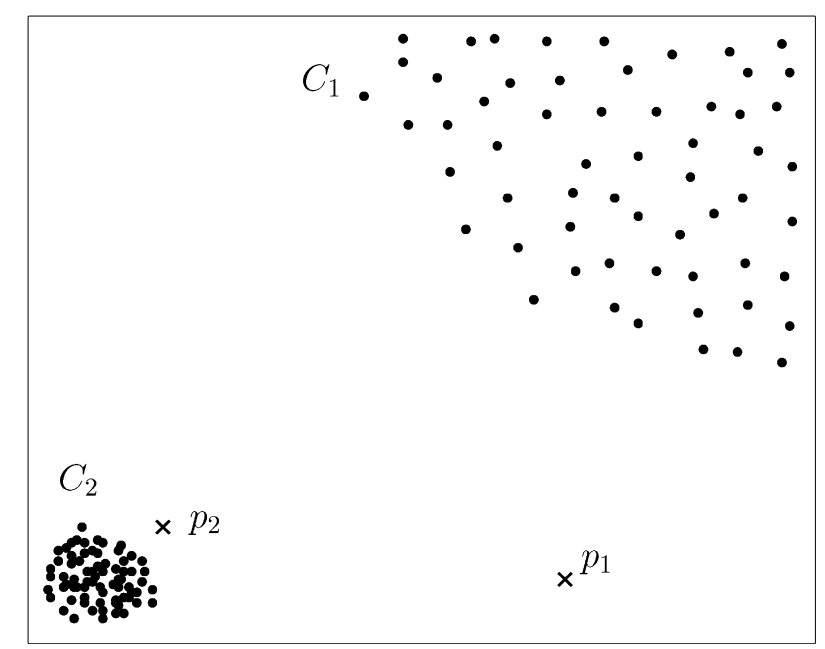

Figura 2.6: Conjunto de dados bidimensional com variação de densidade. Nesse caso, métodos baseados em densidade local apresentam performance melhor que métodos baseados em densidade global. Figura adaptada de (Chandola et al., 2009).

Vários métodos têm sido propostos com o objetivo de tratar conjuntos de dados que possuam variação de densidade. São os métodos baseados em densidade. Os quais, podem ser classificados como uma extensão dos métodos baseados em distância.

Breunig et al. (1999, 2000) propuseram um escore de outlier conhecido com Local Outlier Factor (LOF). Dada uma instância q, o escore LOF é dado pela razão da média da densidade local dos k-vizinhos mais próximos de $q$ sobre a densidade local de $q$. Para calcular a densidade local primeiro é necessário identificar a menor hiperesfera que contenha os k-vizinhos mais próximos de $q$. O raio dessa hiperesfera é dado por $d$. Logo, a densidade local é dada por $k / d$. Quanto menor a densidade local da instância em relação aos seus vizinhos, maior o escore. No exemplo da Figura 2.6 o LOF é capaz de identificar tanto a instância $p_{1}$ como a instância $p_{2}$ como outlier.

Diversas extensões do LOF têm sido propostas. Algumas delas utilizam diferentes métodos para o calculo da densidade local, outras utilizam medidas de distância capazes de tratar conjuntos de dados com atributos de tipos distintos, outras visam tornar o método mais eficiente. Contudo todas seguem o mesmo princípio. 


\section{Métodos Baseados em Agrupamento de Dados}

Agrupamento de dados, ou clustering, é um problema do aprendizado de máquina em que, dado uma coleção, os dados são agrupados de acordo com algum critério de similaridade. Tipicamente, esse dados baseiam-se na abordagem não supervisionada do aprendizado de máquina.

Embora agrupamento de dados e detecção de outlier sejam fundamentalmente diferentes, vários métodos baseados em clustering têm sido estendidos para a identificação de observações outliers. Segundo Chandola et al. (2009), métodos baseados em clustering podem ser agrupados em três categorias.

A primeira categoria baseia-se na suposição de que instâncias normais pertencem a algum cluster enquanto que outliers não pertencem a nenhum cluster. Em técnicas dessa tipo, dado um conjunto de dados, um algoritmo de agrupamento é aplicado sobre os dados, e toda instância que não for encorporada a algum cluster pode ser considerada outlier, de modo que é necessário que sejam utilizados algoritmos de clustering que não forcem toda instância a pertencer a algum cluster. É o caso do DBSCAN (Ester et al., 1996), um método de agrupamento de dados baseado em densidade, capaz de identificar clusters de formas arbitrárias. Em (Yu et al., 2002) os autores apresentam um algoritmo para identificação de outlier em clustering chamado FindOut. Nesse algoritmo os clusters do conjunto de dados são removidos, de modo que as instâncias remanescentes podem ser declaradas outliers. Uma vez que não foram desenvolvidas com o fim de identificar outliers, essas técnicas tipicamente não são muito eficientes para a identificação de outliers, pois envolvem o processamento de todo o conjunto de dados.

A segunda categoria baseia-se na suposição de que instâncias normais estão próximas ao centroide do cluster a que pertence, enquanto que outliers estão muito distantes do centroide mais próximo. Técnicas baseadas nessa suposição consistem em dois passos. Os dados são agrupados de acordo com algum algoritmo de cluster. Então, para cada instância, a distância até o centroide mais próximo é calculada, o que funciona como um escore de outlier. Técnicas como mapas auto-organizáveis (SOM), Expectation Maximization (EM), k-médias e k-medoides tem sido utilizadas com este fim, como por exemplo em (Smith et al., 2002). He et al. (2003) apresentam uma técnica chamada FindCBLOF, onde a cada instância é atribuído um escore de outlier conhecido como Cluster-Based Local Outlier Factor (CBLOF). Esse escore baseia-se no tamanho do cluster ao qual a instância pertence e na distância da instância até o centroide do cluster. Se um cluster possui tamanho e/ou densidade inferior a certo limiar, então todas as suas instâncias podem ser classificadas como outliers. Semelhantemente, diversos métodos têm sido propostos baseados na suposição de que instâncias normais pertencem a clusters grandes e densos, enquanto que instâncias outliers pertencem a clusters pequenos e esparsos. Estes têm o objetivo de identificar clusters de outliers. Em sua maioria variações desse método visam maior eficiência. Essa é a terceira categoria de métodos baseados em agrupamento de dados segundo (Chandola et al., 2009). 


\subsection{Detecção de Outliers Espaciais}

Observações que parecem ser inconsistentes com relação a sua vizinhança são denominadas outliers contextuais. Uma das principais áreas de interesse desse tipo de outlier é a análise de dados espaciais. Dados espaciais são dados cujos atributos podem ser divididos em duas categorias: atributos espaciais e atributos não-espaciais. Posição, forma, entre outras propriedades geométricas e topológicas são ditos atributos espaciais. Temperatura, umidade, índice de precipitação, velocidade do vento idade, entre outras leituras de sensores, são atributos não espaciais. Uma vizinhança, nesse caso, é um subconjunto de observações similares de acordo com os atributos espaciais. Logo, um outlier espacial é uma observação cujo os valores dos atributos não espaciais são significativamente diferentes dos valores dos atributos não espaciais da vizinhança da observação (Lu et al., 2003). De um outro modo, um outlier espacial pode ser denominado como uma instabilidade local.

A princípio, quaisquer métodos, sejam estatísticos ou baseados em mineração de dados e aprendizado de máquina, podem ser adaptados para o tratamento de dados espaciais. Kou et al. (2006), por exemplo, estenderam a técnica (Ramaswamy et al., 2000) para o tratamento de dados espaciais.

Shekhar et al. (2001), por outro lado, introduziram uma abordagem diferenciada para a detecção de outliers espaciais, através da representação do conjunto de dados na forma de grafos. Com base nos atributos espaciais um grafo de similaridades é construído. Cada instância é representada através de um nó, e a similaridade entre as instâncias é representada por uma ligação. Uma vez representado através de um grafo, é calculada a distância entre cada nó e seus vizinhos utilizando apenas os atributos não espaciais. Essa abordagem tornou-se uma abordagem muito interessante para a avaliação de métodos de detecção de outlier espaciais (Shekhar et al., 2003). Com base nessa abordagem, Lu et al. (2003) propuseram um framework para algoritmos de detecção de outliers espaciais.

\subsection{Considerações Finais}

Este capítulo apresentou uma revisão sobre o tema outliers. Foram apresentadas definições, exemplos de aplicações e motivação, e alguns dentre os principais métodos de identificação de outliers. Desde métodos paramétricos, baseados em um modelo gerador, a métodos baseados em distância, densidade e agrupamento de dados, têm sido propostos para a identificação de outliers. Assim como os métodos baseados em agrupamento, existe um número muito grande de métodos adaptados do aprendizado de máquina e mineração de dados para a identificação de outliers. Desde métodos simbólicos, baseados em arvores de decisão, regras de decisão, entre outros, a métodos conexionistas. Uma revisão mais extensa, abordado muitos desses métodos pode ser encontrada em (Hodge \& Austin, 2004) e em (Chandola et al., 2009). 
No Capítulo 4 do presente trabalho, será apresentado um método de identificação de outliers em redes complexas. O método proposto é um método não paramétrico, não-supervisionado, baseado em caminhada aleatória em redes. Com base apenas nessa caminhada, o método calcula um índice de dissimilaridade entre pares de nós e computa um escore de outlier para cada nó. Esse escore é uma medida global a rede. Logo, os nós identificados como outlier, são os mais anormais na rede. Como será mostrado nesse capítulo, esses nós evidenciam inclusive funcionalidade e estruturas diferenciadas.

Um pouco semelhante a abordagem proposta, Moonesignhe \& Tan (2006) apresentaram um método para a identificação de outliers baseado em grafos e em caminhada aleatória. Nesse caso, os autores propõem a construção de um grafo a partir do conjunto de dados de entrada e a computação de um escore de outlier baseado na distância de uma caminhada aleatória. Essa distância é obtida a partir de um algoritmo iterativo proposto no trabalho. Esse algoritmo é executado até a convergência do vetor de ponto fixo de uma cadeia de Markov.

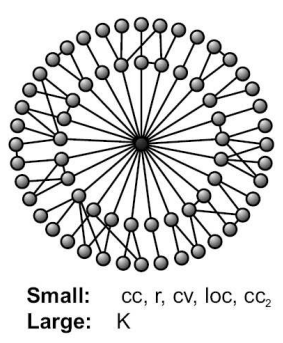

(a)

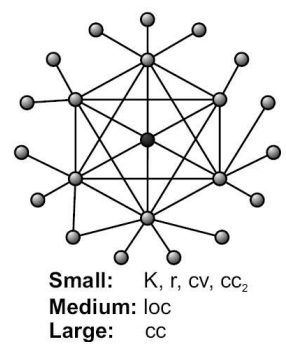

(e)

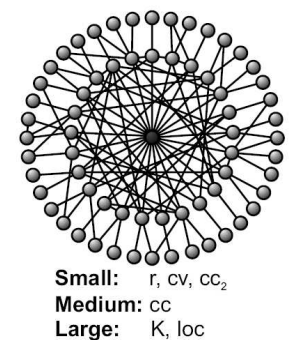

(b)

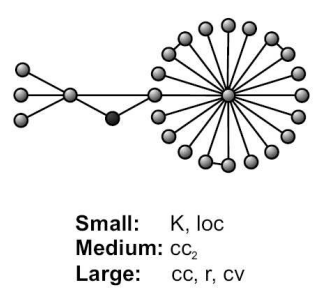

(f)

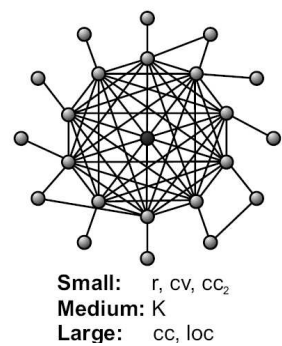

(c)

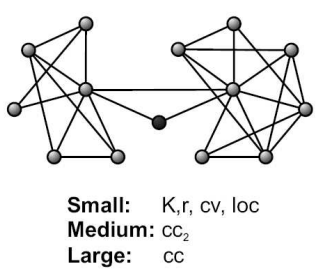

$(\mathrm{g})$

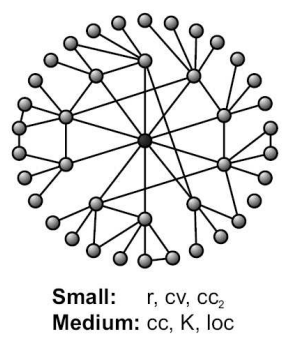

(d)

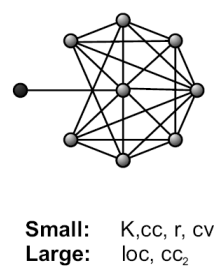

(h)

Figura 2.7: Tipos de outliers identificados segundo o método proposto em (Costa et al., 2009). O outlier aparece destacado em preto. Os autores identificam (a) como hub de retransmissão global, (b) como hub de retransmissão local, (c) como integrador local, (d) como integrador, (e) como centro de comunidade, (f) como extremidade-cluster, (g) como cluster-cluster, e (h) como extremidade. Figura adaptada de (Costa et al., 2009).

Contudo, embora (Shekhar et al., 2001, 2003; Lu et al., 2003; Moonesignhe \& Tan, 2006; Costa et al., 2009) trabalhem com métodos baseados em redes, este assunto tem sido pouco explorado. Costa et al. (2009) propuseram um método para a identificação de outliers em redes complexas, com base em seis medidas locais de redes: grau médio normalizado $(r)$, coeficiente de variação do grau de vizinhos imediatos $(c v)$, coeficiente de clustering ( $c c)$, índice de localidade (loc), coeficiente de clustering hierárquico de nível 2 $\left(c c_{2}\right)$, e o grau normalizado do nó $(K)$. Eles projetaram o conjunto de dados em um espaço 
bidimensional, através da técnica de análise de componentes principais, construíram uma distribuição de probabilidade e identificaram os outliers através da medida de Mahalanobis em uma abordagem com Parzen-windows. O método proposto foi aplicado à uma rede de interações entre proteínas, à rede Roget's thesaurus, e a uma rede de aeroportos. Além de identificar os nós mais outliers nessas redes, os autores apresentaram ilustrações de estruturas de nós outliers, segundo os nós identificados pelos mesmos. A Figura 2.7 mostra os tipos identificados. Entre os 20 mais outliers, foram identificados na rede de aeroportos, 11 nós com a estrutura (b), 8 com a estrutura (f) e apenas 1 com a estrutura (h); na rede de interações entre proteínas, 9 com estrutura (c), 8 com estrutura (a) e 3 com estrutura (f); na rede Roget's thesaurus, 6 com a estrutura (g), 5 com a estrutura (e), 5 com a estrutura (h) e 4 com a estrutura (d).

Uma vez que Redes Complexas é um tema recente e atual, estando presente nas mais diversas áreas da ciência, a identificação de outliers em redes complexas é um tema bastante relevante. Antes de apresentarmos o método proposto e os resultados obtidos, o próximo capítulo trará uma revisão sobre o tema Redes Complexas. 


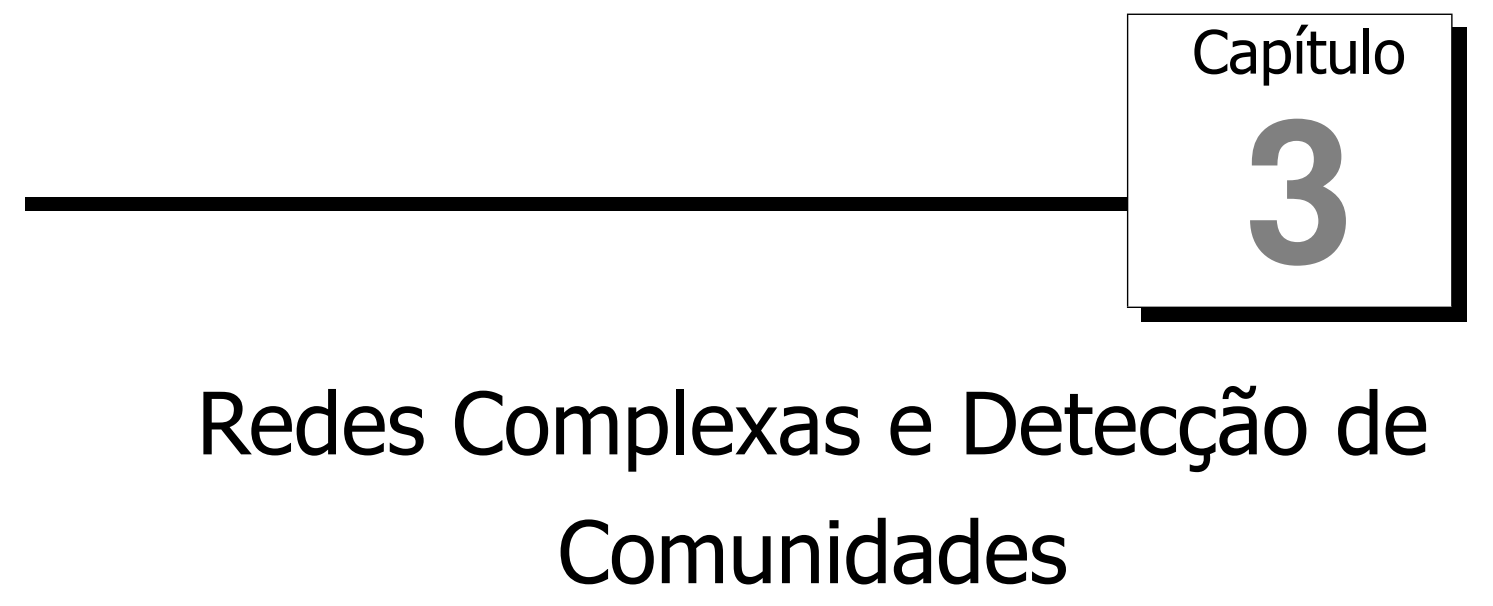

O tópico Redes Complexas refere-se ao estudo de redes de grande escala que possuem padrões de conexões não triviais, suas propriedades e modelos. O termo redes pode ser tomado como sinônimo de grafos. Entretanto, muitas das propriedades estudas na Teoria dos Grafos não possuem grande relevância do ponto de vista de redes de grande escala. Esse capítulo irá apresentar uma revisão sobre esse tópico.

\subsection{Introdução}

Por volta de 1735, quando da sua estada em Königsberg, o matemático suíço Leonhard Euler lidou com o problema das sete pontes de Königsberg. A cidade de Königsberg era uma cidade mercantil cortada pelo rio Pregel e algumas ilhas fluviais, de modo que mantinha algumas pontes para manter o transito entre os portos e armazéns, como ilustra a Figura 3.1(a). Devido a uma lenda popular, a população local discutia a possibilidade de se fazer uma passeio através das sete pontes que cruzavam o rio Pregel e retornar ao ponto de partida, passando uma única vez por cada ponte. Por ocasião, Euler desenvolveu um método de abstração utilizando pontos para representar as porções de terra, e linhas para representar cada ponte (Figura 3.1(b)). A partir dessa abstração, Euler foi capaz de provar que não era possível realizar o percurso cogitado. Mais ainda, foi capaz de demonstrar que tal percurso apenas seria possível se cada porção de terra possuísse um número par de pontes incidentes. Mais tarde, os pontos ficaram conhecidos como vértices (ou nós); as linhas como arestas (ou ligações); o método de abstração como grafo (ou rede); a solução cogitada como circuito euleriano; e o grafo que permite tal solução como 
um grafo euleriano. Esse é conhecidamente um dos primeiros passos no estudo sobre redes. De tal, originou-se a Teoria Matemática dos Grafos (Bondy \& Murty, 2007).

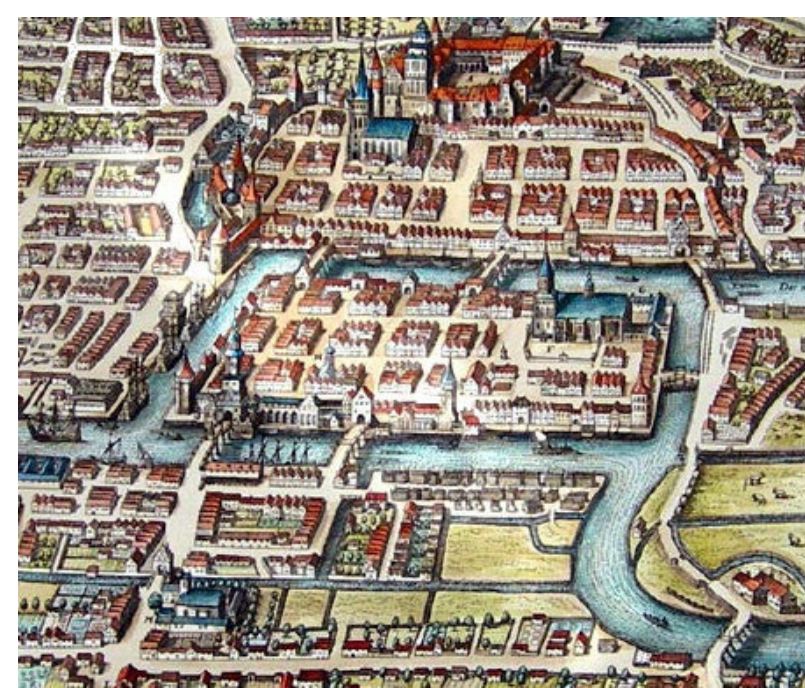

(a)

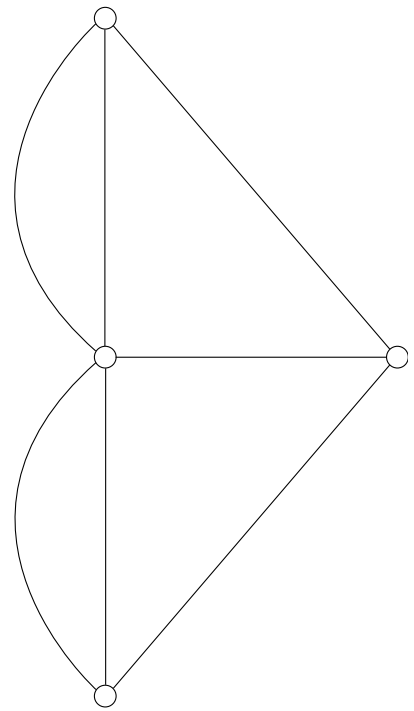

(b)

Figura 3.1: Problema das sete pontes de Königsberg. (a) Ilustração da cidade de Königsberg. (b) Grafo representando o problema das sete pontes de Königsberg. Cada porção de terra é representada por um nó e cada ponte é representada por uma aresta.

Nos últimos anos, tem-se testemunhado uma significativa mudança nos estudos nessa área. Motivado principalmente pela grande disponibilidade de recursos computacionais e de redes de comunicação, que permitem a análise de dados em uma escala muito maior do que fora possível anteriormente, as redes passaram a ser analisadas de uma maneira mais ampla. Enquanto que com os recursos existentes nos séculos anteriores apenas era possível a análise de redes da ordem de dezenas, quando muito, centenas de nós. Hoje, frequentemente pode-se observar análises de redes da ordem de milhões ou mesmo bilhões de nós.

Adicionalmente, pode-se dizer também que houve uma mudança com relação a visualização. Enquanto que para redes com dezenas de nós era relativamente simples desenhar um grafo e responder questões acerca da sua estrutura observando sua representação, em redes da ordem de milhares de nós essa abordagem torna-se inviável. Logo, propriedades triviais e soluções exatas deixam de ser o alvo, para dar lugar a propriedades complexas e soluções aproximadas. Propriedades típicas da Teoria dos Grafos, tais como coloração, clique, menor caminho, diâmetro da rede etc (Bondy \& Murty, 2007), deixam de ser o alvo para dar lugar a propriedades como transitividade (ou clustering), efeito de pequeno-mundo, distribuição de grau, centralidade, resiliência, estruturas de comunidades, processos de espalhamento de informação, sincronização, transição de fase, percolação, entre outros. Sistemas complexos, como a Internet (Faloutsos et al., 1999), a World Wide Web (Albert et al., 1999) (Figura 3.2), redes de distribuição de energia elétrica (Albert et al., 2004), redes de colaboração entre cientistas (Newman, 2001), redes de interações sociais entre indivíduos (Scott, 2000) (Figura 3.3), redes de interações entre 
companhias e organizações (Mizruchi, 1982), cadeias de contatos sexuais (Liljeros et al., 2001), cadeias alimentares (Montoya \& Solé, 2002), cadeias de interações metabólicas (Jeong et al., 2000), o sistema de distribuição da corrente sanguínea (West et al., 1999), redes neurais biológicas (Sponrs, 2002), entre outros, tem sido estudados sob essa abordagem.

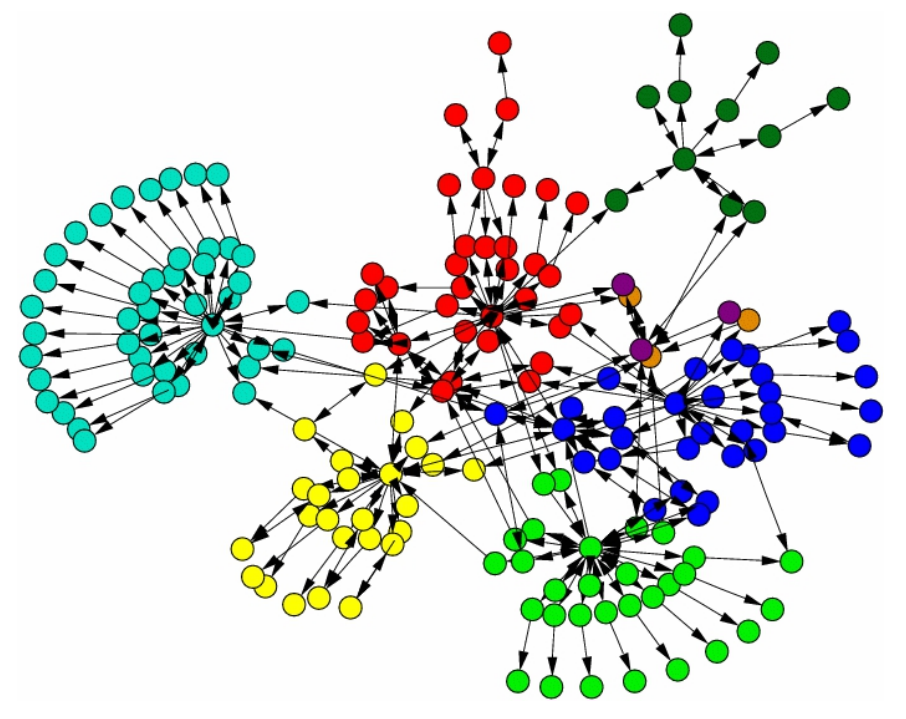

Figura 3.2: Wold Wide Web. Páginas conectam-se a outras páginas através de ligações direcionadas. Páginas muito conectadas entre sí podem caracterizar temas relacionados. Além disso, a distribuição de grau influencia diretamente em como a informação se propaga na rede.

Redes Complexas têm se mostrado um tópico unificador, de modo que acredita-se que Redes Complexas é uma área de pesquisa muito promissora e que muitas das questões que não foram respondidas ou foram respondidas apenas parcialmente pela ciência reducionista, podem ser melhor examinadas e talvez explicadas do ponto de vista da ciência do complexo. Contudo, ainda existem muitos tópicos a serem estudados.

Segundo Costa et al. (2007), três tópicos foram os principais responsáveis pelo avanço dos estudos em Redes Complexas na última década: o efeito de pequeno mundo (Watts \& Strogatz, 1998), a distribuição livre de escala (Barabási \& Albert, 1999), e a estrutura de comunidades (Girvan \& Newman, 2002). Cada um desses tópicos será abordado a seguir. Além disso serão apresentados: definição formal de redes; algumas propriedades de redes; modelos de construção de redes sintéticas; e alguns métodos de detecção de estruturas de comunidades.

\subsection{Definição e Propriedades}

Do ponto de vista matemático, rede e grafo são termos sinônimos. Um grafo (ou rede) pode ser classificado como direcionado, ou dígrafo, quando suas arestas são direcionadas; quando suas ligações possuem pesos, um grafo também pode ser denominado ponderado.

Considere um dígrafo ponderado, $G$, definido pelo par ordenado $(V, E)$, que consiste em um conjunto $V$, de $N$ vértices (ou nós), em um conjunto $E$, de $M$ arestas (ou ligações), 


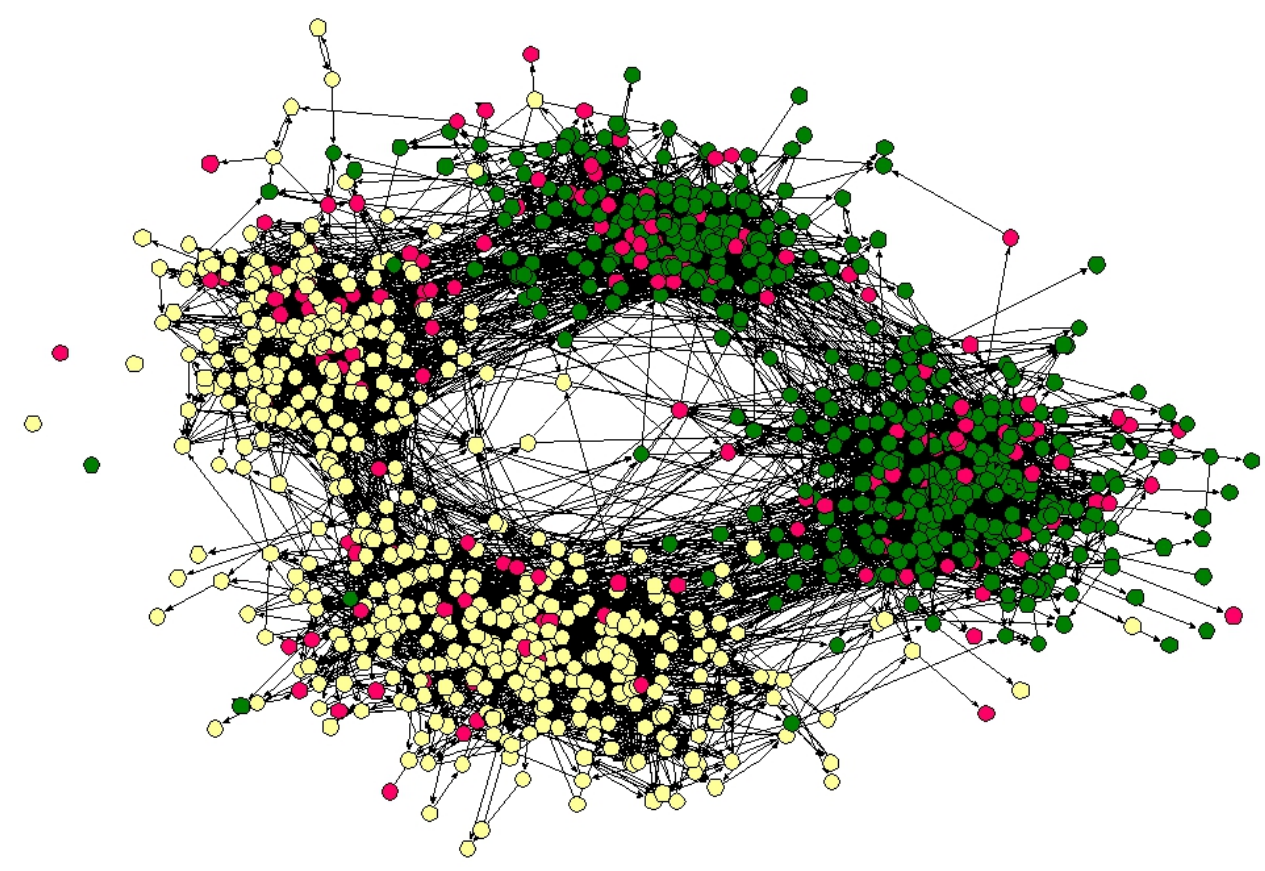

Figura 3.3: Rede social entre alunos de uma escola americana. As cores representam as etnias. Note-se que existe uma separação bem definida com relação a etnia dos indivíduos. Além disso, existe uma separação bem definida entre os alunos que cursam o high school e os alunos que cursam o medium school. Essas estruturas são conhecidas como comunidades. Figura obtida de (Newman, 2003)

e em um mapeamento $\omega: E \mapsto \mathbb{R}$. Cada nó pode ser identificado por um valor inteiro $i=1,2, \ldots, N$; e cada ligação pode ser identificada por um par $(i, j)$ que representa a ligação de $i$ até $j$, cujo o peso é dado por $\omega(i, j)$. No caso de uma rede não ponderada, as ligações não possuem peso, logo o mapeamento $\omega$ não é necessário. No caso de um grafo não direcionado (com ou sem peso), as ligações não possuem direção, logo, a presença de $(i, j)$ em $E$ significa que existe uma ligação tanto de $i$ até $j$, como também de $j$ até $i$.

De outra forma, uma rede pode ser completamente representada por uma matriz ponderada, $W$, denominada matriz de adjacências generalizada, em que cada entrada $w_{i j}=\omega(i, j)$ representa o peso de uma ligação de $i$ até $j$. Se a rede $G$ é uma rede não direcionada, então $W$ é uma matriz simétrica, isto é, $W=W^{t}$. Seja $G$ uma rede sem pesos, uma entrada $w_{i j} \in W$ assume valor 1 caso exista uma ligação de $i$ até $j$, ou 0 , caso contrário. $W$ é dita matriz de adjacências, tipicamente representada por $A$.

Em uma rede não direcionada, se $a_{i j} \neq 0$, diz-se que $i$ e $j$ são adjacentes, ou vizinhos. Em uma rede direcionada, se $a_{i j} \neq 0$ diz se que $j$ é vizinho de (ou adjacente a) $i$. A vizinhança de um vértice $i$ é dada pelo conjunto $v(i)$ de todos os nós adjacentes a $i$. $\mathrm{O}$ grau de um nó $i, k_{i}$ é dado pelo número de vizinhos de $i$, isto é, a cardinalidade de $v(i)$. Em uma rede não direcionada, $k_{i}$ é dado por

$$
k_{i}=\sum_{j} a_{i j}
$$

O grau médio de uma rede é dado por $\langle k\rangle$; a média de $k_{i}$, para todo $i$ em $V$, 


$$
\langle k\rangle=\frac{1}{N} \sum_{i} k_{i}=\sum_{i j} a_{i j} .
$$

Em uma rede direcionada pode-se considerar tanto o grau de saída, $k_{i}^{\text {out }}$, como o grau de entrada, $k_{i}^{i n}, k_{i}^{i n}+k_{i}^{\text {out }}=k_{i}$. O grau de saída corresponde ao número de ligações saindo de $i$,

$$
k_{i}^{o u t}=\sum_{j} a_{i j}
$$

enquanto que o grau de entrada corresponde ao número de ligações que incidem sobre $i$,

$$
k_{i}^{i n}=\sum_{j} a_{j i}
$$

Redes complexas, tipicamente são redes esparsas, isto é, apenas uma pequena fração do total de possíveis ligações existe de fato. Embora não adjacentes, dois nós $i$ e $j$ podem estar conectados através de uma sequencia de $m$ ligações, $\left(i, k_{1}\right),\left(k_{1}, k_{2}\right), \ldots,\left(k_{m-1}, j\right)$. Essa sequencia é denominada um passeio de $i$ até $j$ de comprimento $m$. Dizemos que dois nós estão conectados, se existe pelo menos um passeio conectando-os. Um conjunto de nós conectados é dito um componente. Se todos os nós em um passeio são distintos, então este passeio pode ser denominado um caminho. O tamanho do menor caminho entre dois nós, $i$ e $j$, é dito distância geodésica, $d_{i j}$. A distância média de uma rede é dada pela média da distância geodésica,

$$
\langle d\rangle=\frac{1}{N(N-1)} \sum_{i \neq j} d_{i j} .
$$

Se o passeio começa e terminando no mesmo nó, e passa apenas uma vez por cada nó $k_{n}$, este é denominado um ciclo, ou circuito. É o caso do circuito euleriano, em que, especificamente, todas as ligações do grafo são percorridas.

\subsubsection{Distribuição de Grau}

Assim como o grau é uma informação relevante localmente, a distribuição de grau é uma informação relevante da rede. A distribuição de grau, $P(k)$ expressa a fração de nós da rede que possui grau $k$, ou, de outro modo, a probabilidade de um nó escolhido aleatoriamente possuir grau $k$. O gráfico da distribuição cumulativa de grau pode representar muito bem como se comporta uma rede em relação a conectividade. Redes randômicas (Seção 3.3.1) possuem distribuição de Poisson. Redes livre de escala (Seção 3.3.3) possuem distribuição que segue a lei de potência (Figura 3.2). A Figura 3.4 mostra a distribuição de grau de algumas redes reais. O gráfico log-log da distribuição cumulativa permite identificar se uma distribuição segue a lei de potência. 


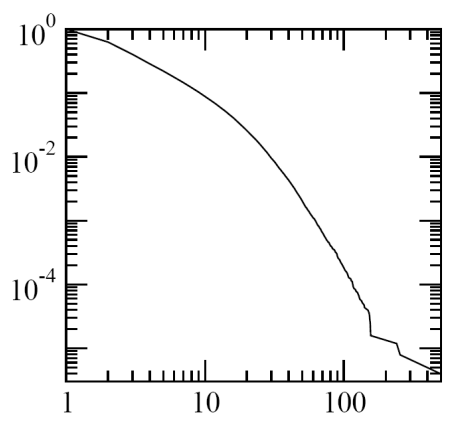

(a)

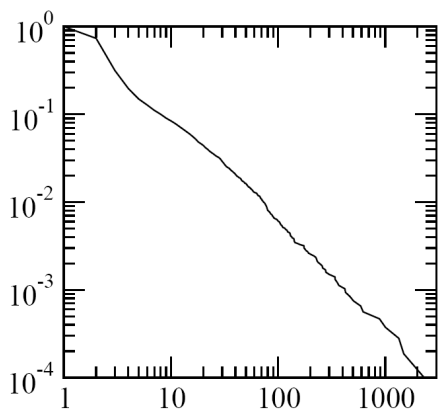

(d)

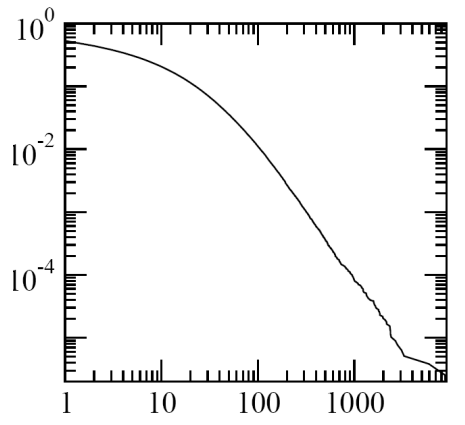

(b)

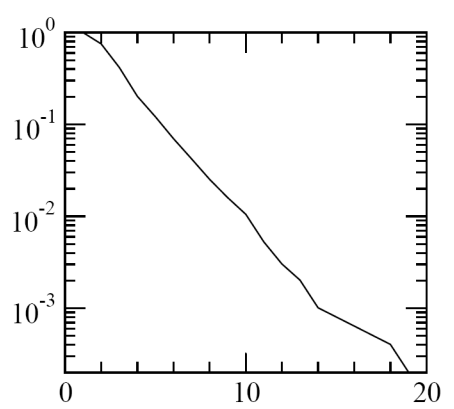

(e)

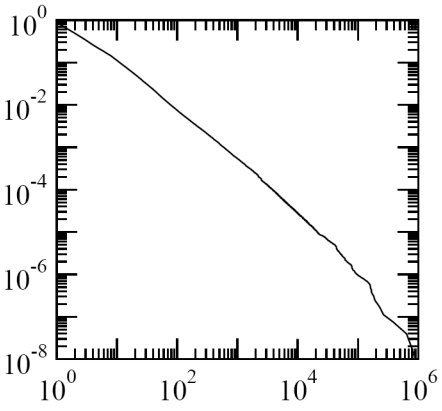

(c)

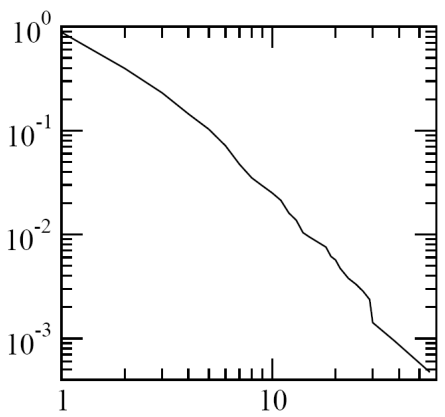

(f)

Figura 3.4: Distribuição cumulativa de grau de seis redes reais: (a) rede de colaboração entre matemáticos; (b) rede de citações; (c) a World Wide Web; (d) a Internet; (e) rede de energia do lado oeste dos Estados Unidos; (f) rede de interações entre proteínas. Em cada gráfico, o eixo das abcissas representa o grau $k$ (o grau de entrada, $k^{i n}$, no caso da rede de citações e da World Wide Web) enquanto que o eixo das ordenadas representa a probabilidade da distribuição, $P(k)$. Dessas redes, as representadas em (c), (d) e (f), possuem distribuição de grau que segue a lei de potência. Como representada em escala log-linear, (e) segue uma lei exponencial. Embora (a) e (b) sejam representadas em escala log-log, ambas desviam-se acentuadamente da distribuição alvo, especialmente com relação a nós com alto grau. Figura adaptada de (Newman, 2003).

\subsubsection{Transitividade}

A propriedade de transitividade é caracterizada pela existência de pequenos ciclos locais. Essa propriedade pode ser verificada através do coeficiente de clustering,

$$
C=\frac{3 N_{\triangle}}{N_{3}}
$$

onde $N_{\triangle}$ é o número de triângulos na rede e $N_{3}$ é o número de triplas de nós conectados. Um triângulo é um conjunto de três nós com ligações entre cada par de nós. O coeficiente de clustering é medido em razão do número de triplas de nós, de modo que $0 \leq C \leq 1$. O número de triângulos em uma rede pode ser calculado por

$$
N_{\triangle}=\sum_{k>j>i} a_{i j} a_{i k} a_{j k},
$$

enquanto que o número de triplas de nós conectados pode ser calculado por 


$$
N_{3}=\sum_{k>j>i}\left(a_{i j} a_{i k}+a_{j i} a_{j k}+a_{k i} a_{k j}\right)
$$

Watts \& Strogatz (1998) apresentam em seu trabalho uma definição alternativa de coeficiente de clustering, baseada no coeficiente de clustering local,

$$
C_{i}=\frac{N_{\triangle}^{i}}{N_{3}^{i}}
$$

onde $N_{\triangle}^{i}$ é o número de triângulos envolvendo o nó $i$ e $N_{3}^{i}$ é o número de triplas que incluem $i$. Logo, o coeficiente de clustering da rede é dado por

$$
C=\frac{1}{N} \sum_{i} C_{i} .
$$

\subsubsection{Efeito de Pequeno Mundo}

A propriedade de pequeno mundo é certamente uma das propriedades de redes de maior interesse de estudo. Por volta de 1967, o psicólogo e cientista social Milgram, conduziu um experimento no intuito de identificar a distância geodésica entre indivíduos nos Estados Unidos (Milgram, 1967). Ele chegou a conclusão de que o menor distância entre dois indivíduos é de aproximadamente 6 passos, o que ficou conhecido como efeito de pequeno mundo, e deu origem ao termo "seis graus de separação" (Watts, 1999, 2004). No contexto de redes sociais, isso significa que quaisquer dois indivíduo no mundo estão conectados um ao outro através de uma pequena cadeia de interações sociais. Esse comportamento deve-se tanto a existência de atalhos espaço-temporais como a propriedade de transitividade nas redes.

$\mathrm{O}$ efeito de pequeno mundo afeta diretamente a dinâmica dos processos que ocorrem em um rede. Por exemplo, considere o espalhamento de informação através de uma rede. Uma rede com propriedade de pequeno mundo certamente irá espalhar informações mais rapidamente. Na rede social dos Estados Unidos, em 6 passos todos os indivíduos seriam atingidos.

\subsubsection{Estruturas de Comunidades}

Muitas redes reais apresentam estruturas não homogêneas, onde existem conjuntos de nós densamente conectados entre si, cujas ligações com nós de fora do grupo são esparsas. São as chamadas estruturas de comunidades (Figura 3.5). Na World Wide Web (Figura 3.2), grupos de páginas muito conectadas entre si, podem corresponder a páginas com tópicos relacionados (Flake et al., 2002); em redes sociais, conjuntos de indivíduos relacionados entre sí podem corresponder a grupos sociais bem definidos, comunidades (Girvan \& Newman, 2002) (Figura 3.3); em redes de metabolismo, divisões naturais, podem prover evidencias da existência de módulos funcionais, responsáveis por diferentes 
funcionalidades (Holme et al., 2003). Por isso, a identificação e caracterização desses grupos é muito importante, e tem sido um tópico de pesquisa em Redes Complexas, bastante estudado. A Seção 3.4 irar abordar mais extensamente Deteç̧ão de Comunidades.

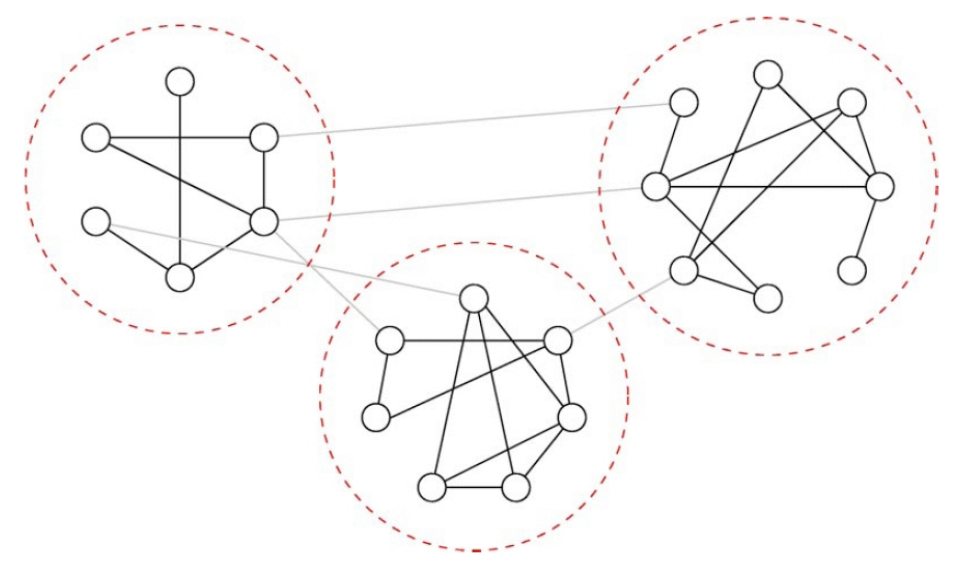

Figura 3.5: Rede com três estruturas de comunidades bem definidas. Nós que pertencem a mesma comunidade estão densamente conectados, enquanto que ligações entre nós de comunidades distintas são esparsas. Figura obtida de (Newman \& Girvan, 2004).

\subsection{Modelos de Redes}

Diversos modelos de redes tem sido propostos com o propósito de estudar melhor as propriedades observadas nas redes reais. O modelo de redes randômicas, o modelo de redes de pequeno mundo e o modelo de redes livre de escala são conhecidamente os mais populares. Cada um desses modelos será apresentado a seguir, juntamente com o modelo de redes com estruturas de comunidades e com o modelo de redes geográficas.

\subsubsection{Redes Randômicas}

Um dos primeiros passos no sentido de se reproduzir sinteticamente uma rede foi dado por Erdös \& Rényi (1959). Diante da diversidade de sistemas e de suas particularidades, os matemáticos húngaros propuseram um modelo randômico para construção de redes, denominado Grafos Randômicos (Random Graphs) ou Redes Randômicas.

Dado inicialmente uma rede com $N$ nós totalmente desconectados, cada par de nós, dentre os $\frac{1}{2} N(N-1)$ possíveis pares, é apresentado e, com uma probabilidade $p$ constante, é estabelecida uma ligação (não direcionada e sem pesos) entre eles. O resultado é uma rede homogênea com uma dentre as $C_{N(N-1) / 2}^{M}$ possíveis configurações de redes com $N$ nós e $M$ arestas, sem ligações retroativas ou ligações duplicadas. Para $p=0$, nenhuma ligação será estabelecida. Para $p=1$, todas as possíveis ligação são estabelecidas. O resultado é uma rede totalmente conectada, com grau médio $\langle k\rangle=N-1$. Para uma probabilidade $p$ qualquer, o grau médio da rede será $\langle k\rangle=p(N-1)$. A Figura 3.6 mostra algumas configurações de redes randômicas com 8 nós. 
Uma rede formada segundo esse modelo possui distribuição de grau bastante homogênea, seguindo a distribuição binomial

$$
P(k)=\left(\begin{array}{c}
N \\
k
\end{array}\right) p^{k}(1-p)^{N-k} .
$$

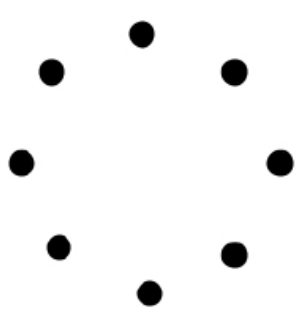

(a)

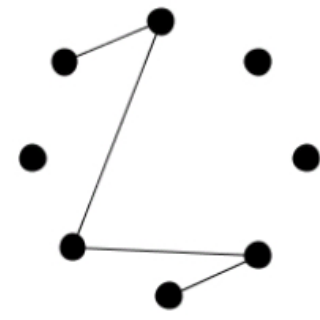

(b)

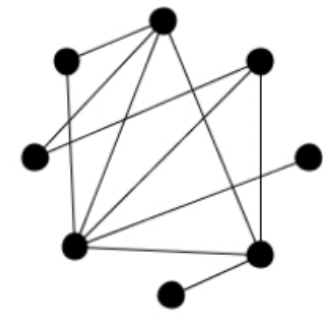

(c)

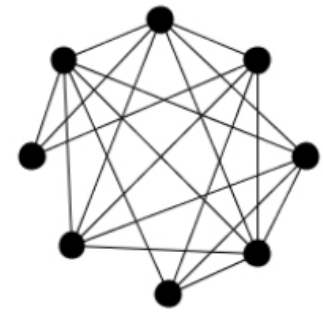

(d)

Figura 3.6: Configurações de redes randômicas com 8 vértices: (a) $p=0$; (b) $p=0.1$; (c) $p=0.3 ;(\mathrm{d}) p=0.8$.

Para $N \rightarrow \infty$, uma rede de grande dimensão, essa distribuição é uma distribuição de Poisson,

$$
P(k)=\frac{e^{-\langle k\rangle}\langle k\rangle^{k}}{k !} .
$$

A Figura 3.7 mostra a distribuição de grau média de 10 redes randômica com 10000 nós e probabilidade $p=0.2$. O coeficiente de clustering de uma rede randômica é dado por $C=p$. A distância média da rede é dada por

$$
\ell \sim \frac{\ln N}{\ln \langle k\rangle}
$$

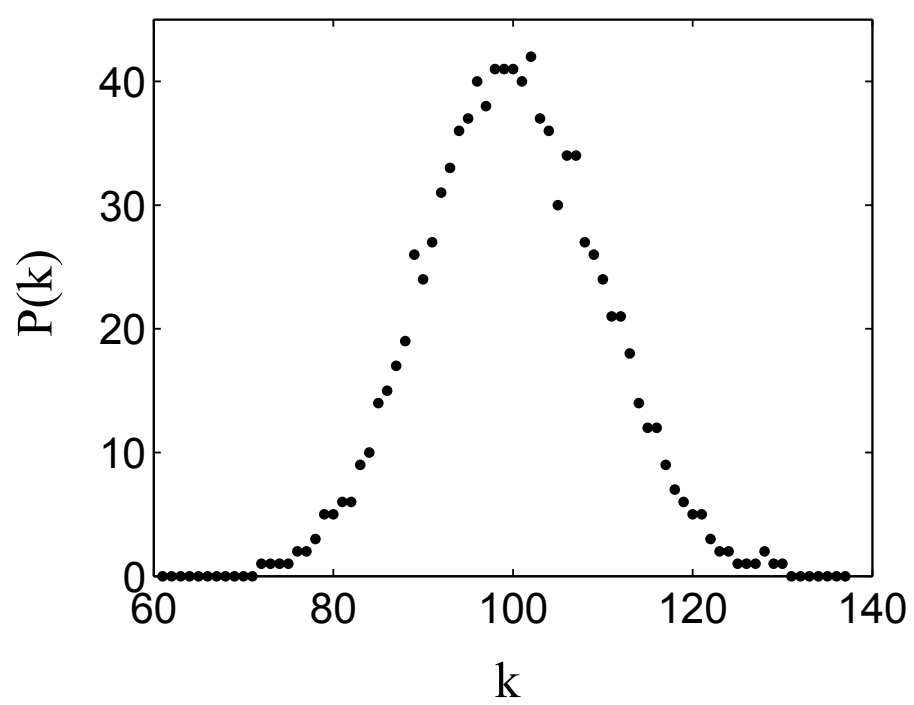

Figura 3.7: Distribuição de grau média de 10 redes randômicas com 1000 nós e probabilidade $p=0.1$. Uma distribuição de Poisson. 
Embora a distância média de uma rede randômica seja pequena, quanto maior o número de nós, menor a probabilidade de existirem ciclos locais. Uma vez que ciclos locais são comuns em redes reais, essa característica torna as redes randômicas deficientes na representação de redes reais.

\subsubsection{Redes de Pequeno Mundo}

Watts \& Strogatz (1998) propuseram um modelo de rede que reproduz a propriedade de pequeno mundo. Esse modelo apresenta um meio termo entre redes regulares e redes randômicas através do restabelecimento de algumas ligações randômicas em uma rede regular, acrescentando aleatoriedade a rede. Consequentemente, são criados atalhos na rede, de modo que a distância média da rede cai significativamente, mantendo a maioria dos ciclos locais de uma rede regular.

Dado uma rede com $N$ nós, onde cada nó está conectado aos $\kappa$ vizinhos mais próximos em cada direção e $\langle k\rangle=2 \kappa$. Cada ligação é restabelecida com probabilidade $p$. Para $p=0$ temos uma rede regular, um reticulado, com alto coeficiente de clustering e distância média grande. Quando $p \rightarrow 1$, temos uma rede randômica com distância média pequena mas também com coeficiente de clustering pequeno. Entretanto, como apresentado por Watts \& Strogatz (1998), para uma valor pequeno de $p, 0.01<p<0.1$, obtemos uma rede com distância media pequena e coeficiente de clustering grande; uma Rede de Pequeno Mundo. A Figura 3.8 ilustra o processo de transformação de uma rede regular $(\kappa=2)$ numa rede aleatória. Note que, na rede de pequeno mundo, a distância geodésica entre os nós destacados diminui substancialmente, enquanto que mantêm-se alto o coeficiente de clustering. A Figura 3.9 mostra como se comportam o coeficiente de clustering e a distância média em função de $p$.

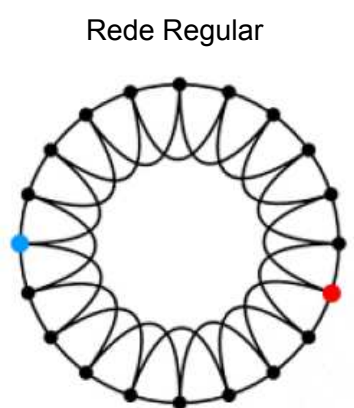

$p=0$

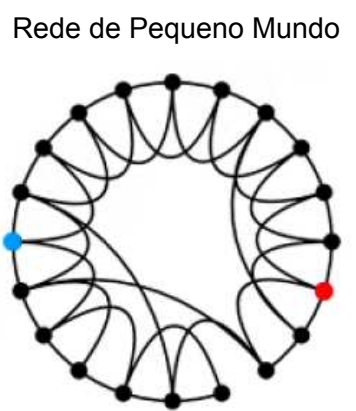

crescimento do numero de arestas modificadas

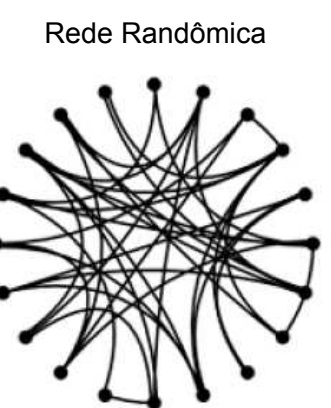

$p=1$

Figura 3.8: Modelo de redes de pequeno mundo de Watts \& Strogatz (1998). Para $p=0$ temos uma rede regular. Quanto maior a probabilidade $p$, mais o modelo se aproxima de uma rede randômica. Para $0.01<p<0.1$ a rede se comporta como uma rede de pequeno mundo. Note-se que a distância entre os nós identificados em vermelho e em azul diminui, enquanto que o coeficiente de clustering mantem-se alto. Figura adaptada de (Watts \& Strogatz, 1998). 


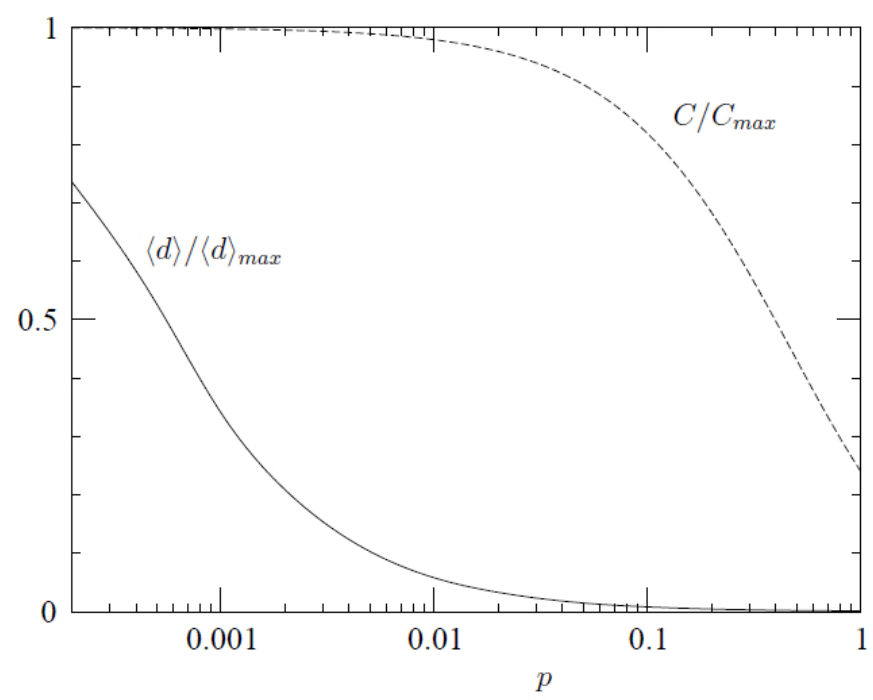

Figura 3.9: Comportamento da distância média e do coeficiente de clustering em função de $p$, segundo o modelo de Watts \& Strogatz (1998). Tanto o coeficiente de clustering como a distância média são apresentados em razão dos respectivos valores máximos. Para $0.01<p<0.1$ temos o efeito de pequeno mundo. Figura obtida de (Newman, 2003).

\subsubsection{Redes Livre de Escala}

Barabási \& Albert (1999) mostraram que muitas redes reais são caracterizadas por uma distribuição de grau desigual, diferentemente dos modelos de Erdös \& Rényi (1959) e de Watts \& Strogatz (1998). Enquanto que alguns nós são altamente conectados, a maioria dos nós é pouco conectada. Mais especificamente, Barabási \& Albert (1999) mostraram que muitas redes reais possuem uma distribuição de grau que segue a lei de potência,

$$
P(k) \sim k^{-\gamma}
$$

Esse comportamento pode ser verificado em redes como a World Wide Web (Figura 3.2), a Internet, e a rede de interações entre proteínas, como mostra a Figura 3.4. Essas redes são chamadas Redes Livre de Escala. Os nós altamente conectados são chamados de hubs.

Barabási \& Albert (1999) propuseram um modelo de rede para a construção de redes livre-de-escala. Esse modelo consiste em dois fundamentos básicos: crescimento e ligação preferencial. Dada uma rede qualquer, inicialmente com $n_{0}$ nós, iterativamente são adicionados novos nós, até que atinja uma configuração com $N$ nós. Para cada nó adicionado, $m$ novas ligações serão estabelecidas entre o novo nó e os nós preexistentes. Os nós selecionados para estabelecer ligação com o novo nó, são escolhidos preferencialmente, proporcional ao seu grau. Isto é, dado um novo nó $i, i$ será conectado a um nó preexistente $j$ com probabilidade

$$
P(i \rightarrow j)=\frac{k_{j}}{\sum_{u} k_{u}}
$$


Inicialmente, os nós com mais ligações na rede tendem a ser preteridos nas ligações, e logo destacam-se dos demais. Esses nós tendem a ser altamente conectados e iterativamente tornam-se ainda mais conectados, efeito conhecido como "o rico torna-se mais rico" (Barabasi, 2003). Ao final, temos uma rede com $N=n_{0}+t$ nós e $M=m t$ ligações, onde t é o número de iterações. Especificamente, o modelo gera redes com distribuição de grau,

$$
P(k) \sim k^{-3}
$$

o grau médio é dado por $\langle k\rangle=2 m$.

A Figura 3.10 mostra a distribuição média de 10 redes geradas segundo o modelo de Barabási \& Albert (1999), com 10000 nós e $m=5$.

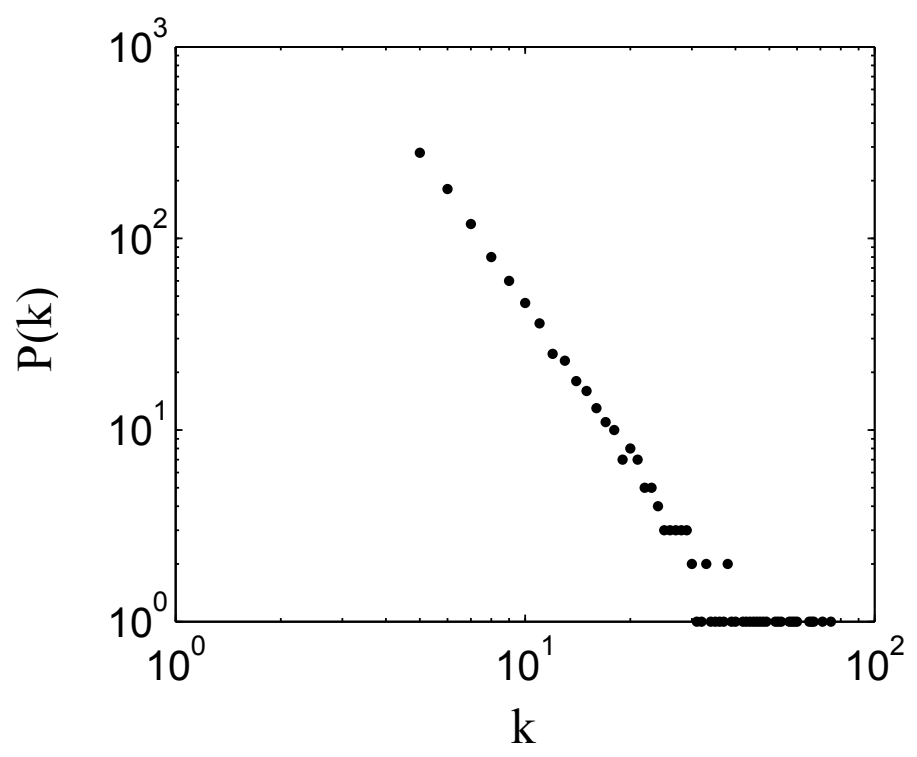

Figura 3.10: Distribuição de grau média de 10 redes geradas segundo o modelo de Barabási \& Albert (1999) com 1000 nós e $m=5$.

\subsubsection{Redes com Estruturas de Comunidade}

Com o propósito de estudar as estruturas de comunidades, Girvan \& Newman (2002) propuseram uma extensão do modelo de redes randômicas com o propósito de gerar redes com estruturas de comunidades. Nessa caso, a probabilidade de estabelecer uma ligação entre nós que pertencem a uma mesma comunidade é diferente da probabilidade de estabelecer uma ligação entre comunidades.

Dado um conjunto de $N$ nós, classificados em $c$ comunidades. Iterativamente, cada par de nós é selecionado, e é estabelecida uma ligação entre eles como probabilidade $p_{i n}$, caso pertençam a mesma comunidade, caso contrário, com probabilidade $p_{\text {out }}$, se pertencem a comunidades distintas. Para valores de $p_{\text {out }} \ll p_{\text {in }}$ as comunidades são bem definidas. Por outro lado, para $p_{\text {out }}$ grande, as comunidades resultantes são sobrepostas. A Figura 3.11 mostra um exemplo de rede 64 nós e 4 estruturas de comunidades bem definidas geradas a partir desse modelo. 


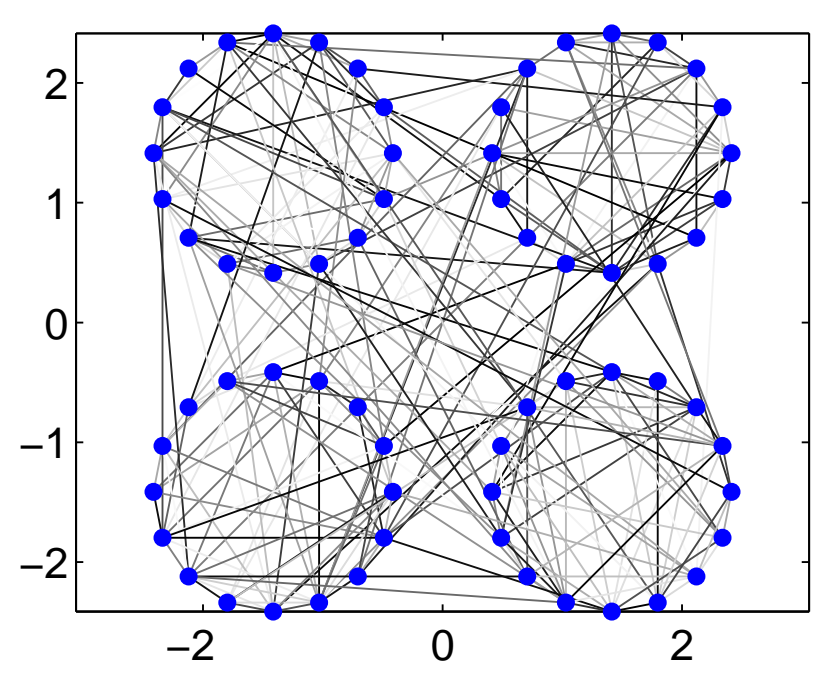

Figura 3.11: Exemplo de rede com 64 nós e 4 estruturas de comunidades bem definidas gerada segundo o modelo de Girvan \& Newman (2002).

\subsubsection{Redes Geográfica}

De um modo geral, redes complexas são consideradas em um espaço abstrato, onde a posição dos nós não possui qualquer significado geográfico. É o caso de redes como a World Wide Web, redes de colaboração entre cientistas, rede de interação entre proteínas, entre outras. Entretanto, algumas redes têm sua topologia relacionada a características espaciais, de modo que a posição de cada nó é uma informação importante, e influencia no crescimento da rede. É o caso da Internet, redes de rodovias, redes de rotas aéreas, redes de distribuição de energia, entre outras. Nesses casos a posição dos roteadores, cidades, aeroportos e estações elétricas pode ser identificadas em um mapa, enquanto que a ligações entre eles correspondem a ligações físicas, tais como fibra óptica, rodovias, rotas aéreas e cabos de alta tensão, respectivamente. Esse tipo de rede é conhecida como rede geográfica ou rede espacial.

Em redes geográficas, a existência de ligações entre nós depende diretamente de algumas restrições, como distância, acidentes geográficos, disponibilidade de recursos, limite territorial entre outros. Logo, um modelo de construção de redes geográficas precisa considerar essas restrições. Segundo Costa et al. (2007), uma maneira de gerar uma rede geográfica é distribuir $N$ nós randomicamente em um espaço bidimensional e conecta-los de acordo com uma probabilidade inversamente proporcional a distância entre eles, como

$$
P(i \rightarrow j) \sim e^{-\lambda d_{i j}}
$$

onde $d_{i j}$ é a distância entre os nós $i$ e $j$, e $\lambda$ é uma constante; quanto menor o valor de $\lambda$ maior a probabilidade de criação de conexões e mais conectada a rede. Esse modelo resulta em uma rede com distribuição de grau de Poisson, como uma rede randômica.

Esse mesmo método pode ser utilizado para construir uma rede geográfica a partir de 
conjuntos de dados. Dado $N$ observações com $r$ atributos, estas podem ser projetadas em nós num espaço bidimensional, e ligadas com probabilidade $P(i \rightarrow j)$. Quaisquer distâncias podem ser consideradas, desde que possam tratar adequadamente os tipos de dados dos atributos. Outra regra que pode ser considerada nesse caso é a ligação preferencial de acordo com a distância (Karypis et al., 1999). Nessa caso, cada observação $i$ será conectada as $k$ observações mais próximas segundo o espaço $r$-dimensional. Adicionalmente, pode-se manter um peso, inversamente proporcional a distância entre as observações, no intuito de ponderar as ligações.

\subsection{Detecção de Comunidades}

As estruturas de comunidades são caracterizadas pela existência de nós densamente conectados entre si, cujas ligações com nós de fora do grupo são esparsas. Essas estruturas caracterizam agrupamentos naturais, e estão presentes em diversos tipos de redes. Por isso, as estruturas de comunidades têm sido estudadas em diversos tipos de redes, tais como redes sociais (Girvan \& Newman, 2002), redes metabólicas (Holme et al., 2003) e a World Wide Web (Flake et al., 2002). Além disso, comunidades podem representar padrões de interação bem definidos, explicitando similaridades topológicas e até mesmo similaridades funcionais. Clauset et al. (2004), por exemplo, apresentam um método de identificação de comunidades aplicado a identificação de comunidades em uma rede de itens à venda de um dos sites de maior rentabilidade da web, o Amazon.com. Nessa rede, itens frequentemente comprados pelos usuários em uma mesma transação estão conectados. O algoritmo foi capaz de identificar comunidades correspondentes a tópicos específicos dos itens, gêneros literários, e gêneros musicais, revelando tendências de compra dos clientes fortemente relacionadas.

Eventualmente, uma comunidade pode ser uma composição de comunidades, de modo que comunidades podem ser decompostas hierarquicamente em outras comunidades, ainda mais específicas. Uma questão fundamental para a detecção de comunidades é identificar qual configuração de comunidades é mais adequada. Em redes reais, geralmente não existem informações disponíveis acerca do número de comunidades existentes. Uma vez que estamos interessados em detectar agrupamentos naturais de nós, não é interessante preestabelecer o número de comunidades que devem ser identificadas. A fim de resolver esse problema, Newman \& Girvan (2004) apresentaram em seu trabalho uma medida de qualidade de uma divisão particular em comunidades, chamada de modularidade.

Considere uma rede dividida em $c$ comunidades. A modularidade dessa configuração, $Q$, é calculada através da composição de uma matriz simétrica $E, c \times c$, chamada matriz de mistura. Nessa matriz, as entradas ao longo da diagonal principal, $e_{i i}$, informam a fração de ligações entre nós de cada comunidade $i$; as demais entradas, $e_{i j}, i \neq j$, informam a fração de ligações entre nós de diferentes comunidades. O índice de modularidade da configuração é dado por 


$$
Q=\sum_{i}\left[e_{i i}-\left(\sum_{j} e_{i j}\right)^{2}\right] .
$$

Se $Q \approx 0$, caracteriza a inexistência de comunidades. Se $Q \approx 1$, caracteriza a existência de comunidades isoladas. Tipicamente $Q$ assume valores no intervalo [0.3,0.7]. Essa medida tem sido utilizada em diversos trabalhos para a identificação da melhor configuração de comunidades, especialmente em algoritmos divisivos e em algoritmos aglomerativos. Especificamente, Newman (2004b) propôs um método de identificação de comunidades baseado nessa medida para a identificação de comunidades. Essa seção irá apresentar alguns dentre os principais métodos de detecção de comunidades. O método (Newman, 2004b) é certamente um dos mais populares.

\subsubsection{Método Baseado em Betweenness}

Girvan \& Newman (2002) apresentaram um método de detecção de comunidades divisivo. Os métodos que consistem nessa abordagem, fundamentam-se na ideia de que identificando e removendo as arestas que conectam nós de diferentes comunidades, é possível identificar os grupos de nós que compreendem cada comunidade.

No método apresentado em (Girvan \& Newman, 2002; Newman \& Girvan, 2004) as arestas entre comunidades são identificadas de acordo com uma medida de separabilidade, conhecida como betweenness. Dado o conjunto de caminhos entre pares de nós $C$, definido para todos os pares de nós possíveis em uma rede $G=(V, E)$, para cada aresta em $E$, é computada a sua frequência nos caminhos do conjunto $C$. A ideia é que, uma vez que exitem menos arestas entre nós de diferentes comunidades de que entre nós de uma mesma comunidade, as arestas entre comunidades tendem a ser sobrecarregadas, estando mais frequentes em $C$, e consequentemente obtendo maior índice de betweenness.

Existem diversas maneiras de gerar o conjunto $C$. Três desses métodos foram destacados em (Newman \& Girvan, 2004) e serão apresentadas nas próximas subseções. Eventualmente, mais que uma aresta pode interligar duas comunidades, e com igual probabilidade compor caminhos entre essas comunidades. Nesse caso, o algoritmo de construção dos caminhos não é capaz de ponderar igualmente os caminhos com eficiência. Logo, um dos caminhos será preterido em detrimento dos demais, resultando na sobrecarga de apenas uma aresta. Por isso, sempre que uma aresta é removida, é necessário recalcular a medida de betweenness, dando igual oportunidade às arestas prejudicas. Logo, cada iteração do método consiste em:

1. Calcular a medida de betweenness de todas as arestas.

2. Identificar e remover a aresta com maior medida de betweenness.

O algoritmo será executado iterativamente até que todas as arestas sejam removidas da rede, resultando em uma árvore hierárquica. O índice de modularidade é um excelente 
indicador da partição mais adequada da rede. A Figura 3.12 ilustra uma arvore hierárquica obtida da rede ilustrada na Figura 3.5. O corte horizontal, indica a configuração com melhor índice de modularidade.

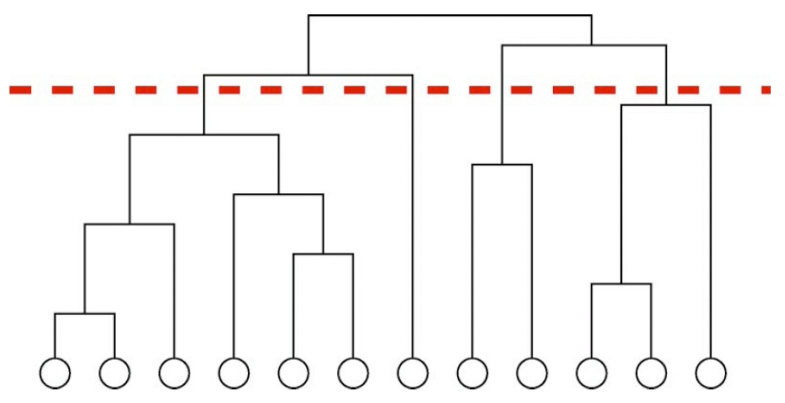

Figura 3.12: Arvore hierárquica (ou dendograma) ilustrando o resultado do método de detecção de comunidades de Newman \& Girvan (2004) aplicado a rede da Figura 3.5. Os círculos na base da figura representam os nós da rede. Movendo-se sentido a raiz da árvore, temos partições cada vez maiores. No caso do algoritmo de Newman \& Girvan (2004), trata-se de um método divisivo. Nesse caso, a visualização mais adequada é a partir da raiz sentido as folhas. O corte horizontal refere-se a partição de comunidades com maior índice de modularidade. Figura obtida de (Newman \& Girvan, 2004).

\section{Betweenness do Menor Caminho}

Uma das maneiras de gerar o conjunto de caminhos $C$ é através da identificação do menor caminho entre pares de nós. Esse método é sem dúvidas o método mais simples e intuitivo para essa tarefa. Considerando uma rede não ponderada com $N$ nós e $M$ arestas, pode-se utilizar uma estratégia de busca em largura, cujo o custo computacional é dado por $O\left(N^{2} M\right)$. Newman \& Girvan (2004) observaram em seu trabalho que, em redes sem pesos, a remoção de uma aresta, afeta apenas o índice de betweenness do menor caminho das arestas conectadas aos nós da aresta removida. Portanto, nesse caso, só é necessário recalcular o índice de betweenness dessas arestas a cada iteração. Essa adaptação do método reduz sua ordem de complexidade para $O(N M)$. Note-se também que, como a cada passo uma aresta será removida, o custo computacional ira diminuir iterativamente.

Para uma rede ponderada entretanto, se faz necessário o uso de um algoritmo de menor caminho aproximado, como o algoritmo de Dijkstra ou o algoritmo A* (Bondy \& Murty, 2007). Nesse caso é um pouco mais complicado considerar uma heurística menos custosa para a atualização da medida de betweenness das arestas. Os algoritmos de Dijktra e A*, possuem complexidade da ordem $O\left(N^{2} \log (N)\right)$ e $O\left(N^{3}\right)$, respectivamente.

\section{Betweenness de uma Caminhada Aleatória}

A medida de betweennes de uma caminhada aleatória, afere o número de vezes que uma caminhada aleatória de um nó $s$ até um nó $t$ passa por uma aresta particular, $(v, w)$. Uma caminhada aleatória não leva em consideração qualquer heurística para selecionar 
o próximo vértice a ser visitado. A cada iteração o algoritmo calcula o número de vezes que cada aresta $(u, w)$ é utilizada na caminhada aleatória de $s$ a $t$, para todo $s, t$ em $V$. Quando $s$ e $t$ pertencerem a comunidades distintas, arestas inter-comunidades certamente serão utilizada para transitar entre as comunidades e a probabilidade de escolher aleatoriamente uma mesma aresta inter-comunidades é maior que a de escolher aleatoriamente uma aresta intra-comunidade, pois existem menos arestas inter-comunidades de que intracomunidade. No caso de uma rede ponderada, estaremos lidando com uma caminhada aleatória com bias.

\section{Betweenness de Fluxo de Corrente}

A medida de betweenness de fluxo de corrente é fundamentada na teoria dos circuitos. Assim sendo, cada aresta da rede equivale a uma resistência. Iterativamente, todos os pares de nós $(s, t), s, t \in V$, são selecionados respectivamente como fonte e sumidouro. Uma corrente percorre o circuito por todos os caminhos em paralelo, a partir da fonte sentido sumidouro. Os caminhos com menor resistência serão circulados por maior porção de corrente, como em um circuito elétrico. Para todo par $(s, t)$, a aresta pela qual circula maior corrente possui maior valor de betweenness. Nesse caso, o valor de betweenness é aferido segundo as leis de Kirchhoff. No caso de uma rede ponderada, pode-se assumir valores distintos de resistência para cada aresta. O valor da resistência de cada aresta é inversamente proporcional à força da interação.

\subsubsection{Método Baseado em Modularidade}

Baseado na medida de modularidade, Newman (2004b) propôs um algoritmo aglomerativo de detecção de comunidades. Dada uma rede com $N$ nós e $M$ arestas, inicialmente composta por $c=N$ comunidades, cada nó pertencendo a uma comunidade, como nas folhas de uma árvore hierárquica. A cada iteração, duas comunidades são agrupadas, no sentido de maximizar o índice de modularidade, $Q$. Cada junção de duas comunidades, $i$ e $j$, proporciona a variação, $\Delta Q$ no índice de modularidade,

$$
\Delta Q=e_{i j}+e_{j i}-2 a_{i} a_{j}=2\left(e_{i j}-a_{i} a_{j}\right)
$$

onde $e_{i i}$ informa a fração de ligações entre nós da comunidade $i$ e $e_{i j}$ a fração de nós entre as comunidades $i$ e $j ; a_{i}$ indica o número de ligações incidentes sobre nós da comunidade i. Logo, a cada iteração é agrupado o par de comunidades que proporcione a maior incremento (ou menor decremento) na modularidade. Esse processo aglomerativo pode ser realizado iterativamente até que reste uma única comunidade. O particionamento com maior índice de modularidade é a melhor configuração de comunidades da rede.

Cada iteração desse algoritmo apresenta complexidade de tempo da ordem $O(M+N)$. Como existirão até $N-1$ junções de comunidades, pode-se dizer que o algoritmo apresenta complexidade da ordem $O((M+N) N)$, ou simplesmente $O\left(N^{2}\right)$ no caso de redes esparsas. 


\subsubsection{Método Baseado em Caminhada Aleatória}

Baseado no movimento de uma partícula Browniana em uma rede, também conhecido como caminhada aleatória, Zhou (2003b) propôs a medida de distância de uma caminhada aleatória como uma medida para a identificação das comunidades em uma rede. Baseado nessa medida, dois métodos foram gerados: um baseado no conceito de atratores locais e atratores globais (Zhou, 2003b); outro baseado no índice de dissimilaridade (Zhou, 2003a).

Considere uma rede $G=(V, E)$ não direcionada com $N$ nós, $V=\{1,2, \ldots, n\}$, e $M$ arestas, representada através de uma matriz de adjacências generalizada $W$, que indica não apenas a existência de ligações entre os nós, mas também o peso dessas ligações. Se $w_{i j}=0$ não existe uma ligação conectando o nó $i$ ao nó $j$; se $w_{i j}=w_{j i}>0$ existe uma aresta conectando $i$ a $j$ com peso $w_{i j}$. Uma partícula Browniana, move-se do nó $i$ para um nó $j$, vizinho de $i$ com probabilidade $p_{i j}$ dada pela matriz de transferência $P$,

$$
p_{i j}=\frac{a_{i j}}{\sum_{k=1}^{N} a_{i k}} .
$$

Zhou (2003b) define a distância $d_{i j}$, do nó $i$ ao nó $j$, como o número médio de passos necessários a uma partícula que inicia sua caminhada no nó $i$ mover-se até o nó $j$. Segundo Zhou, essa distância pode ser calculada através da solução algébrica da seguinte equação:

$$
d_{i, j}=\sum_{m=1}^{N}\left(\frac{1}{I-B(j)}\right)_{i m},
$$

onde $I$ é a matriz identidade $N \times N$, e $B(j)$ é a matriz de transferência $P$ a menos de que $B_{m j}(j)=0, \forall m \in V$. A distância de todos os nós da rede a $j$ pode ser obtida a partir da resolução da Equação (3.1).

$$
[I-B(j)]\left\{d_{1, j}, d_{2, j}, \ldots, d_{N, j}\right\}^{T}=\{1, \ldots, 1\}^{T}
$$

Dado um nó $i$, se $d_{i j} \leq d_{i m}, \forall m \in V, j$ é dito atrator global de $i$. Se $j$ for vizinho de $i$ e $d_{i j} \leq d_{i m}$ para todo $m$ vizinho de $i$, então diz-se que $j$ é um atrator local de $i$. Dada uma rede com comunidades bem definidas, o autor acredita que um nó $i$ pertence a mesma comunidade que seu atrator local $j$, uma vez que, dentre todos os nós vizinhos de $i, j$ apresenta a menor distância $d_{i j}$. Desse modo, dado um nó $i$ participante de uma comunidade $L$, um nó $j$ é acrescentado a comunidade $L$ se $j$ for um atrator local de $i$ ou se $i$ for um atrator local de $j$.

Esse método foi estendido em (Zhou, 2003a) com a adição de um índice de dissimilaridade entre pares de nós, obtido a partir da distância de uma caminhada aleatória. Esse índice indica a dissimilaridade entre dois nós em uma rede, sendo usado para dividir a rede, hierarquicamente. Dado um nó $i$, e o conjunto distâncias de $i$ até os demais nós, $\left\{d_{i, 1}, d_{i, 2}, \ldots, d_{i, n}\right\}$, e um nó $j,\left\{d_{j, 1}, d_{j, 2}, \ldots, d_{j, n}\right\}$, a medida de dissimilaridade é dada por $\Lambda(i, j)$, 


$$
\Lambda(i, j)=\sqrt{\frac{\sum_{k \neq i, k \neq j}\left(d_{i k}-d_{j k}\right)^{2}}{N-2}} .
$$

Se $i$ e $j$ pertencem a mesma comunidade, eles tendem a ter índice de dissimilaridade pequeno. Caso contrário tendem a ter um índice de dissimilaridade alto. Dado inicialmente uma rede, em que todos nós pertencem a uma única comunidade. A cada iteração um limiar é estabelecido, de acordo com o maior índice entre pares de nós vizinhos, $(i, j) \in E$, e as comunidades são decompostas, hierarquicamente.

\subsubsection{Método Baseado em Competição de Partículas}

Quiles et al. (2008) apresentam um modelo de detecção de comunidades dinâmico, baseado em caminhada aleatória e competição de partículas. Neste modelo, várias partículas são colocadas para caminhar em uma rede, competindo entre si para marcar vértices sob seu domínio e rejeitar partículas intrusas. Cada partículas possui uma variável que representa o seu poder de exploração, denominado potencial de partícula, e cada vértice possui uma variável que representa quão intenso é o domínio realizado por sua partícula dona, denominado potencial do vértice. Quando uma partícula visita um vértice do qual é dona, ou mesmo um vértice sem dono, o potencial do vértice e o potencial da partícula são reforçados; quando uma partícula visita um vértice que pertence à outra partícula, o potencial de ambos é enfraquecido. Desta forma, cada comunidade será dominada por uma única partícula. Esse processo é similar a muitos processos naturais, tais como competição de recursos entre animais, campanha eleitoral, etc.

Esse modelo considera dois tipos de dinâmica, a dinâmica das partículas e a dinâmica dos vértices. Cada partícula $p_{j}$ pode ser descrita por duas variáveis $p_{j}^{v}(t)$ e $p_{j}^{w}(t)$; a primeira usada para indicar o vértice $v_{i}$ que a partícula esta visitando no instante $t$, e a segunda para indicar o potencial da partícula no intervalo $\left[w_{\text {min }}, w_{\text {max }}\right]$, também compreendido como sua habilidade para explorar no instante $t$. Os valores $w_{\min }$ e $w_{\max }$ representam o potencial máximo e mínimo pré-definidos. A dinâmica dessas partículas pode ser expressa pelas seguintes equações:

$$
\begin{gathered}
p_{j}^{v}(t+1)=v_{i}, \\
p_{j}^{w}(t+1)=\left\{\begin{aligned}
p_{j}^{w}(t) & \text { se } v_{i}^{p}(t)=0 \\
p_{j}^{w}(t)+\left(w_{\max }-p_{j}^{w}(t)\right) \Delta_{p} & \text { se } v_{i}^{p}(t)=p_{j} \neq 0 \\
p_{j}^{w}(t)-\left(p_{j}^{w}(t)-w_{\text {min }}\right) \Delta_{p} & \text { se } v_{i}^{p}(t) \neq p_{j} \neq 0
\end{aligned}\right.
\end{gathered}
$$

onde $\Delta_{p}$ é um parâmetro para controlar a velocidade com que o potencial de cada partícula é alterado (aumentado ou diminuido).

De forma simétrica, cada vértice $v_{i}$ também é caracterizado por duas variáveis $v_{i}^{p}(t)$ e $v_{i}^{w}(t)$. A primeira é usada para registrar a qual partícula o vértice $v_{i}$ pertence no instante $t$; 
esta variável assume o valor $p_{j}$ se pertence ao território demarcado pela partícula $p_{j}$, ou 0 se o vértice estiver no estado livre, i.e., se o vértice não está sendo dominado por nenhuma partícula. A segunda variável, $v_{i}^{w}$, semelhante a $p_{j}^{w}(t)$, tem como objetivo armazenar o potencial do vértice $v_{i}$ no instante $t$. Este potencial representa a força com que a partícula $p_{j}$ domina o vértice $v_{i}$. Deste modo, valores altos para $v_{i}^{w}$ significa que o vértice $v_{i}$ é fortemente dominado pela partícula $p_{j}$, enquanto que valores menores representam uma dominação mais amena. Especificamente, se $v_{i}^{w} \leq w_{\text {min }}$, indica que o vértice $v_{i}$ está no estado livre, e pode ser dominado pela primeira partícula que o visitar. A dinâmica das partículas pode ser resumida pelas seguintes equações:

$$
\begin{aligned}
& v_{j}^{p}(t+1)=\left\{\begin{array}{rl}
v_{j}^{w}(t) & \text { se } v_{i}^{\gamma}=0 \\
p_{j} & \text { se } v_{i}^{\gamma}=1 \text { e } v_{j}^{w}(t) \leq w_{\min }
\end{array},\right. \\
& v_{j}^{w}(t+1)=\left\{\begin{array}{rl}
v_{j}^{w}(t) & \text { se } v_{i}^{\gamma}=0 \\
\max \left\{w_{\min }, v_{i}^{w}(t)-\Delta_{v}\right\} & \text { se } v_{i}^{\gamma}=1 \text { e } v_{i}^{p}(t) \neq p_{j} \\
p_{i}^{w}(t+1) & \text { se } v_{i}^{\gamma}=1 \text { e } v_{i}^{p}(t)=p_{j}
\end{array},\right.
\end{aligned}
$$

onde, $\Delta_{v}$, semelhante a Eq. 3.2, é utilizado para controlar a velocidade com que o potencial do vértice é alterado, enquanto que $v_{i}^{\gamma}$ é um valor binário e simplesmente indica se o vértice está sendo visitado por alguma partícula no instante $t$.

A aplicação do modelo ao processo de detecção de comunidades pode ser descrito como segue: inicialmente $k$ partículas são inseridas em $k$ vértices selecionados aleatoriamente. Cada uma dessas partículas e todos os vértices possuem um potencial inicial igual ao potencial mínimo, $w_{\text {min }}$. No instante inicial todos os vértices encontram-se no estado livre, $v_{i}^{p}(t)=0$. Iniciado o processo, a cada iteração cada partícula escolhe um vértice vizinho ao vértice onde esteve na última iteração para visitar, desde que este já ainda não tenha sido visitado nessa iteração, $v_{i}^{\gamma}=0$. No momento da visita, cada partícula ira encontrar uma das três seguintes situações:

1. Se o vértice visitado $v_{i}$ não pertence a nenhuma partícula, $v_{i}^{p}(t)=0$, então o potencial da partícula não é alterado. O vértice é então marcado como pertencente à partícula $p_{j}$ e assume potencial igual ao da partícula.

2. Se o vértice visitado já pertence à partícula corrente, o potencial da partícula aumenta, o vértice continua tendo a partícula por dona, e o vértice assume o potencial da partícula.

3. Se, no entanto, o vértice visitado pertencer a uma partícula diferente da partícula que o está visitando, então ambos os potenciais são reduzidos. Se $p_{i}^{w}(t)$ for reduzido um valor inferior a $w_{\text {min }}, p_{i}$ é descartada do processo, e uma nova partícula com potencial igual a $w_{\text {min }}$ é inserida em um vértice escolhido de maneira aleatória na rede. Se o potencial do vértice chegar tornar-se inferior a $w_{\text {min }}$, então a pertinência do vértice retoma o valor inicial, $v_{i}^{p}(t+1)=0$, indicando que este não pertence a nenhuma partícula. 
Dessa forma, o grau de pertinência de um vértice é reforçado se este for visitado frequentemente pela mesma partícula, e reduzido, ou mesmo alterado, se visitado frequentemente por partículas que não seja a partícula que o dominava inicialmente. $\mathrm{O}$ processo continua até o momento em que o equilíbrio dinâmico é alcançado. Neste caso o equilíbrio dinâmico é atingido quando, durante algum tempo, a maioria dos vértices não sofrer mudanças com relação a seu domínio. A Figura 3.13 ilustra o processo de detecção de comunidades via competição de partículas.

Além disso, o método se utiliza de uma regra para ajustar o nível de aleatoriedade na caminhada das partículas, de tal maneira que a escolha do próximo vértice a ser visitado pode ser uma escolha determinística com probabilidade $p_{\text {det }}$. Os melhores resultados do modelo foram observados para um valor intermediário de $p_{\text {det }}$, como mostra a Figura 3.14.

\subsection{Considerações Finais}

Este capítulo apresentou o uma revisão sobre o tema redes complexas. Foram apresentados definição e exemplos de redes complexas, algumas propriedades de redes, os principais modelos de construção de redes sintéticas e alguns dentre os principais métodos de identificação de comunidades.

Propriedades como transitividade, distribuição de grau, estruturas de comunidades e efeito de pequeno mundo foram abordadas nessa revisão. Além dessas propriedades, outras como centralidade, resiliência, processos de espalhamento de informação, sincronização, transição de fase, percolação entre outros têm sido estudadas extensivamente. Processos de espalhamento de informação, por exemplo, estão diretamente relacionados a como doenças infectocontagiosas, vírus, informações, renda, entre outros são distribuídos em redes de interações sociais, biológicas, etc. Esse tipo de análise é tipicamente tratado no sentido de identificar se existe ou não um potencial epidemiológico, isto é, se o agente tende a continuar se espalhando através da rede, ou se será extinto. Pastor-Satorras \& Vespignani (2001) apresentam um dos primeiros estudos sobre epidemiologia em redes. Albert \& Barabási (2002); Newman (2003); Costa et al. (2007) apresentam uma revisão sobre alguns desses tópicos.

O método baseado em separabilidade (Newman \& Girvan, 2004) e o método baseado em modularidade (Newman, 2004b) são certamente dois dos mais populares métodos de detecção de comunidades. Muitos métodos tem sido propostos como extensão desses dois métodos: Radicchi et al. (2004), por exemplo, apresenta um método divisivo, diferentemente de (Newman \& Girvan, 2004), baseado no coeficiente de clustering; Duch \& Arenas (2005); Pujol et al. (2006); Ye et al. (2008) propõem extensões do método aglomerativo baseado em modularidade. Diferentemente, Newman (2006) propõe uma abordagem utilizando análise espectral, baseada na análise dos auto vetores da matriz Laplaciana. Danon et al. (2005); Newman (2004a) apresentam uma análise comparativa de desempenho entre diversos métodos de detecção de comunidades. Além desses, alguns métodos tem sido 


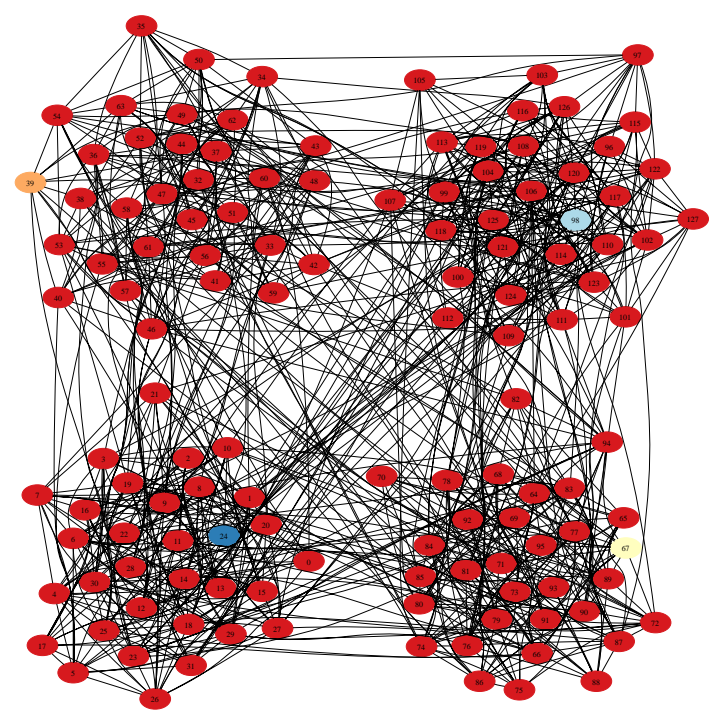

(a)

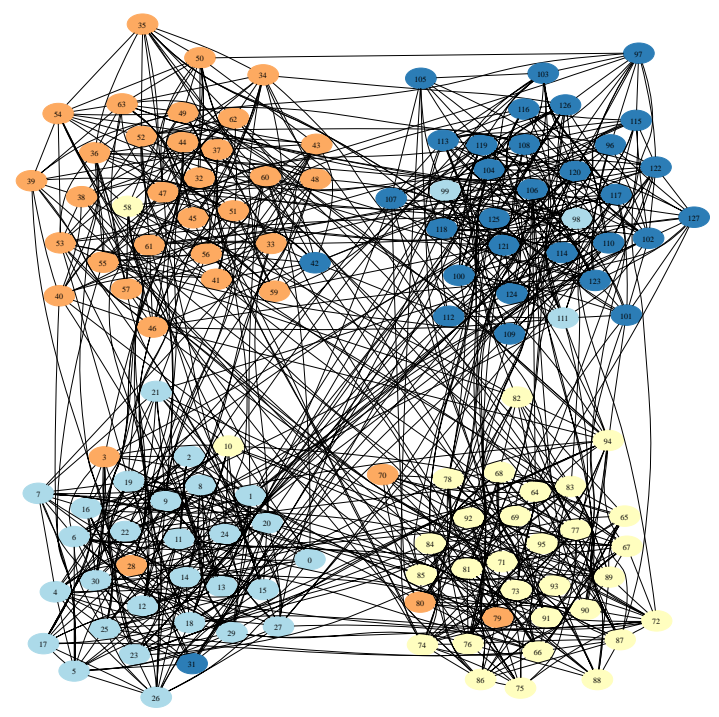

(c)

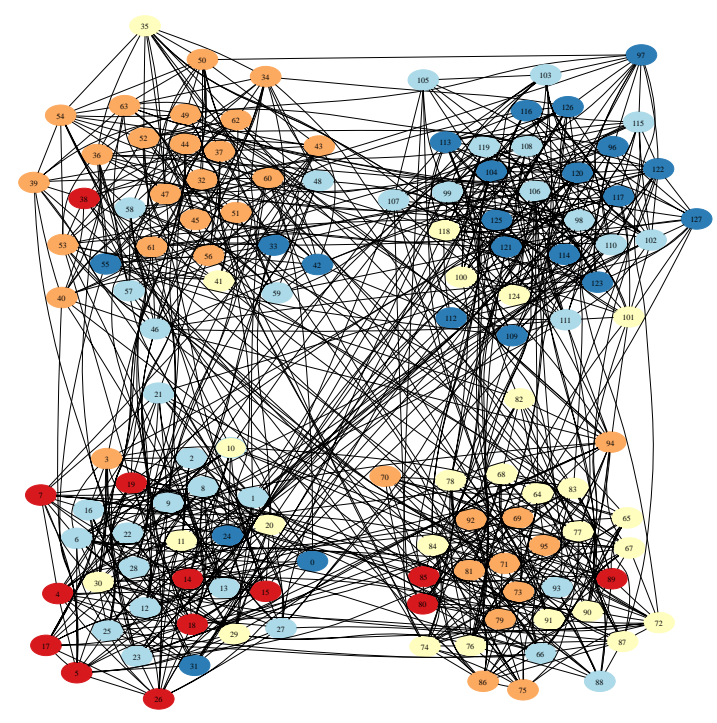

(b)

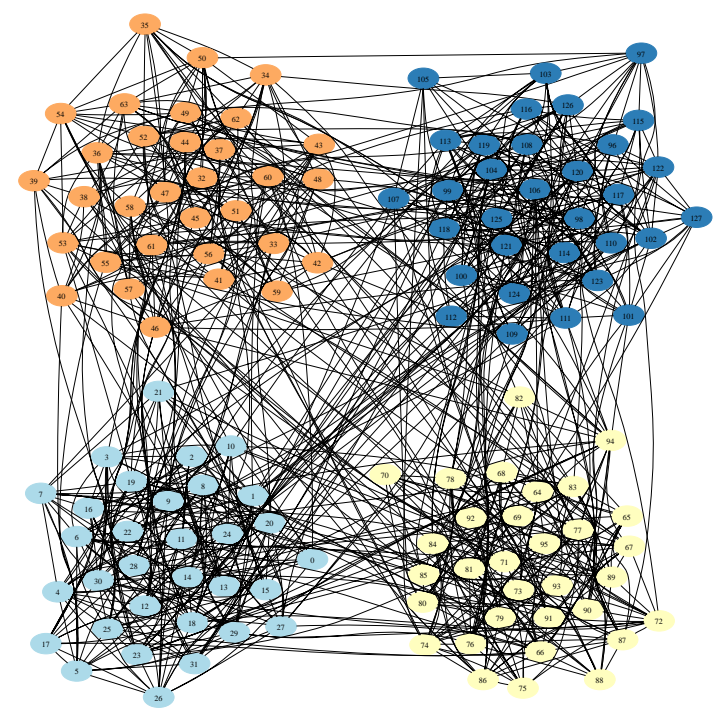

(d)

Figura 3.13: Ilustração do processo de detecção de comunidades segundo o método de competição de partículas e caminhada aleatória. A rede possui 128 vértices, 4 comunidades bem definidas, grau médio $\langle k\rangle=16$ e proporção de conexões entre comunidade $p_{\text {out }}=0.2$. (a) Configuração inicial: quatro partículas nas cores amarelo, ciano, laranja, e azul são colocadas em vértices aleatórios da rede; os vértices em vermelho estão livres. Em (b) domínio das partículas na iteração 250. Em (c) domínio das partículas na iteração 3500 . Em (d) domínio das partículas na iteração 7000. Figura obtida de (Quiles et al., 2008). 


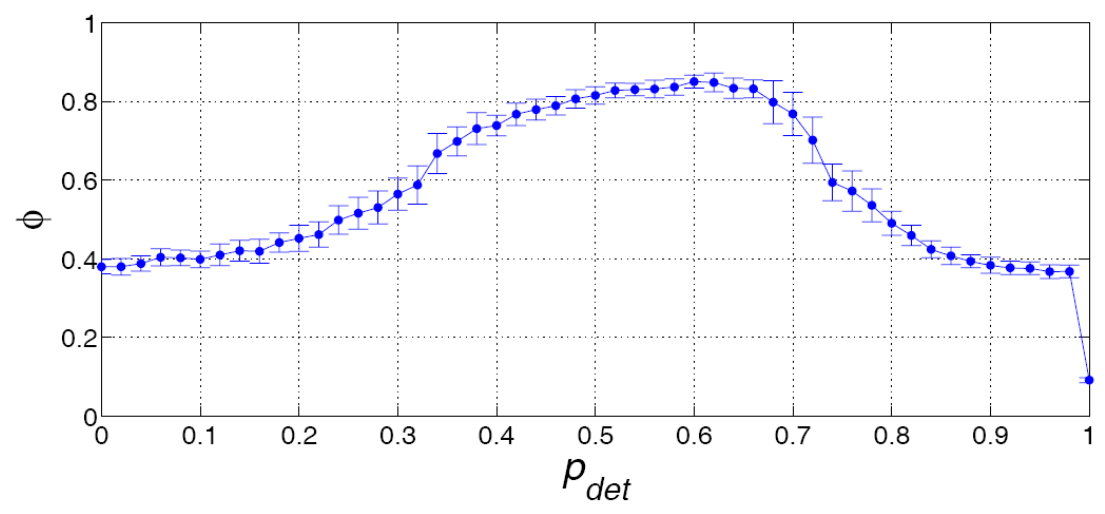

Figura 3.14: Fração de nós identificados corretamente em sua comunidade segundo o método de Quiles et al. (2008) em relação ao nível de determinismo da caminhada. Cada ponto da curva representa a média de 200 execuções em uma rede com 128 nós, $\langle k\rangle=16$, e $p_{\text {out }}=0,5$. A barra de erro representa o desvio padrão. Figura obtida de (Quiles et al., 2008).

propostos sob uma abordagem semi-supervisionada (Allahverdyan et al., 2010; Ma et al., 2010). É também o caso do método baseado em caminhada aleatória e competição de partículas apresentado em Quiles et al. (2008), estendido sob essa abordagem em (Breve et al., 2009).

O Capítulo 4, irá apresentar um método de detecção de outliers em redes complexas baseado em caminhada aleatória. Adicionalmente, foi identificado que os nós outleirs, segundo o método proposto, são bons candidato à rotulação a priori para a detecção de comunidades semi-supervisionada. Adicionalmente, um método de detecção de comunidades semi-supervisionado, baseado na propagação de informações é proposto. 


\section{Capítulo}

\section{Identificação de Outliers em Redes Complexas e Aplicação à Detecção de Comunidades}

A detecção de outliers é uma tarefa muito importante para a mineração de dados. Em se tratando de redes, a identificação de nós anormais pode ajudar na caracterização da rede, revelando, por exemplo, propriedades estruturais e funcionais. Essa identificação pode ser realizada levando-se em consideração diversos critérios. Se considerarmos, por exemplo, a conectividade dos nós em uma rede livre de escala, certamente, os nós mais anormais serão os hubs, pois sua conectividade é muito maior que a conectividade média da rede. Em uma rede como a Internet, hubs equivalem aos grandes roteadores. Esses elementos são fundamentais para a distribuição de informações na rede. Entretanto, o grau é uma propriedade local dos nós, e não permite caracterizar globalmente a rede. Considerando-se, no entanto, a medida de distância de uma caminhada aleatória é possível estimar o comportamento global da rede, pois a caminhada aleatória considera todos os possíveis caminhos entre pares de nós na rede.

Esse capítulo irá apresentar um método de identificação de nós anormais em redes baseado na medida de distância de uma caminhada aleatória e em um índice de dissimilaridade. Esse método foi aplicado a diversas redes, tanto sintéticas como reais, e foi possível observar que seus resultados são abrangentes, possibilitando a identificação de nós periféricos, como também de nós centrais (hubs), de acordo com a funcionalidade dos mesmos para a rede. Adicionalmente foi identificado que esse nós são bons candidatos à rotulação a priori na abordagem de detecção de comunidades semi-supervisonada. Logo, a Seção 4.1 irá apresentar a medida de distância de uma caminha aleatória, a Seção 4.2 irá apresentar 
o método proposto, a Seção 4.3 irá demonstrar como o método funciona, a Seção 4.4 irá apresentar resultados obtidos de redes reais e a Seção 4.5 irá apresenta os resultados obtidos da aplicação de outliers à detecção de comunidades semi-supervisionada, além de um método de detecção de comunidades semi-supervisionado utilizado para validar os resultados.

\subsection{Medida de Distância de uma Caminhada Aleatória}

Uma caminhada aleatória consiste na tomada sucessiva de passos randômicos. A cada iteração o caminhante seleciona um dentre os possíveis passos com igual probabilidade. Em se tratando de uma rede, supondo que o caminhante esteja em um nó $i$ escolhido arbitrariamente, cujo grau é $k_{i}$, em um passo o caminhante mover-se-á com igual probabilidade para um dentre os nós vizinhos, de modo que a probabilidade do caminhante mover-se de $i$ até um nó vizinho $j$ é dada por $p_{i j}^{(1)}=1 / k_{i}$. Essa probabilidade é denominada probabilidade de transição. Existem diversos casos específicos de caminhadas aleatórias. Alguns desses são a difusão Browniana, o processo markoviano e a caminhada aleatória auto-excludente (Madras \& Slade, 1996). Uma cadeia de Markov de estados finitos é o processo que melhor descreve uma caminhada aleatória em um grafo (Woess, 2000).

\subsubsection{Caminhada Aleatória em Redes}

Esse problema pode ser definido da seguinte forma. Considere uma rede $G=(V, E)$ com $n$ nós, $V=\{1,2, \ldots, n\}$, cujo as ligações entre os nós $E$ estão representadas na matriz de adjacências generalizada $A$. Se não existe uma ligação de um nó $i$ para um nó $j, a_{i j}=0$, caso contrário $a_{i j}>0$, e equivale a força da ligação de $i$ até $j$; se a rede for não direcionada necessariamente $a_{i j}=a_{j i}$. A probabilidade de o caminhante mover-se entre dois nós em um passo (Figura 4.1(a)) é dada pela matriz de transição $P^{(1)}$,

$$
p_{i j}^{(1)}=\frac{a_{i j}}{\sum_{l=1}^{n} a_{i l}},
$$

a probabilidade de o caminhante mover-se entre dois nós em dois passos (Figura 4.1(b-e)) é dada pela matriz de transição $P^{(2)}$, onde

$$
p_{i j}^{(2)}=\sum_{k_{1} \neq j} p_{i k_{1}}^{(1)} p_{k_{1} j}^{(1)},
$$

e a probabilidade de o caminhante mover-se entre dois nós em três passos é dada pela matriz de transição $P^{(3)}$, onde

$$
p_{i j}^{(3)}=\sum_{k_{1} \neq j ; k_{2} \neq j} p_{i k_{1}}^{(1)} p_{k_{1} k_{2}}^{(1)} p_{k_{2} j}^{(1)}
$$


Logo, a probabilidade de o caminhante mover-se entre dois nós em qualquer número de passos é dada pela matriz de transição $P$, onde

$$
p_{i j}=p_{i j}^{(1)}+\sum_{m=1}^{\infty}(m+1) \sum_{k_{1} \neq j ; \ldots ; k_{m} \neq j} p_{i k_{1}}^{(1)} p_{k_{1} k_{2}}^{(1)} \ldots p_{k_{m} j}^{(1)} .
$$

Nesse caso, a solução exata da equação de probabilidade de transição é obtida no domínio de $m, \forall m \in \mathbb{N}$. Essa solução não é trivial.

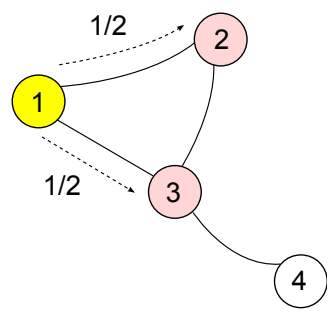

(a)

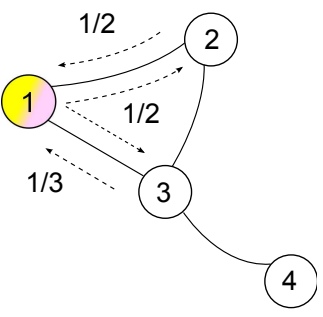

(b)

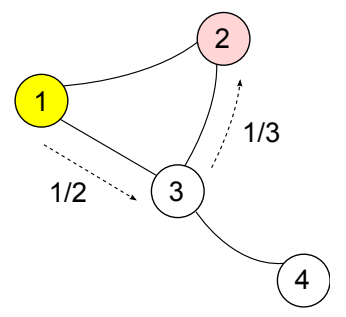

(c)

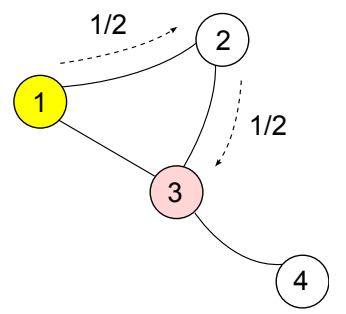

(d)

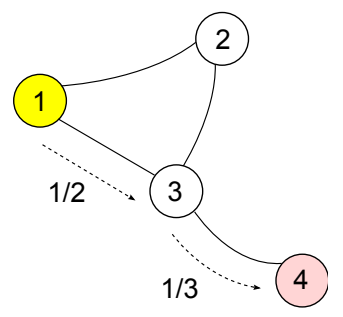

(e)

Figura 4.1: Caminhada aleatória em redes: (a) probabilidade de o caminhante mover-se a partir do nó 1 até os nós vizinhos em uma iteração; (b-e) probabilidade de o caminhante mover-se a partir do nó 1 até os nó 1, 2, 3 e 4 em duas iterações.

\subsubsection{Cadeias de Markov}

Por outro lado, uma caminhada aleatória em uma rede também pode ser vista como um processo markoviano, uma cadeia de Markov de estados finitos. Em uma caminhada aleatória em uma rede, a partir do estado atual é possível saber a probabilidade de se estar em cada nó em um momento futuro (Woess, 2000; Anton \& Rorres, 2005). Isto é, dado $P^{(1)}$, uma matriz de probabilidade de transição de estados, e $x(m)$, um vetor probabilidade de estado no $m$-ésimo passo,

$$
x(m+1)=x(m) P^{(1)} .
$$

Desse teorema segue que 


$$
\begin{aligned}
x(1) & =x(0) P^{(1)}, \\
x(2) & =x(1) P^{(1)} \\
& =x(0) P^{(1)} P^{(1)} \\
& =x(0) P^{(1)},
\end{aligned}
$$

e $\log O$

$$
x(m)=x(0) P^{(1)^{m}} .
$$

Adicionalmente, $P^{(1)^{m}}$ equivale a $P^{(m)}$.

\section{Vetor de Estado Estacionário}

O Teorema de Convergência de Markov (Anton \& Rorres, 2005) diz que, dado $P^{(1)}$, uma matriz de transição regular, em que

$$
p_{i 1}^{(1)}+p_{i 2}^{(1)}+\ldots+p_{i n}^{(1)}=1
$$

cujo todas as potências possuem entradas não-negativas, então

$$
P^{(1)^{m}} \rightarrow\left[\begin{array}{cccc}
q_{1} & q_{2} & \ldots & q_{n} \\
q_{1} & q_{2} & \ldots & q_{n} \\
\vdots & \vdots & \ddots & \vdots \\
q_{1} & q_{2} & \ldots & q_{n}
\end{array}\right]
$$

quando $m \rightarrow \infty$, em que $q_{i}$ são números não-negativos e $q_{1}+q_{2}+\ldots+q_{n}=1$. De outro modo, da Equação (4.2) temos também que, seja o vetor de estado inicial $x(0)$ um vetor de probabilidade qualquer, então

$$
x(0) P^{(1)^{m}} \rightarrow\left\{\begin{array}{llll}
q_{1} & q_{2} & \ldots & q_{n}
\end{array}\right\}
$$

quando $m \rightarrow \infty$. O vetor $q=\left\{\begin{array}{llll}q_{1} & q_{2} & \ldots & q_{n}\end{array}\right\}$ é um vetor de probabilidade fixo, independente de $m$, cujas entradas são não-negativas. Este vetor também é conhecido como vetor de estado estacionário e é o único vetor que satisfaz a seguinte equação (Anton \& Rorres, 2005):

$$
P^{(1)}\left(\begin{array}{c}
q_{1} \\
q_{2} \\
\vdots \\
q_{n}
\end{array}\right)=\left(\begin{array}{c}
q_{1} \\
q_{2} \\
\vdots \\
q_{n}
\end{array}\right)
$$


Dessa equação, podemos obter que

$$
\left[I-P^{(1)}\right]\left(\begin{array}{c}
q_{1} \\
q_{2} \\
\vdots \\
q_{n}
\end{array}\right)=0 .
$$

Solucionando essa equação algébrica é possível obter o vetor de estado estacionário $q$.

\subsubsection{Medida de Distância}

Podemos obter a probabilidade de um caminhante mover-se em qualquer número de passos até um determinado nó $j$ partindo de qualquer nó em $V$ a partir da solução da seguinte equação algébrica obtida da Equação (4.4) e da Equação (4.3):

$$
[I-B(j)]\left(\begin{array}{c}
q_{1} \\
q_{2} \\
\vdots \\
q_{n}
\end{array}\right)=\left(\begin{array}{c}
1 \\
1 \\
\vdots \\
1
\end{array}\right)
$$

onde $B(j)$ equivale a matriz de transição $P^{(1)}$ exceto que todas as entradas da $j$-ésima linha possuem valor nulo. Logo, $[I-B(j)]$ significa que o caminhante está em $j$ no estado estacionário. Solucionando essa equação para todo $j \mathrm{em} V$, obtemos a matriz de transição de estado estacionário $P$, equivalente a solução da Equação (4.1).

O índice $p_{i j}$ diz a probabilidade de um caminhante que começou a caminhada em $i$ estar em $j$ no estado estacionário. Logo, $p_{i j}$ equivale ao número médio de passos de $i$ até $j$ ou a distância de $i$ até $j$. E ainda, $p_{i j}$ representa a "visão" que $i$ tem de $j$. Essa definição será aplicada a partir deste momento para facilitar o entendimento do método de deteç̧ão de outliers proposto. Diga-se de passagem, não necessariamente $p_{i j}$ é igual a $p_{j i}$. Isto ocorrerá apenas se $i$ e $j$ possuem o mesmo "ponto de vista" e compartilham a mesma "perspectiva" da rede.

\subsection{Método de Detecção de Oultiers em Redes}

Considere uma rede com $n$ nós, cuja distância entre eles está representada na matriz $P$ obtida a partir da Equação (4.5) apresentada na Seção 4.1. Opcionalmente, pode-se optar por normalizar essa matriz com o propósito de limitar suas entradas no intervalo $[0,1]$. Podemos comparar a perspectiva de cada nó no intuito de identificar os nós outliers na rede. Nesse sentido foi escolhido o índice de dissimilaridade apresentado em (Zhou, 2003a), como mostra a seguinte equação:

$$
\Lambda(i, j)=\frac{\sqrt{\sum_{k \neq i, j}^{n}\left(p_{i k}-p_{j k}\right)^{2}}}{(n-2)} .
$$


O índice de dissimilaridade $\Lambda(i, j)$ representa quão diferentes são as perspectivas dos nós $i$ e $j$. Logo, calculando $\Lambda(i, j)$ para todo par $(i, j)$, obtemos a matriz de dissimilaridade $\Lambda$. $\Lambda$ é uma matriz simétrica. Para identificar os nós outliers na rede, iremos computar um escore de outlier para cada nó. Escolhemos a soma do índice de dissimilaridade dividido pela raiz quadrada de $N$, como na seguinte equação:

$$
\sigma(i)=\frac{1}{\sqrt{n}} \sum_{l=1}^{n} \Lambda(i, l),
$$

Desse modo, os escores obtidos matem-se no intervalo $[0,1]$. Ranqueamos o conjunto de nós $V$ em ordem descendente de escore, tal que os primeiros elementos do ranque sejam aqueles como maior escore de outlier. Esses elementos são os nós outliers da rede.

\subsection{Como Funciona o Método de Detecção de Outliers}

Para ilustrarmos como funciona o método proposto, utilizaremos um processo arbitrário de evolução de uma rede. Tomaremos inicialmente uma rede com 5 nós e 4 arestas, como representada na Figura 4.2(a). Aplicando o método proposto sobre essa rede, obtemos que os nós 1 e 5 apresentam o maior escore de outlier. O gráfico de barras da Figura 4.2(c) mostra o escore de outlier de cada nó enquanto que o mapa de cores da Figura 4.2(b) mostra o índice de dissimilaridade entre pares de nós. O resultado obtido mostra que, nesse caso, o método foi capaz de identificar os nós periféricos da rede como outliers. Esse comportamento remete ao comportamento de muitos métodos de detecção de outliers clássicos, capazes de identificar como outliers os nós mais distantes dos centroides (Capítulo 2).

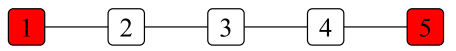

(a)

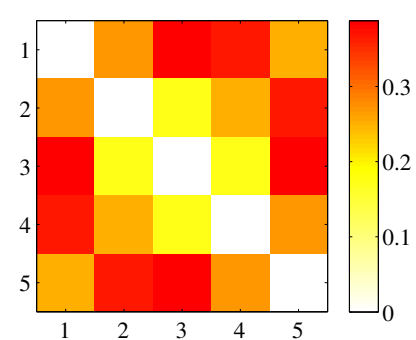

(b)

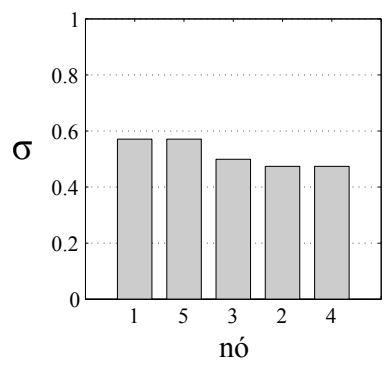

(c)

Figura 4.2: (a) Resultado da aplicação do método de detecção de outliers em uma rede com 5 nós. Estão identificados em vermelho os nós com maior escore de outlier. (b) Matriz de dissimilaridade $\Lambda$. Quanto mais vermelho, maior o índice $\Lambda(i, j)$. (c) Ranque de outliers.

Incrementando a rede através da adição de dois novos ramos ao nó 3 , o resultado é uma rede como 9 nós, como representado na Figura 4.3(a). Embora os nós 1, 5, 7 e 9 sejam os nós mais distantes do centro da rede, nesse caso, o escore de outlier desses nós é superado pelo escore do nó 3. O gráfico de barras da Figura 4.3(c) mostra o escore de 
outlier de cada nó enquanto que o mapa de cores da Figura 4.3(b) mostra o índice de dissimilaridade entre pares de nós. O resultado obtido mostra que, ao invés de identificar os nós periféricos como outliers, foi identificado o nó mais central da rede, que possui maior grau (o $h u b)$. Note-se então que, dependendo da rede apresentada, o método pode identificar diferentes tipos de outliers.

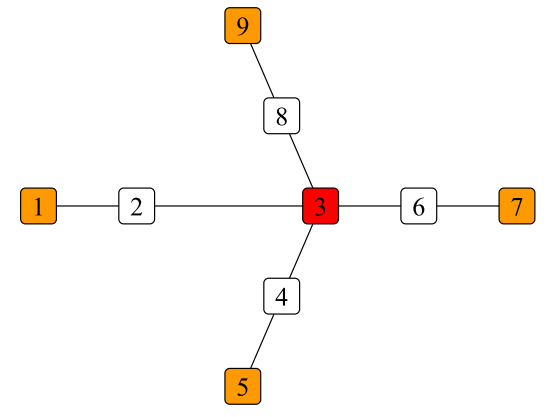

(a)

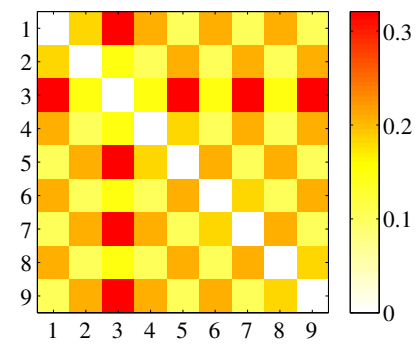

(b)

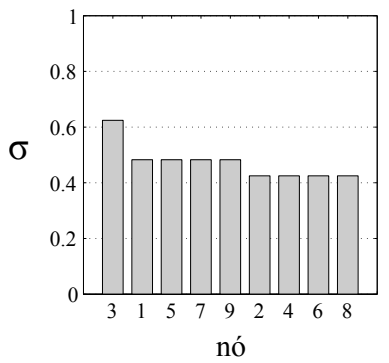

(c)

Figura 4.3: (a) Resultado da aplicação do método de detecção de outliers em uma rede com 9 nós. Estão identificados em vermelho os nós com maior escore de outlier. (b) Matriz de dissimilaridade $\Lambda$. Quanto mais vermelho, maior o índice $\Lambda(i, j)$. (c) Ranque de outliers.

Incrementado a rede ainda mais, adicionando os nó 10, 11, 12 e 13, como mostra a Figura 4.4(a), o método identifica como mais outlier o nó 3, seguido pelos nós 2, 4, 6 e 8. Nesse caso, os nós periféricos ocupam a última posição do ranque. O gráfico de barras da Figura 4.4(c) mostra o escore de outlier de cada nó enquanto que o mapa de cores da Figura 4.4(b) mostra o índice de dissimilaridade entre pares de nós. O nó 3 possui uma perspectiva diferenciada em relação aos demais nós da rede; os nós 2, 4, 6 e 8 compartilham um mesmo ponto de vista; e os nós 1, 5, 7, 9, 10, 11, 12, e 13 compartilham o ponto de vista mais comum da rede.

Adicionalmente, também podemos dizer que o método favorece a identificação de nós dissimilares à maioria dos demais em detrimento de nós muito dissimilares a poucos nós. Através do ranque representado pelo gráfico de barras da Figura 4.4(c) e através da matriz de dissimilaridade representada no mapa de cores da Figura 4.4(b), podemos verificar que, embora os nós 1, 5, 7, 9, 10, 11, 12 e 13, sejam muito dissimilares ao nó 3, como mostra os índices de dissimilaridade do nó 3, o escore dos mesmos é superado pelo escore dos nós 2, 4, 6 e 8. Os nós 2, 4, 6 e 8, não apresentam índices de dissimilaridade tão altos quanto os demais, mas a soma dos seus índices prevalece sobre a soma dos índices dos nós 1, 5, $7,9,10,11,12$ e 13 .

Comparando os resultados apresentados acima, chegamos a conclusão de que o método de detecção de outliers em redes apresentado na Seção 4.2 é capaz de identificar os nós que possuem perspectiva diferenciada na rede, de modo que seu comportamento não atem-se a identificação de nós periféricos, como em muitos métodos clássicos. Hora são identificados nós periféricos; hora nós centrais; hora outros tipos de nós. Dependendo das características da rede apresentada, o método irá identificar como outliers os nós cuja 


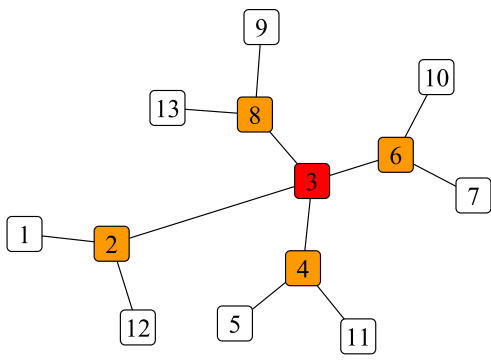

(a)

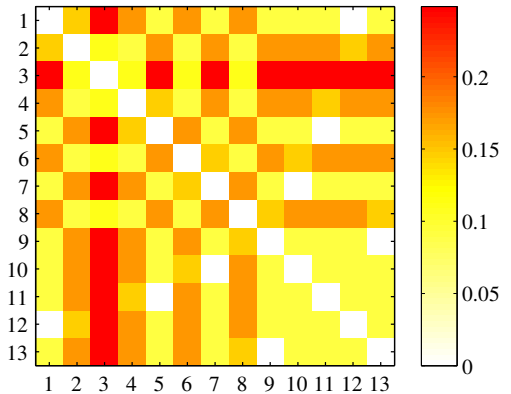

(b)

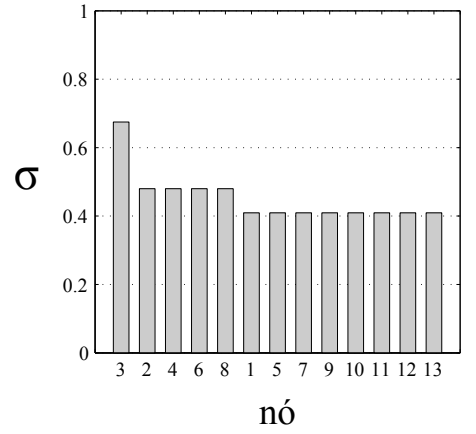

(c)

Figura 4.4: (a) Resultado da aplicação do método de detecção de outliers em uma rede com 13 nós. Estão identificados em vermelho os nós com maior escore de outlier. (b) Matriz de dissimilaridade $\Lambda$. Quanto mais vermelho, maior o índice $\Lambda(i, j)$. (c) Ranque de outliers.

perspectiva difere significativamente dos demais nós. Pode-se dizer então que o método proposto apresenta resultados abrangentes, de modo que podemos concluir que é capaz de identificar os nós mais anormais em uma rede.

\subsection{Resultados Obtidos em Redes Reais}

No intuito de verificar o funcionamento do método proposto aplicamo-no a algumas redes reais. Redes reais tipicamente combinam propriedades de pequeno mundo, transitividades, estruturas de comunidades, propriedades de redes livres de escala, entre outras. Foram selecionadas as redes do clube de karatê registrada em (Zachary, 1977), a rede de colaboração entre cientistas que estudam redes complexas registrada em (Newman, 2006), e a rede de interações entre proteínas do metabolismo da levedura Saccharomyces cerevisiae registrada em (Krogan et al., 2006).

\subsubsection{Rede do Clube de Karatê}

A rede do clube de karatê, registrada por Zachary (1977), trata-se de uma rede social que modela as interações entre membros de um clube de karatê. Esta rede possui 34 indivíduos (nós) e 77 arestas, e está representada na Figura 4.5. A situação em que essa rede foi registrada se dá quando da rescisão do principal instrutor de uma academia de karatê (nó 34). Após a sua saída, a maioria dos alunos da academia transferiram-se para a nova academia do instrutor. Apenas uma pequena parcela dos alunos permaneceu na primeira academia. Pode-se dizer então que nesse cenário existem duas comunidades bem definidas: a comunidade dos membros da nova academia e a comunidade dos membros da antiga acadêmia. A identificação de comunidades nesse cenário tem sido estudada em diversos trabalhos. Em seu estudo original, Zachary (1977) reporta que, no cenário de competição pelos membros, o que tornou a nova academia mais popular foi não apenas a 
transferência do instrutor, mas a transferência consigo de um de seus alunos (nó 33), muito influente na primeira academia. $\mathrm{O}$ administrador da primeira academia está representado pelo nó 1.

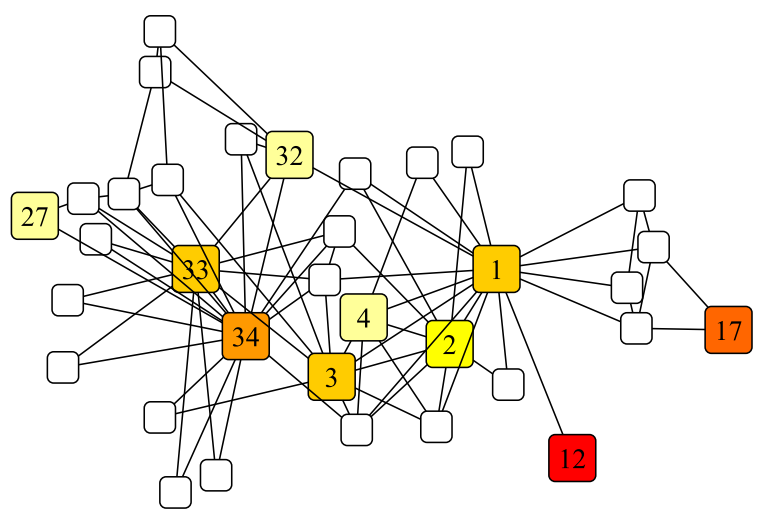

Figura 4.5: Resultado da aplicação do método de detecção de outliers proposto à rede do clube de karatê registrada por Zachary (1977). Os dez nós com maior escore de outlier aparecem coloridos. Quanto mais vermelho maior o escore de outlier do indivíduo.

Aplicando o método de deteç̧ão de outlier a essa rede, os nós 12, 17, 34, 1, 3 e 33 aparecem entre os $20 \%$ com maior escore de outlier. A Tabela 4.1 mostra o escore de outlier dos 10 nós com maior escore de outlier. Adicionalmente, a quarta coluna da Tabela 4.1 mostra o grau de cada nó. Desse modo, é possível observar que o escore de outlier dos nós não está correlacionado ao grau dos mesmos. A identificação dos nós anormais em uma rede se dá em um caráter mais amplo que a conectividade local dos indivíduos.

Tabela 4.1: Ranque dos dez nós com maior escore de outlier na rede do clube de karatê.

\begin{tabular}{|c|c|c|c|}
\hline & id & $\sigma$ & grau \\
\hline $\bar{~} 1^{0}$ & $\overline{12}$ & 0,6120 & $\overline{1}$ \\
\hline $2^{\mathrm{O}}$ & 17 & 0,4319 & 2 \\
\hline $3^{\underline{0}}$ & 34 & 0,3122 & 17 \\
\hline $4^{\mathrm{O}}$ & 1 & 0,3082 & 16 \\
\hline $5^{0}$ & 3 & 0,2863 & 10 \\
\hline $6^{\underline{0}}$ & 33 & 0,2838 & 12 \\
\hline $7^{0}$ & 2 & 0,2637 & 9 \\
\hline $8^{0}$ & 27 & 0,2393 & 2 \\
\hline $9^{\underline{O}}$ & 32 & 0,2264 & 6 \\
\hline $10^{\underline{O}}$ & 4 & 0,2226 & 6 \\
\hline
\end{tabular}

Através da rede representada na Figura 4.5 é possível ver que os nós 12 e 17 podem ser identificados como nós periféricos, uma vez que possuem pequena influência sobre os demais indivíduos. Os nós 34, 1, 3, e 33 representam os indivíduos mais influentes da rede, os nós centrais $(h u b s)$. Adicionalmente, pode-se observar também que o nó 3 apresenta 
grande número de ligações com nós de ambas as comunidades, sendo funcionalmente diferenciado em relação aos demais nós da rede. Logo, de fato os nós 12, 17, 34, 1, 3 e 33 mostram-se os nós mais diferenciados na rede.

\subsubsection{Rede de Colaboração entre Cientistas}

A rede de colaboração entre cientistas que estudam redes complexas (Figura 4.6), compilada por Newman (2006), modela a colaboração entre cientistas como base em suas publicações conjuntas. Se dois indivíduos já realizaram ao menos uma publicação conjuntamente, então existe uma ligação entre os respectivos nós na rede. Em nossos experimentos consideramos apenas o maior componente da rede, a maior sub-rede. Nela destacam-se elementos bastante influentes na área, como M. Newman (nó 26), H. Jeong (nó 5) e A.-L. Barabási (nó 4). No total são 379 indivíduos e 914 ligações entre eles.

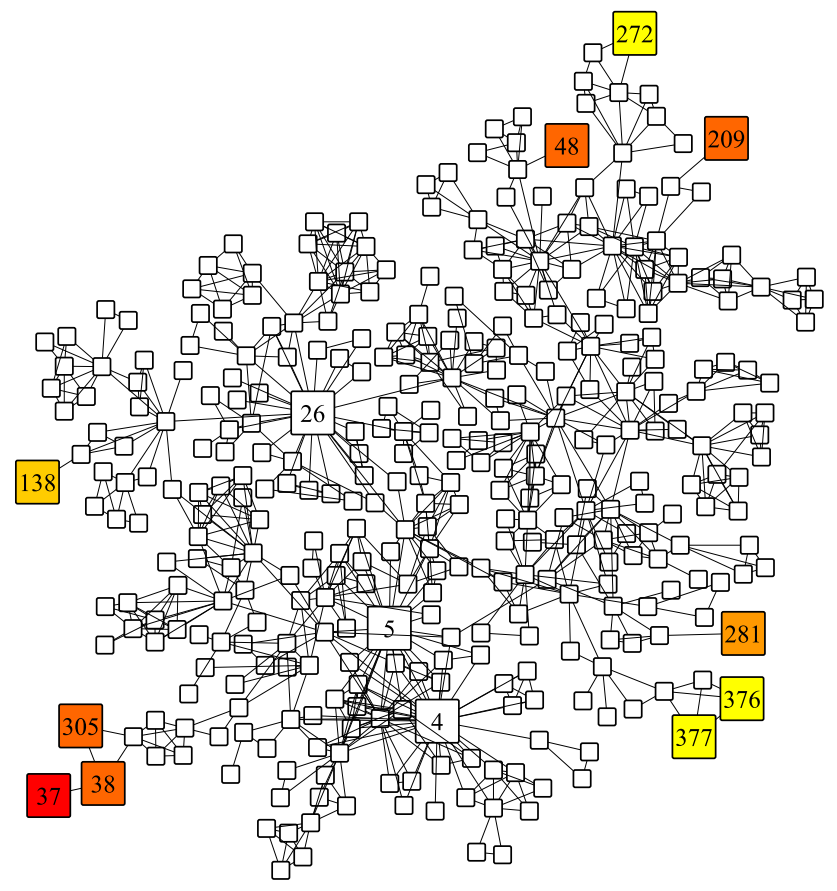

Figura 4.6: Resultado da aplicação do método de detecção de outliers proposto à rede de colaboração entre cientistas registrada por Newman (2006). Os dez nós com maior escore de outlier aparecem coloridos. Quanto mais vermelho maior o escore de outlier do indivíduo. Os indivíduos mais colaborativos da rede também aparecem destacados.

Aplicando o método a rede de colaboração entre cientistas, os nós 37, 209, 305, 38, 48, 281, 138, 272, 377 e 376 apresentam os dez maiores escores de outlier. Como mostra a Tabela 4.2, nenhum desses indivíduos é muito colaborativo na rede. Pelo contrário, são nós periféricos na rede. Podemos verificar também que as características gerais dessa rede assemelham-se às características de uma rede livre de escala. Nós podemos ver por exemplo, que existe uma grande quantidade de indivíduos pouco colaborativos na rede. Contudo, muitos desses indivíduos estão conectados a indivíduos bastante colaborativos. Por isso, na lista dos nós mais outliers, destacam-se os indivíduos que possuem colaboração 
Tabela 4.2: Ranque dos dez nós com maior escore de outlier na rede de colaboração entre cientistas. Também são apresentados os índices e posições dos elementos mais colaborativos na rede.

\begin{tabular}{|c|c|c|c|}
\hline & $\overline{\text { id }}$ & $\sigma$ & "grau \\
\hline 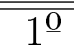 & $\overline{377}$ & $\overline{00,6657}$ & 1 \\
\hline $2^{\underline{O}}$ & 209 & 0,4325 & 1 \\
\hline $3^{\underline{O}}$ & 38 & 0,4157 & 3 \\
\hline $4^{\underline{\underline{O}}}$ & 305 & 0,4156 & 2 \\
\hline $5^{0}$ & 48 & 0,3485 & 1 \\
\hline $6^{\mathrm{O}}$ & 281 & 0,3326 & 1 \\
\hline $7^{\underline{0}}$ & 138 & 0,3226 & 1 \\
\hline $8^{\underline{0}}$ & 272 & 0,3205 & 2 \\
\hline $9^{\underline{O}}$ & 377 & 0,3132 & 3 \\
\hline $10^{\mathrm{O}}$ & 376 & 0,3132 & 3 \\
\hline 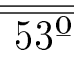 & $\overline{5}$ & 0,2197 & 27 \\
\hline $67^{0} \underline{0}$ & 4 & 0,2099 & 34 \\
\hline $68^{\mathrm{O}}$ & 26 & 0,2085 & 27 \\
\hline
\end{tabular}

e coeficiente de clustering limitados. Os autores muito colaborativos, tais como H. Jeong, A.-L. Barabási e M. Newman aparecem respectivamente na $53^{\mathrm{a}}, 67^{\mathrm{a}}$, e $68^{\mathrm{a}}$ posição do ranque, como mostra a Tabela 4.2. Por outro lado, pode-se dizer também que os nós mais colaborativos aparecem entre os $20 \%$ com maior escore de outlier, semelhante ao que acontece na rede do clube de karatê.

\subsubsection{Redes de Interações entre Proteínas}

De um modo geral, processos biológicos envolvem interações metabólicas, interações entre genes, e interações entre proteínas. Em uma interação proteína-proteína, uma proteína pode interagir com outra brevemente a fim de modificá-la, ou pode interagir por muito tempo a fim de formarem parte de uma proteína mais complexa. Frequentemente, a forma que ocorrem as interações entre proteínas estão relacionadas à funcionalidade das mesmas. Exemplo disso, é como se dá a mediação proteína a proteína de um sinal proveniente do exterior de uma célula sentido ao núcleo, processo conhecido como transdução de sinal. Esse processo envolve sequências ordenadas de reações bioquímicas dentro da célula, resultando em sequências de ativação de proteínas (Schwikowski et al., 2000). Por isso, as interações proteína-proteína são particularmente importantes para a identificação de suas funções biológicas.

Nessa seção, analisaremos a rede de interações proteína-proteína no metabolismo da levedura Saccharomyces cerevisiae registrada por Krogan et al. (2006). Essa rede é um mapa de interações entre proteínas altamente confiável, obtida pela purificação de afinidade em tandem ${ }^{1}$, composta por 2708 proteínas e 7123 interações proteína-proteína. Para

\footnotetext{
${ }^{1}$ Do inglês: Tandem Affinity Purification (TAP).
} 
a nossa análise utilizaremos o componente principal, que é uma sub-rede composta por 2559 proteínas. A função de cada uma dessas proteínas foi especificada de acordo com os dados do Munich Information Center for Protein Sequences (MIPS) (Mewes et al., 2004). Do total de 2559 proteínas, podemos identificar 588 proteínas relacionadas a função de metabolismo, 136 relacionadas a função de energia, 551 relacionadas ao ciclo celular e processamento de DNA, 626 relacionadas a transcrição, 240 relacionadas a síntese de proteínas, 549 relacionadas ao destino de proteínas, 123 relacionadas a regulação do metabolismo, 355 relacionadas a transporte, 108 relacionadas a transdução, e 234 relacionadas a defesa celular. Note-se que muitas proteínas estão relacionadas com mais de uma função.

O método de detecção de outliers foi aplicado a essa rede e foi obtido o escore de outlier $(\sigma)$ de cada proteína. Como pode-se verificar na Figura 4.7, a rede de interações entre proteínas apresenta uma distribuição de $\sigma$ que pode ser aproximada pela lei de potência, especificamente, $P(\sigma) \simeq \sigma^{-3.5}$. O que significa que a rede possui um pequeno número de proteínas que apresenta alto escore de outlier, enquanto que a maioria das proteínas apresenta um escore de outlier pequeno. Podemos concluir também que existe um limiar de separação bem definido entre proteína com alto escore de outlier e proteínas com baixo escore de outlier. Esse limiar poderia ser utilizado na classificação dos nós outliers. Contudo, a análise quanto a função das proteínas mostra-se ainda mais interessante. Por isso, uma vez que o ranque permite a escolha arbitrária do número de outliers, optamos por calcular o número de proteínas que participam em cada função biológica dentre os outliers. Ou seja, calculamos a fração de proteínas de cada grupo funcional que está entre os $n$ nós com maior escore de outlier, como mostra o gráfico da Figura 4.8.

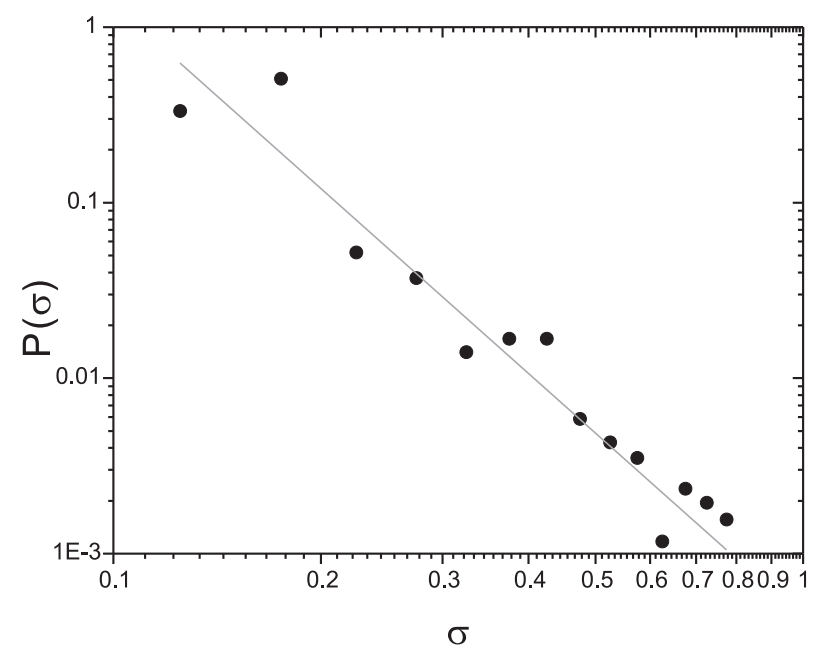

Figura 4.7: Distribuição $(P(\sigma))$ do escore de outlier verificada na rede de interações entre proteínas do metabolismo da levedura Saccharomyces cerevisiae. Essa distribuição segue a lei de potência.

Pelo gráfico da Figura 4.8 podemos verificar que as proteínas relacionadas ao ciclo celular e processamento de DNA e as proteínas relacionadas com metabolismo representam mais que $80 \%$ dos 30 nós com maior escore de outlier. Para valores muito grandes de $n$, a fração de proteínas relacionada às funções tende a ser proporcional a fração das mesmas 


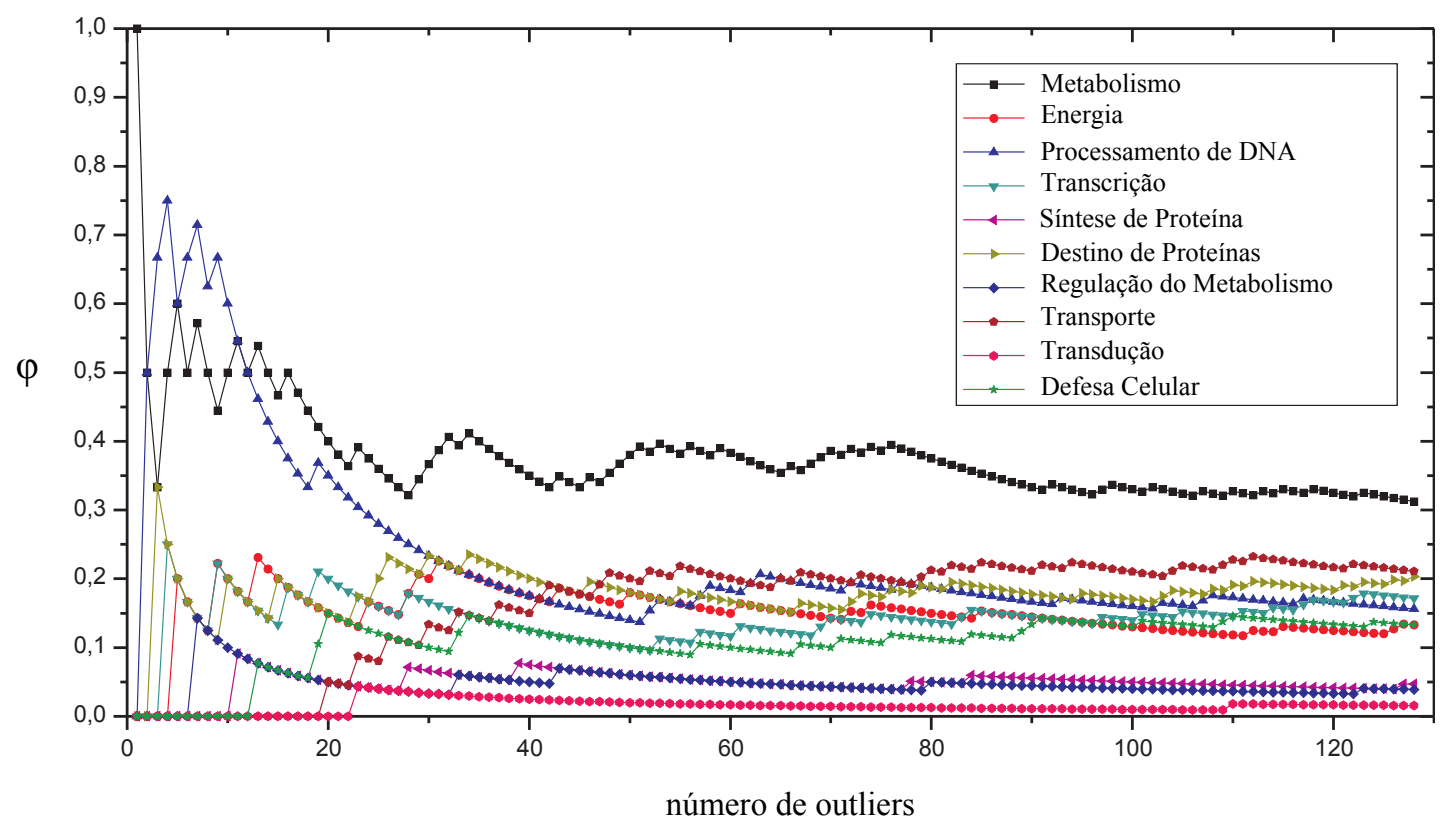

Figura 4.8: Fração $(\varphi)$ de proteínas relacionadas a cada grupo funcional entre os nós com maior escore de outlier. As proteínas relacionadas ao ciclo celular e processamento de DNA e as proteínas relacionadas ao metabolismo destacam-se das demais.

na rede. Assim, podemos inferir que as proteínas relacionadas com metabolismo e as proteínas relacionadas com ciclo celular e processamento de DNA possuem perspectiva diferenciada da rede.

Especificamente, proteínas relacionadas com ciclo celular e processamento de DNA atuam nas transformações que ocorrem durante a divisão celular. Por exemplo, a proteína YIL135c é um supressor de multicópia de parada do ciclo celular na transição G1-S e está conectada apenas a proteína YOR043w, que está relacionada a regulação do crescimento celular e a expressão da ciclina G1. Uma vez que as proteínas relacionadas ao ciclo celular e ao processamento de DNA participam principalmente da duplicação celular, elas tendem a interagir apenas com proteínas específicas e por isso os respectivos nós estão localizados na região de borda da rede. Similarmente, proteínas relacionadas com metabolismo tendem a interagir com proteínas específicas. A Figura 4.9 mostra a estrutura das 5 proteínas com maior escore de outlier, dentre elas a proteína YIL135c. Note-se que de fato estas proteínas equivalem a nós periféricos na rede.

O relacionamento entre as estruturas locais e a sua funcionalidade biológica é uma questão fundamental no estudo dos sistemas biológicos. Em redes de interações entre proteínas, frequentemente a regra da maioria, baseada apenas em ligações com proteínas de funcionalidade conhecida, tem sido aplicada com o propósito de inferir a função de proteínas desconhecidas (Vazquez et al., 2003). Uma vez que pudemos identificar uma relação bem definida entre proteínas outliers e alguns grupos funcionais, acreditamos também que a medida de distância de uma caminhada aleatória pode contribuir adequadamente para a identificação de padrões funcionais.

No sentido de melhorar a compreensão dos resultados obtidos, podemos também exa- 


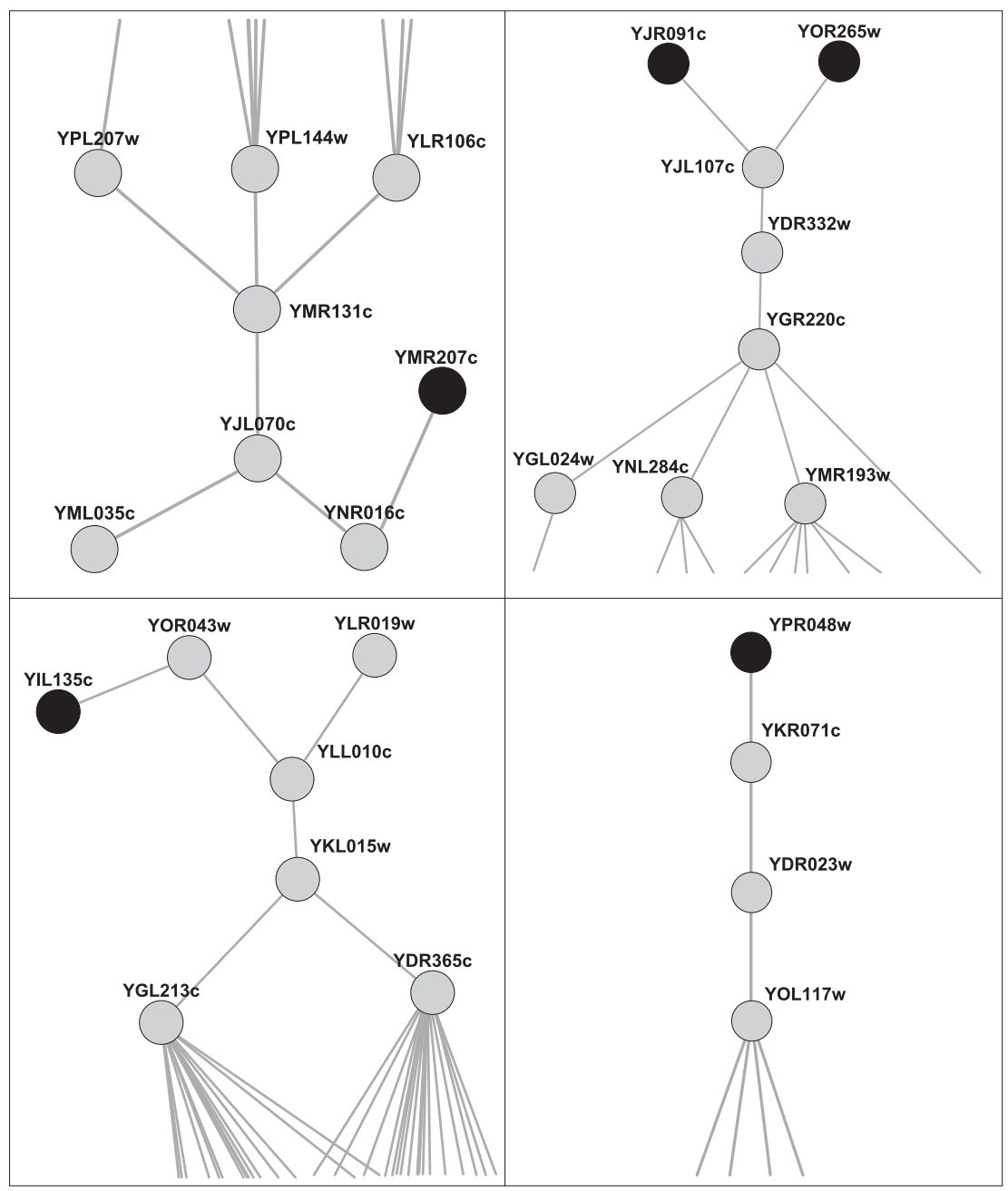

Figura 4.9: Proteínas mais outliers (em preto) e os respectivos arranjos locais. As proteínas YMR207c e YPR048w são proteínas relacionadas a função de metabolismo, enquanto que as proteínas YIL135c, YOR265w e YLR419w atuam no ciclo celular e processamento de DNA. As proteínas YJR091c e YJL194w estão relacionadas com ambas as funções.

minar a estrutura local de nós não outliers. A Figura 4.10 mostra uma proteína tipicamente não outlier que apresenta o menor escore de outlier. Assim como na rede de colaboração entre cientistas, os nós (proteínas) não outlier tendem a estar conectadas a hubs e possuem alto coeficiente de clustering. Essa configuração caracteriza nós propícios ao espalhamento de informação. Informações emergentes desses nós podem alcançar outros nós rapidamente. Além disso, nós diretamente conectados a hubs tendem a possuir ponto de vista similar aos mesmos. Uma vez que hubs conectam-se com muitos nós, existem muitos nós que compartilham ponto de vista similar, fazendo com que essa perspectiva seja comum a rede. Podemos concluir que em redes livres de escala, embora a distribuição de grau caracterize os nós hubs como diferenciados, a alta conectividade dos mesmos resulta em que um grande número de nós compartilhe ponto de vista semelhante, sendo funcionalmente similares, por isso, nesse caso, os nós mais anormais tendem a ser os nós de borda, e não os nós centrais. 


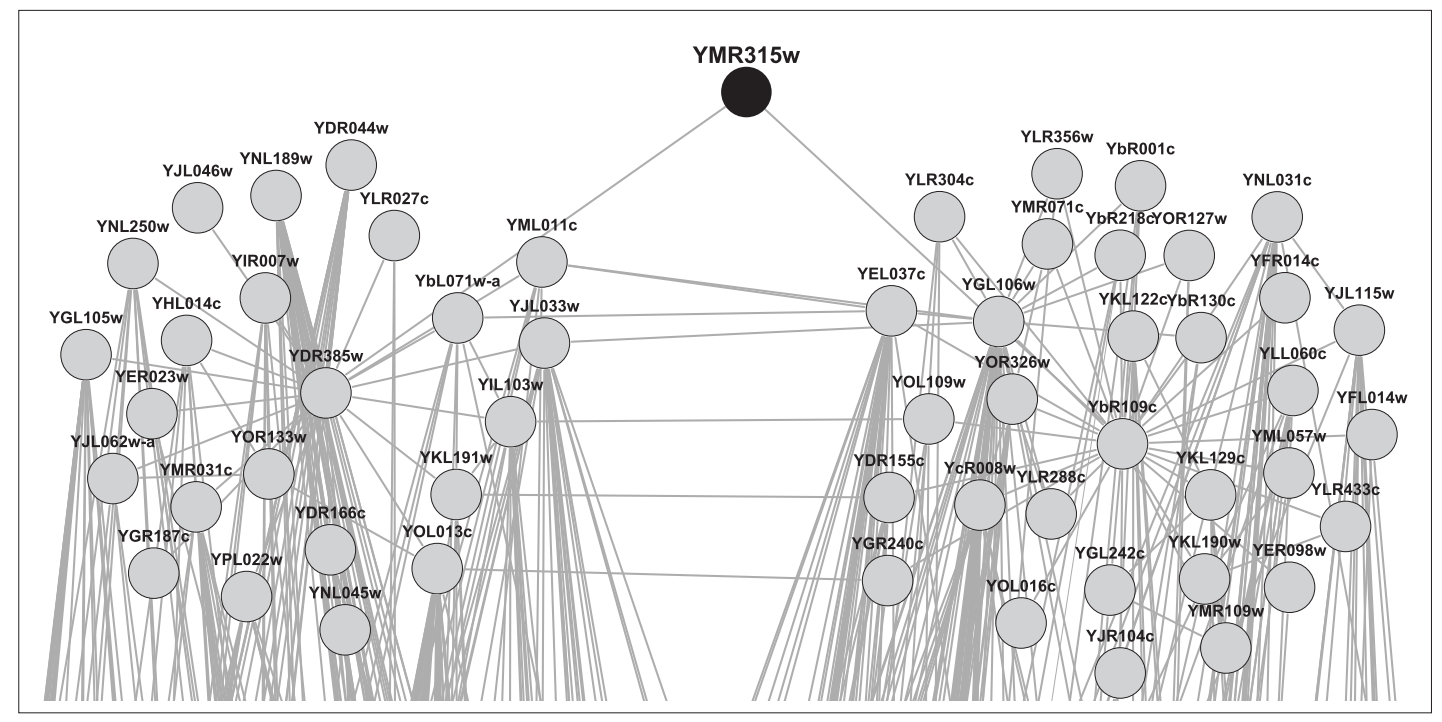

Figura 4.10: Uma proteína tipicamente não outlier (em preto). A proteína com menor escore de outlier.

\subsection{Aplicação à Detecção de Comunidades}

Como apresentado na Seção 3.4, as estruturas de comunidades são caracterizadas pela existência de nós densamente conectados entre si, cujas ligações com nós de fora do grupo são esparsas. Essas estruturas caracterizam agrupamentos naturais, e estão presentes em diversos tipos de redes, de modo que a identificação dessas estruturas é uma tarefa muito importante para a análise da rede.

Nos últimos anos, diversos métodos têm sido propostos, entretanto, poucos são capazes de tratar redes complexas adequadamente com baixo custo computacional (Seção 3.4). Por isso o problema de detecção de comunidades é um problema que ainda admite soluções. Em geral, as técnicas de detecção de comunidades podem ser classificadas dentro da abordagem não supervisionada do aprendizado de máquina, onde, visando o agrupamento dos dados (nós), o processo é realizado com base apenas em algum critério de similaridade entre os dados. Pode se dizer que o processo é guiado pelos dados, pois não necessitam de um conhecimento prévio sobre as classes existentes (Mitchell, 1997). Recentemente no entanto, a abordagem semi-supervisionada tem se mostrado uma alternativa a essa abordagem. Utilizando apenas alguns exemplos rotulados a priori de acordo com suas classes, visa-se classificar os demais adequadamente de acordo com critérios de similaridade com os exemplos rotulados (Chapelle et al., 2006). Uma vez que a disponibilidade de rótulo é um problema não solucionado, e que frequentemente conhece-se o rótulo de apenas alguns indivíduos na rede, essa abordagem tem se mostrado uma alternativa viável para o desenvolvimento de métodos para a detecção de comunidades, com baixo custo computacional.

Segundo Chapelle et al. (2006) o aprendizado semi-supervisionado pode ser definido da seguinte maneira. Seja um conjunto de dados $X=\left\{x_{1}, \ldots, x_{n}\right\}$ dividido em duas partes: $X_{l}=\left\{x_{1}, \ldots, x_{l}\right\}$ onde $l \ll n$ e $X_{u}=\left\{x_{l+1}, \ldots, x_{n}\right\}$; e $Y=\{1, \ldots, c\}$ um conjunto 
de rótulos. Para todo exemplo $x_{i} \in X_{l}$ um rótulo $y_{i} \in Y$ é fornecido. Os rótulo do subconjunto $X_{u}$ não são conhecidos a priori. Baseado nesta definição, o aprendizado semi-supervisionado tem como função a classificação de exemplos não rotulados a partir dos exemplos rotulados a priori e adicionalmente a identificação de agrupamentos dos dados, segundo o conjunto de rótulo $Y$. Esse problema é frequentemente denominado na literatura como rotulação de dados. Pode-se dizer que os exemplos rotulados a priori são responsáveis por guiar o processo agrupamento de dados (Chapelle et al., 2006). A Figura 4.11(a) mostra um exemplo de rotulação de dados ideal realizado sobre um conjunto de dados do tipo banana. Esse tipo de conjunto de dados é frequentemente utilizado para a validação do desempenho de métodos de rotulação de dados semi-supervisionado, uma vez que é de difícil agrupamento.

Existe um número razoável de técnicas de aprendizado semi-supervisionado baseadas em grafos listadas na literatura (Chapelle et al., 2006). Nos últimos anos, essa abordagem tem sido uma das mais estudadas. O denominador comum desses métodos é que os dados são representados através de nós em um grafo e arestas são estabelecidas entre os nó de acordo com o a distância entre pares de nós incidentes, como em uma rede geográfica (Seção 3.3.5). No entanto, poucas técnicas de detecção de comunidades semi-supervisionadas têm sido propostas com o fim específico de detectar comunidades (Breve et al., 2009). E além disso, pouco tem sido estudado acerca da relevância dos dados rotulados a priori para o desempenho de métodos de detecção de comunidades semi-supervisionados. Com base na medida de distância de uma caminhada aleatória, utilizada para a identificação de outliers em redes, pudemos identificar que os nós centrais segundo essa medida são bons candidatos a rotulação a priori. Para mostrar os resultados, utilizaremos um método de propagação de rótulos bastante simples, apresentado a seguir, aplicado ao conjunto de dados sintético do tipo banana apresentado na Figura 4.11(a), e à rede do clube de karatê (Figura 4.5).

\subsubsection{Método de Propagação de Rótulo}

Baseado em como se comporta o espalhamento de informação em uma rede, foi proposto o seguinte método de propagação de rótulo. Considere uma rede $G=(V, E)$ com $n$ nós, cujo as arestas em $E$ estão representadas através da matriz de adjacências generalizada $A$. Os nós em $V=\left\{v_{1}, \ldots, v_{n}\right\}$ estão divididos em duas partes: $V_{l}=\left\{v_{1}, \ldots, v_{l}\right\}$, onde $l \ll n$ e $V_{u}=\left\{v_{l+1}, \ldots, v_{n}\right\}$. Existe também um conjunto de rótulos $Y=\{1, \ldots, c\}$. Para todo exemplo $v_{i} \in V_{l}$ um rótulo $y_{i} \in Y$ é conhecido, enquanto que os rótulo do subconjunto $V_{u}$ não são conhecidos. Cada nó $v_{i} \in V_{u}$ possui um vetor de energia $v_{i}^{w}(t)=\left\{v_{i}^{w_{1}}(t), v_{i}^{w_{2}}(t), \ldots, v_{i}^{w_{c}}(t)\right\}$ do mesmo tamanho de $Y$, cujo o índice $k$ de cada elemento $v_{i}^{w_{k}}(t)$ corresponde a um rótulo em $Y$.

Inicialmente, os nós em $V_{u}$ possuem vetor de energia nulo, enquanto que o vetor de energia dos nós em $V_{l}$ possuem valor não nulo apenas no elemento cujo índice $k$ equivale ao respectivo rótulo em $Y, v_{i}^{w_{k}}=w_{\max }$. A cada instante de tempo, o vetor de energia de 
cada nó $v_{j} \in V_{u}$ é atualizado de acordo com o vetor de energia dos nós vizinhos,

$$
v_{j}^{w_{k}}(t+1)=v_{j}^{w_{k}}(t)+\beta \sum_{i=1}^{n} a_{i j}\left(v_{i}^{w_{k}}(t)-v_{j}^{w_{k}}(t)\right),
$$

onde $\beta$ é uma constante de velocidade de propagação dos rótulos. Além disso, a cada iteração, cada elemento $k$ do vetor de energia $v_{j}^{w}$ é ajustado em relação a energia do elemento de maior energia de cada nó $v_{j}, v_{j} \in V_{u}$, como segue:

$$
v_{j}^{w_{k}}(t+1)=\left\{\begin{array}{rl}
v_{j}^{w_{k}}(t) & \text { se } k=\Phi\left(v_{j}^{w_{\max }}(t)\right) \\
v_{j}^{w_{k}}(t)-\eta\left(v_{j}^{w_{\max }}(t)-v_{j}^{w_{k}}(t)\right) & \text { caso contrário }
\end{array},\right.
$$

onde $v_{j}^{w \max }(t)$ é o elemento do vetor de energia $v_{j}^{w}(t)$ com maior energia, $\eta$ é uma constante de velocidade de ajuste do vetor de energia e $\Phi(\cdot)$ é a função índice do elemento. Uma vez que os nós $v_{i} \in V_{l}$ possuem valor de energia $w_{\max }$ no elemento equivalente ao respectivo rótulo, $v_{j}^{w_{k}}$ varia no intervalo $\left[0, w_{\max }\right]$. Quanto maior o valor de $v_{j}^{w_{\max }}(t)$, os elementos correspondentes aos demais rótulos são mais rapidamente depreciados. O rótulo de cada nó $v_{j}$ em um instante $t$, é dado por $\Phi\left(v_{j}^{w_{\max }}(t)\right)$.

A regra de propagação de rótulos do método baseia-se em como a informação se propaga em uma rede de interações sociais. Um indivíduo que não possui opinião bem definida sobre um determinado conhecimento, baseia sua opinião na opinião dos indivíduos com os quais está relacionado, proporcional a força da interação. A medida que o indivíduo vai formando sua própria opinião, a definição que prevalece acerca daquele conhecimento tende a reprimir demais definições.

Em redes de interações sociais, frequente existem indivíduos mais influente que os demais, os quais são os principais responsáveis pela difusão de informação. O método proposto é sensível aos nós rotulados a priori. Se rotulados os indivíduos mais difusivos, então o método terá melhor desempenho. Uma vez que a difusão é um caso específico de caminhada aleatória, utilizou-se a medida de distância de uma caminhada aleatória com o fim de identificar nós candidatos a rotulação a priori. Será apresentado a seguir como identificar bons difusores de informação, com base nesta medida.

\subsubsection{Rotulação de Dados Guiada por Outliers}

Como discutido acima, os nós outliers segundo o método proposto podem ser classificados como outliers periféricos ou outliers centrais. Outliers centrais tipicamente estão em regiões centrais de comunidades, muitas vezes sendo caracterizados como hubs; outliers periféricos, por sua vez, encontram-se nas regiões de borda de comunidade. O método de propagação de rótulos apresentado acima foi aplicado a detecção de comunidades rotulando-se a priori os outliers centrais, e foi obtido que, em relação a rotulação a priori aleatória, rotular a priori esses nós resulta em um bom desempenho do método. Serão apresentados a seguir, junto aos resultados obtidos com os nós outliers, o resultado médio e desvio padrão, obtidos da escolha randômica de nós rotulados a priori, de modo 
que seja possível comparar o desempenho dos mesmos.

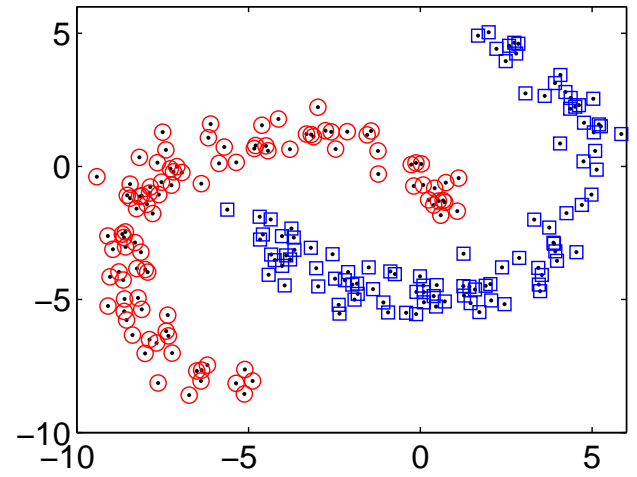

(a)

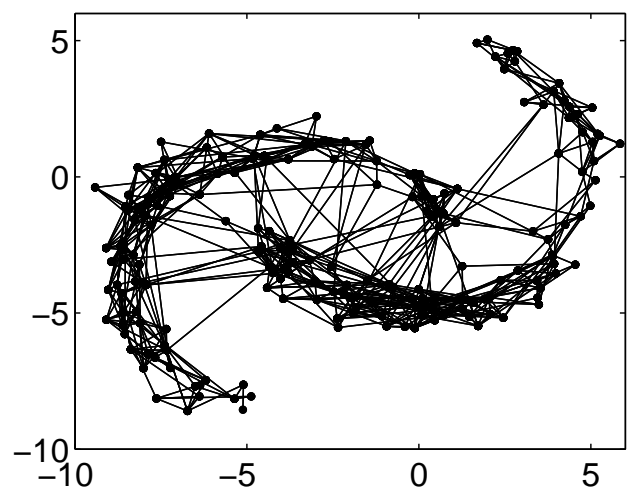

(b)

Figura 4.11: (a) Rotulação de dados ideal de uma base de dados sintética do tipo banana com 200 exemplos, sendo 100 pertencentes a classe vermelha (circulo) e 100 pertencentes a classe azul (quadrados). (b) Rede geográfica do conjunto de dados em (a), construída segundo o método apresentado na Seção 3.3.5, $\operatorname{com} \lambda=1$.

Dado um conjunto de dados do tipo banana com 200 observações, representado na Figura 4.11(a), construímos uma rede geográfica (Seção 3.3.5) assumindo o parâmetro $\lambda=1$, como mostra a Figura 4.11(b). Aplicando o método de propagação de rótulos com $\beta=0.01$ e $\eta=0.01$ a essa rede, para a escolha randômica dos nós rotulados a priori, obtemos índice de acerto como representado na Figura 4.12(a). Utilizando os outliers centrais, obtemos os resultados expressos na Figura 4.12(b).

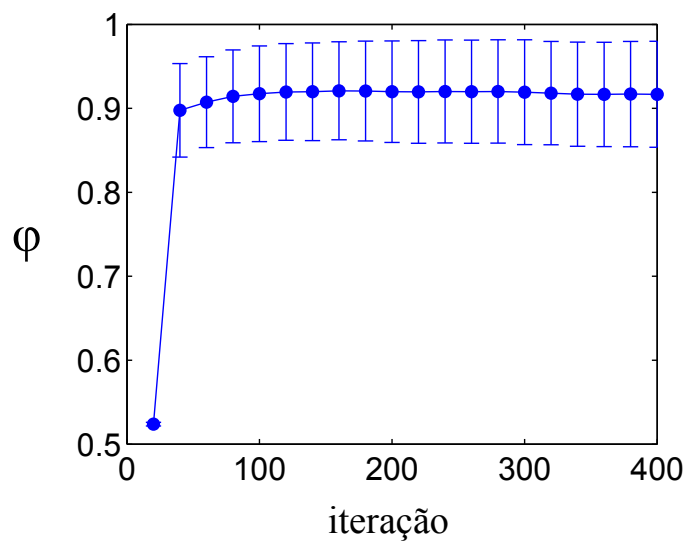

(a)

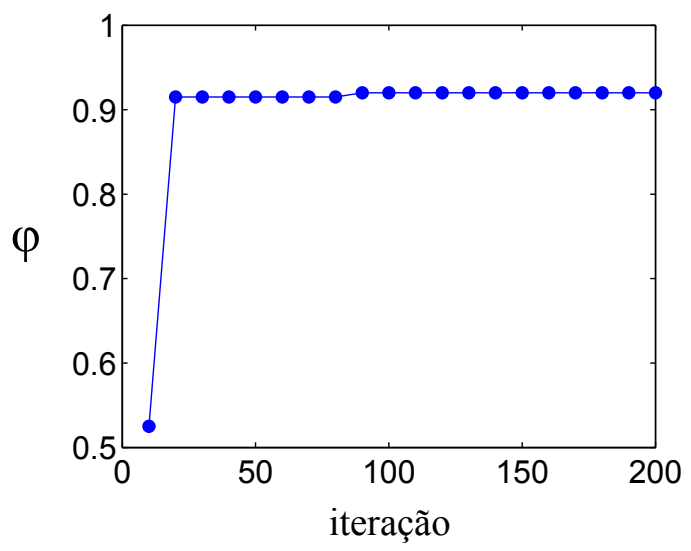

(b)

Figura 4.12: Resultado do método de propagação de rótulos proposto aplicado à rede construida a partir do conjunto de dados da Figura 4.11(a): (a) com base em 40 configurações de 10 nós rotulados a priori, escolhidos randomicamente, sendo 5 de cada comunidade; (b) com base nos 5 outliers centrais de cada comunidade. $\varphi$ é a precisão de detecção de comunidades a cada iteração.

Aplicando o método de propagação de rótulos $\operatorname{com} \beta=0.01$ e $\eta=0.01$, a rede do clube de karatê, apresentada acima, para a escolha randômica dos nós rotulados a 
priori, obtemos índice de acerto como representado na Figura 4.13(a). Utilizando outliers centrais, obtemos os resultados expressos na Figura 4.13(b).

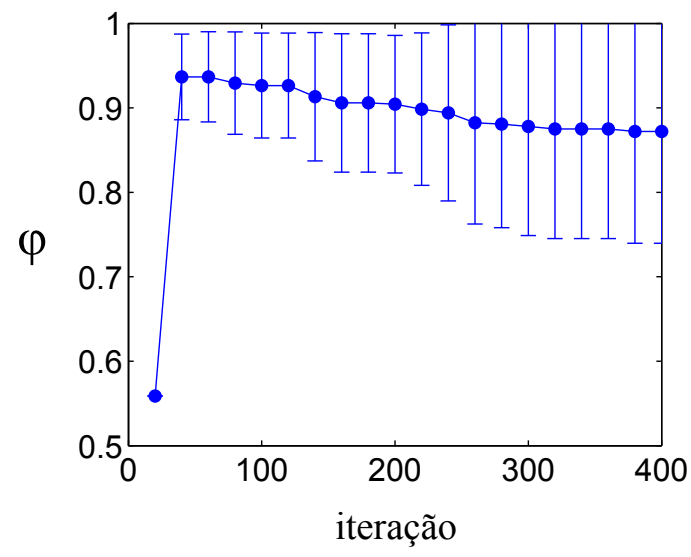

(a)

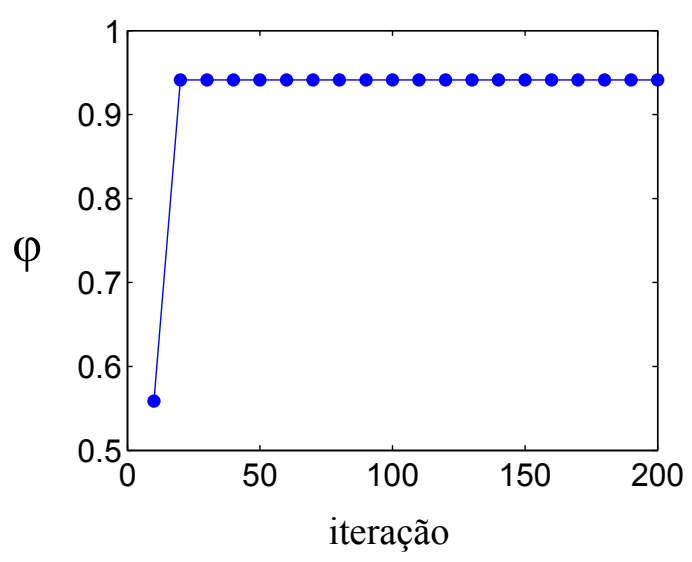

(b)

Figura 4.13: Resultado do método de propagação de rótulos proposto aplicado à rede do clube de karatê (Figura 4.5): (a) com base em 20 configurações de 4 nós rotulados a priori, escolhidos randomicamente, sendo dois de cada comunidade; (b) com base nos nós 34, 1, 3 e 33, dois outliers centrais de cada comunidade. $\varphi$ é a precisão de detecção de comunidades a cada iteração.

Os resultados obtidos com a rotulação a priori dos outliers centrais é melhor que os resultados obtidos da rotulação a priori randômica. Outliers centrais mostram-se bons difusores. Resultados preliminares também mostram que outliers periféricos também têm bastante relevância no processo de propagação de rótulos. Isto se deve ao fato de que muitas vezes nós de borda de comunidades estão em regiões entre comunidades, onde é difícil a rotulação, e cujo os nós podem ser classificados em ambas comunidades.

Desse modo, pode-se concluir que os nós outliers, segundo a medida de distância de uma caminhada aleatória, são bastante relevante para o problema de rotulação de dados. Uma vez identificados os nós mais adequados à rotulação a priori, torna-se menos custoso o processo de rotulação através de um especialista de domínio.

\subsection{Considerações Finais}

O presente capítulo apresentou um método de identificação de nós anormais em redes, baseado na medida de distância de uma caminhada aleatória e em um índice de dissimilaridade. Esse método foi aplicado a diversas redes, tanto sintéticas como reais, e foi possível observar que seus resultados são abrangentes, possibilitando a identificação de nós periféricos, como também de nós centrais (hubs), de acordo com a funcionalidade dos mesmos para a rede. Como apresentado no Capítulo 3, redes reais tipicamente encorporam propriedade de pequeno mundo, transitividade, estruturas de comunidades, propriedades de redes livres de escala, entre outras. Por isso, foram selecionadas as redes do clube de karatê, uma rede de colaboração entre cientistas, e uma rede de interações 
entre proteínas no propósito de evidenciar em que as citadas propriedades influiriam no comportamento do método. Pelos resultados obtidos na rede do clube de karatê, podemos identificar a influência dos hubs e das estruturas de comunidade em redes com poucos nós. Pelos resultados obtidos da rede de colaboração entre cientistas, vemos a influência da propriedade livre de escala, bem como da transitividade. Na rede de interações entre proteínas, além da influência da propriedade livre de escala e da transitividade, podemos verificar também a relação com propriedades funcionais das proteínas.

Adicionalmente, o método foi aplicado a seleção dos nós rotulados a priori em um método de detecção de comunidades semi-supervisionado. Os resultados obtidos mostram que, ao menos em relação a escolha randômica, os nós outliers mostram-se bons candidatos a rotulação a priori.

Um vez que a medida de distância de uma caminhada aleatória tem se mostrado interessante para a identificação de padrões, sejam outliers, nós centrais, nós periféricos, entre outros, acredita-se que existam outras aplicações onde pode-se obter resultados bastante relevante. Logo, o próximo capítulo apresentará a relevância dos resultados obtidos, conclusões, e perspectivas de trabalhos futuros. 


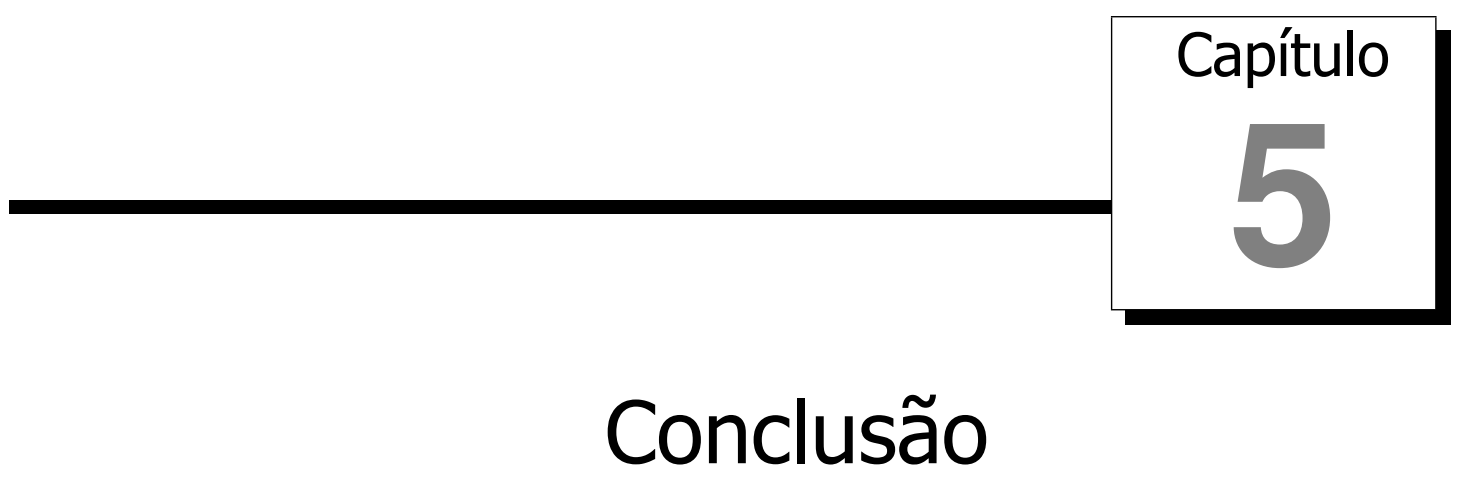

O presente trabalho dissertou sobre o tema Detecção de Outliers em Redes Complexas. Para isso, foi apresentado uma revisão sobre o tema Outliers, abordando desde a sua concepção estatísticas até aplicações e problemas atuais, inclusive relacionadas às redes complexas (Capítulo 2). Também foi apresentado uma revisão sobre o tema Redes Complexas, abordando sua definição, aplicações, propriedades, e modelos, além do sub-tópico Detecção de Comunidades (Capítulo 3).

No Capítulo 4 foi apresentado uma método proposto para a identificação de outliers em redes complexas. Esse método baseia-se numa medida de distância de uma caminhada aleatória, e em uma medida de dissimilaridade. Uma vez que considera a distância média entre dois nós, a medida de distância de uma caminhada aleatória pode ser considerada uma medida global da rede. De modo que a distância de um nó $i$ a um nó $j$, pode ser denominada como a perspectiva que $i$ tem de $j$ através da rede, e $i$ pode ser considerado um "ponto de vista". A medida de dissimilaridade, por sua vez, computa quão diferente são dois pontos de vista. Através do escore de outlier proposto, podemos identificar os nós em uma rede que possuem ponto de vista diferenciado, sendo denominados outliers.

O método proposto foi aplicado a redes sintéticas e reais, e foi possível identificar que, de acordo com uma caminhada aleatória, nós outliers, nem sempre estão distantes dos nós centrais, como a maioria dos métodos de detecção de outliers propunham. Muitas vezes nós centrais da rede $(h u b s)$ podem ser classificados como outliers. Podemos concluir que, segundo a medida de distância de uma caminhada aleatória, os nós mais outliers em uma rede são aqueles que possuem ponto de vista diferenciado, isto é diferente da maioria dos demais. Essa característica, leva-nos ao fato de que muitas vezes o ponto de vista relacional de um nó está associado a sua função no sistema. Pudemos verificar que em redes de interações entre proteínas, proteínas (nós) outliers possuem funções bem 
definidas, relacionadas ao ciclo celular e processamento de DNA. Proteínas relacionadas a essa função participam principalmente da duplicação celular e tendem a interagir apenas com proteínas específicas, por tanto participando de regiões de borda da rede, como mostra a Seção 4.4.3.

Adicionalmente, a medida de distância de uma caminhada aleatória foi aplicada para a seleção de nós rotulados a priori para a tarefa de detecção de comunidades semisupervisionada baseada em propagação de rótulos. Pudemos identificar, que nós outliers, hora nós centrais, hora periféricos, têm um papel muito importante na tarefa de rotulação de dados. Enquanto que os nós centrais são excelentes concentradores e espalhadores de informação, os nós periféricos encontram-se frequentemente em regiões de borda de comunidade, onde a classificação não é trivial. Rotulando-os a priori, métodos de rotulação de dados aplicados a detecção de comunidades, obtiveram bom desempenho, como mostra a Seção 4.5.

Com base nesses resultados acreditamos que o escore proposto é um bom estimador de nós que possuem estrutura diferenciada nas redes, ou ainda que possuem funções especiais no respectivo sistema. Por isso, acreditamos que a abordagem proposta pode ser classificada como uma nova abordagem nos estudos sobre outliers, podendo contribuir tanto para a mineração de dados, como para o aprendizado de máquina. Do ponto de vista da mineração de dados, identificar observações inconsistentes é uma tarefa muito importante para manter a consistência dos dados. Identificar observações diferenciadas, por outro lado, é muito importante para garantir o comportamento adequando de métodos de aprendizado de máquina. Em relação ao problema de rotulação de dados, tornase evidente que observações outliers são relevantes para o desempenho de métodos de propagação de rótulo.

\subsection{Trabalhos Futuros}

Além dos problemas abordados nessa dissertação, existem diversas aplicações, onde a medida de distância de uma caminhada aleatória, pode ser aplicada. A seguir, será destacado alguns problemas, onde é possível aplicar a medida de distância de uma caminhada aleatória com um fim bem definido.

Além de regiões de borda e regiões centrais, cujo os nós foram destacados como outliers, muitas vezes redes complexas possuem regiões de regularidade, onde existem padrões de conexões bem definidos, semelhantes a redes regulares (Seção 3.3.2). Essas regiões tipicamente caracterizam simplicidade. Contrario ao conceito de anormalidade e novidade, inerentes ao conceito de outlier, simplicidade caracteriza regiões com pouca informação. Uma vez que foi possível identificar regiões de outliers, pode-se acreditar que seja possível identificar regiões de simplicidade em redes complexas. Mais ainda, que seja possível propor um índice de simplicidade/complexidade para redes, e até mesmo inferir se uma rede é mais complexa/simples que outra. Assim, considerando-se a propriedade de cres- 
cimento de rede, destacada na Seção 3.3.3, dadas diferentes configurações de uma rede ao longo do tempo, é possível analisar o seu comportamento evolutivo, podendo-se inferir até mesmo se esta rede tende a se auto-organizar e tornar-se mais simples, ou a tornar-se cada vez mais complexa. Esse tipo de análise é muito interessante do ponto de vista de redes sociais e biológicas (Costa \& Rodrigues, 2009).

Como destacado na Seção 4.5, a disponibilidade de rótulos em redes reais geralmente é pequena, porém com a rotulação de poucos indivíduos, é possível se caracterizar comunidades em uma rede. Esse tipo de perspectiva pode ser aprofunda no sentido de construir métodos tolerantes a tipos diversos de nós rotulados a priori, como também no sentido de identificar quais nós em uma rede são mais importantes para rotulação a priori. Sabendo que os nós centrais do ponto de vista de uma caminhada aleatória são bons candidatos a essa função, pode-se aprofundar nesse segmento com o propósito de validar tais resultados para quaisquer tipos de redes, como também pode-se propor outras medidas, tão adequadas quanto, ou ainda mais adequadas, para esse fim.

Como pode ser observado na rede de interações entre proteínas (Seção 4.4.3), nós (proteínas) outliers podem estar associados a funções bem definidas em redes complexas. Dada a relevância desse tipo de análise para a classificação de padrões, tanto sobre a rede de interações entre proteínas, como também para demais redes complexas, essa análise pode deve ser aprofundada. A aplicação dessa análise a redes com diferentes características, redes geográfica, livres de escala, de pequeno mundo, com estruturas de comunidades, podem revelar diferentes tipos de relações bem definidas com a função dos nós para a rede.

Com relação a essas perspectivas de trabalhos futuros, já foram obtidos alguns resultados relacionados a regiões de simplicidade e a simplicidade de redes em modelos sintéticos, os quais mostram-se bastante motivadores. Com relação a identificação de padrões em redes reais diversas e construção de métodos tolerantes a tipos diversos de nós rotulados a priori, alguns passos estão sendo dados. Além disso, podem ser aplicadas tipos específicos de caminhadas aleatórias, tais como a caminhada aleatória auto-excludente. 


\section{Bibliografia}

Albert, R., Albert, I., \& Nakarado, G. L. (2004). Structural vulnerability of the north american power grid. Physical Review E, 69(2), 025103.

Albert, R. \& Barabási, A.-L. (2002). Statistical mechanics of complex networks. Reviews of Modern Physics, 74, 47-97.

Albert, R., Jeong, H., \& Barabási, A.-L. (1999). Internet: Diameter of the world wide web. Nature, 401, 130-131.

Allahverdyan, A. E., Steeg, G. V., \& Galstyan, A. (2010). Community detection with and without prior information. Euro Physics Letters, 90, 18002.

Anton, H. \& Rorres, C. (2005). Elementary Linear Algebra with applications. Wiley, 5th edition.

Barabasi, A.-L. (2003). Linked: How Everything Is Connected to Everything Else and What It Means. Plume.

Barabási, A.-L. \& Albert, R. (1999). Emergence of scaling in random networks. Science, 286(5439), 509-512.

Barnett, V. (1978). The study of outliers: Purpose and model. Applied Statistics, 27(3), $242-250$.

Barnett, V. \& Lewis, T. (1994). Outliers in Statistical Data. John Wiley \& Sons, 3nd edition.

Bishop, C. M. (2006). Pattern recognition and machine learning. Springer.

Bondy, A. \& Murty, U. (2007). Graph Theory. Springer.

Bornholdt, S. \& Schuster, H. G. (2003). Handbook of Graphs and Networks: From the Genome to the Internet. Wiley-VCH. 
Breunig, M. M., Kriegel, H.-P., Ng, R. T., \& Sander, J. (1999). OPTICS-OF: Identifying local outliers. In 3rd European Conference on Principles of Data Mining and Knowledge Discovery (pp. 262-270). London: Springer-Verlag.

Breunig, M. M., Kriegel, H.-P., Ng, R. T., \& Sander, J. (2000). LOF: identifying densitybased local outliers. In ACM SIGMOD International Conference on Management of Data (pp. 93-104). New York: ACM Press.

Breve, F., Zhao, L., \& Quiles, M. (2009). Particle competition in complex networks for semi-supervised classification. In Complex Sciences (pp. 163-174). Berlin: Springer.

Chamberlain, R. (1970). The first week of life. In British Births Heinemann Medical, London.

Chandola, V., Banerjee, A., \& Kumar, V. (2009). Anomaly detection: A survey. ACM Computing Surveys, 41(15), 1-57.

Chapelle, O., Schölkopf, B., \& Zien, A. (2006). Semi-Supervised Learning. The MIT Press.

Clauset, A., Newman, M. E. J., \& Moore, C. (2004). Finding community structure in very large networks. Physical Review E, 70, 066111.

Costa, L. d. F. \& Rodrigues, F. A. (2009). Seeking for simplicity in complex networks. Euro Physics Letters, 85, 48001.

Costa, L. d. F., Rodrigues, F. A., Hilgetag, C. C., \& Kaiser, M. (2009). Beyond the average: Detecting global singular nodes from local features in complex networks. Euro Physics Letters, 87, 18008.

Costa, L. d. F., Rodrigues, F. A., Travieso, G., \& Boas, P. R. V. (2007). Characterization of complex networks: A survey of measurements. Advances in Physics, 56(1), 167-242.

Danon, L., Díaz-Guilera, A., Duch, J., \& Arenas, A. (2005). Comparing community structure identification. Journal of Statistical Mechanics: Theory and Experiment, (pp. P09008).

Davies, L. \& Gather, U. (1993). The identification of multiple outliers. American Statistical Association, 88(423), 782-792.

Duch, J. \& Arenas, A. (2005). Community detection in complex networks using extremal optimization. Physical Review E, 72, 027104.

Erdös, P. \& Rényi, A. (1959). On random graphs. Publicationes Mathematicae, 6, 290297. 
Ester, M., Kriegel, H.-P., Sander, J., \& Xu, X. (1996). A density-based algorithm for discovering clusters in large spatial databases with noise. In 2nd International Conference on Knowledge Discovery and Data Mining (pp. 226-231). Portland, USA: AAAI Press.

Everitt, B. S., Landau, S., \& Leese, M. (2009). Cluster Analysis. Wiley, 4th edition.

Faloutsos, M., Faloutsos, P., \& Faloutsos, C. (1999). On power-law relationship of the internet topology. Computer Communication Review, 29, 251-262.

Flake, G. W., Lawrence, S., Giles, C. L., \& Coetzee, F. M. (2002). Self-organization and identification of web communities. IEEE Computer, 35(3), 66-71.

Girvan, M. \& Newman, M. E. J. (2002). Community structure in social and biological networks. PNAS, 99(12), 7821-7826.

Grubbs, F. E. (1969). Procedures for detecting outlying observations in samples. Technometrics, 11(1), 1-21.

Hawkins, D. (1980). Identification of outliers. London: Chapman \& HaIl.

He, Z., Xu, X., \& Deng, S. (2003). Discovering cluster-based local outliers. Pattern Recognition Letters, 24(9-10), 1641-1650.

Hodge, V. J. \& Austin, J. (2004). A survey of outlier detection methodologies. Artificial Intelligence Review, 22(2), 85-126.

Holme, P., Huss, M., \& Jeong, H. (2003). Subnetwork hierarchies of biochemical pathways. Bioinformatics, 19(4), 532-538.

Jain, A. K. \& Dubes, R. C. (1988). Algorithms for Clustering Data. Prentice Hall.

Jeong, H., Tombor, B., Albert1, R., Oltvai, Z. N., \& Barabási, A.-L. (2000). The large scale organization of metabolic networks. Nature, 407, 651-654.

Karypis, G., Han, E.-H., \& Kumar, V. (1999). Chameleon: hierarchical clustering using dynamic modeling. Computer, 32(8), 68-75.

Knorr, E. M. \& Ng, R. T. (1997). A unified approach for mining outliers. In Conference of the Centre for Advanced Studies on Collaborative research (pp.111). Toronto, Canada: IBM Press.

Knorr, E. M. \& Ng, R. T. (1998). Algorithms for mining distance-based outliers in large datasets. In 24rd International Conference on Very Large Data Bases (pp. 392-403). San Francisco, USA: Morgan Kaufmann Publishers Inc.

Knorr, E. M. \& Ng, R. T. (1999). Finding intensional knowledge of distance-based outliers. In 25th International Conference on Very Large Data Bases (pp. 211-222). San Francisco, USA: Morgan Kaufmann Publishers Inc. 
Knorr, E. M., Ng, R. T., \& Tucakov, V. (2000). Distance-based outliers: algorithms and applications. The VLDB Journal, 8(3-4), 237-253.

Kou, Y., Lu, C.-T., \& Chen, D. (2006). Spatial weighted outlier detection. In SIAM Conference on Data Mining (pp. 613-617).

Krogan, N. J., Cagney, G., Yu, H., Zhong, G., Guo, X., Ignatchenko, A., Li, J., Pu, S., Datta, N., Tikuisis, A. P., et al. (2006). Global landscape of protein complexes in the yeast Saccharomyces cerevisiae. Nature, 440, 637-643.

Liljeros, F., Edling, C. R., Amaral, L. A. N., Stanley, H. E., \& Åberg, Y. (2001). The web of human sexual contacts. Nature, 411, 907-908.

Liu, H., Shah, S., \& Jiang, W. (2004). On-line outlier detection and data cleaning. Computers and Chemical Engineering, 28, 1635-1647.

Lu, C.-T., Chen, D., \& Kou, Y. (2003). Algorithms for spatial outlier detection. In 3rd IEEE International Conference on Data Mining (pp. 597-600).

Ma, X., Gao, L., Yong, X., \& Fu, L. (2010). Semi-supervised clustering algorithm for community structure detection in complex networks. Physica A: Statistical Mechanics and its Applications, 389, 187-197.

Madras, N. \& Slade, G. (1996). The Self-Avoiding Walk. Boston: Birkhäuser.

Marr, D. (1982). Vision: A Computational Investigation into the Human Representation and Processing of Visual Information. New York: Freeman.

Mewes, H., Amid, C., Arnold, R., Frishman, D., Guldener, U., Mannhaupt, G., Munsterkotter, M., Pagel, P., Strack, N., Stumpflen, V., et al. (2004). MIPS: analysis and annotation of proteins from whole genomes. Nucleic acids research, 32(Database Issue), D41-D44.

Milgram, S. (1967). The small-world problem. Psychology Today, 1, 61-67.

Mitchell, T. M. (1997). Machine Learning. McGraw-Hill.

Mizruchi, M. S. (1982). The American Corporate Network, 1904-1974. Sage.

Montoya, J. M. \& Solé, R. V. (2002). Small world patterns in food webs. Journal of Theoretical Biololgy, 214(3), 405-412.

Moonesignhe, H. D. K. \& Tan, P.-N. (2006). Outlier detection using random walks. In 18th IEEE International Conference on Tools with Artificial Intelligence (pp. 532-539).

Newman, M., Barabasi, A.-L., \& Watts, D. J. (2006). The Structure and Dynamics of Networks. Princeton: Princeton University Press. 
Newman, M. E. J. (2001). The structure of scientific collaboration networks. PNAS, 98(2), 404-409.

Newman, M. E. J. (2003). The structure and function of complex networks. SIAM Review, $45(2), 167-256$.

Newman, M. E. J. (2004a). Detecting community structure in networks. The European Physical Journal B, 38(2), 321-330.

Newman, M. E. J. (2004b). Fast algorithm for detecting community structure in networks. Physical Review E, 69, 066133.

Newman, M. E. J. (2006). Finding community structure in networks using the eigenvectors of matrices. Physical Review E, 74, 036104.

Newman, M. E. J. \& Girvan, M. (2004). Finding and evaluating community structure in networks. Physical Review E, (pp. 026113).

Pastor-Satorras, R. \& Vespignani, A. (2001). Epidemic spreading in scale-free networks. Physical Review Letters, 86, 3200-3203.

Penny, K. I. \& Jolliffe, I. T. (2001). A comparison of multivariate outlier detection methods for clinical laboratory safety data. The Statistician, 50(3), 295-308.

Pujol, J. M., Béjar, J., \& Delgado, J. (2006). Clustering algorithm for determining community structure in large networks. Physical Review E, 74, 016107.

Quiles, M. G., Zhao, L., Alonso, R. L., \& Romero, R. A. F. (2008). Particle competition for complex network community detection. Chaos (Woodbury), 18, 033107.

Radicchi, F., Castellano, C., Cecconi, F., Loreto, V., \& Parisi, D. (2004). Defining and identifying communities in networks. PNAS, 101, 2658-2663.

Ramaswamy, S., Rastogi, R., \& Shim, K. (2000). Efficient algorithms for mining outliers from large data sets. In ACM SIGMOD International Conference on Management of Data (pp. 427-438). New York, USA: ACM Press.

Schwikowski, B., Uetz, P., \& Fields, S. (2000). A network of protein-protein interactions in yeast. Nature Biotechnology, 18(12), 1257-1261.

Scott, J. (2000). Social network analysis: a handbook. Sage, second edition.

Shekhar, S., Lu, C.-T., \& Zhang, P. (2001). Detecting graph-based spatial outliers: algorithms and applications (a summary of results). In Seventh ACM SIGKDD international conference on Knowledge discovery and data mining (pp. 371-376). New York, USA: ACM. 
Shekhar, S., Lu, C.-T., \& Zhang, P. (2003). A unified approach to detecting spatial outliers. GeoInformatica, 7(2), 139-166.

Smith, R., Bivens, A., Embrechts, M., Palagiri, C., \& Szymanski, B. (2002). Clustering approaches for anomaly-based intrusion detection. In Intelligent Engineering Systems through Artificial Neural Networks (pp. 579-584). New York: ASME Press.

Sponrs, O. (2002). Networks analysis, complexity, and brain function. Complexity, 8, $56-60$.

Vazquez, A., Flammini, A., Maritan, A., \& Vespignani, A. (2003). Global protein function prediction from protein-protein interaction networks. Nature biotechnology, 21(6), 697700.

Watts, D. J. (1999). Small Worlds. Princeton University Press.

Watts, D. J. (2004). Six Degrees: The Science of a Connected Age. W. W. Norton \& Company.

Watts, D. J. \& Strogatz, S. H. (1998). Collective dynamics of "small-world" networks. Nature, 393, 440-442.

West, G. B., Brown, J. H., \& Enquist, B. J. (1999). A general model for the structure and allometry of plant vascular systems. Nature, 400, 664-667.

Woess, W. (2000). Random Walks on Infinite Graphs and Groups. Cambridge University Press.

Ye, Z., Hu, S., \& Yu, J. (2008). Adaptive clustering algorithm for community detection in complex networks. Physical Review E, 78, 046115.

Yu, D., Sheikholeslami, G., \& Zhang, A. (2002). FindOut: Finding outliers in very large datasets. Knowledge and Information Systems, 4(4), 387-412.

Zachary, W. W. (1977). An information flow model for conflict and fission in small groups. Journal of Anthropological Research, 33, 452.

Zhou, H. (2003a). Distance, dissimilarity index, and network community structure. Physical Review E, 67, 061901.

Zhou, H. (2003b). Network landscape from a brownian particle's perspective. Physical Review E, 67, 041908. 